\title{
Electrochromics for smart windows: thin films of tungsten oxide and nickel oxide, and devices based on these
}

\author{
Gunnar A. Niklasson and Claes G. Granqvist \\ Received 23rd August 2006, Accepted 13th October 2006 \\ First published as an Advance Article on the web 8th November 2006 \\ DOI: $10.1039 / \mathrm{b} 612174 \mathrm{~h}$
}

Electrochromic (EC) materials are able to change their optical properties, reversibly and persistently, by the application of an electrical voltage. These materials can be integrated in multilayer devices capable of modulating the optical transmittance between widely separated extrema. We first review the recent literature on inorganic EC materials and point out that today's research is focused on tungsten oxide (colouring under charge insertion) and nickel oxide (colouring under charge extraction). The properties of thin films of these materials are then discussed in detail with foci on recent results from two comprehensive investigations in the authors' laboratory. A logical exposition is obtained by covering, in sequence, structural features, thin film deposition (by sputtering), electronic band structure, and ion diffusion. A novel conceptual model is given for structural characteristics of amorphous W oxide films, based on notions of defects in the ideal amorphous state. It is also shown that the conduction band density of states is obtainable from simple electrochemical chronopotentiometry. Ion intercalation causes the charge-compensating electrons to enter localized states, implying that the optical absorption underlying the electrochromism can be described as ensuing from transitions between occupied and empty localized conduction band states. A fully quantitative theory of such transitions is not available, but the optical absorption can be modeled more phenomenologically as due to a superposition of transitions between different charge states of the $\mathrm{W}$ ions $(6+, 5+$, and $4+)$. The $\mathrm{Ni}$ oxide films were found to have a porous structure comprised of small grains. The data are consistent with EC coloration being a surface phenomenon, most likely confined to the outer parts of the grains. Initial electrochemical cycling was found to transform hydrated Ni oxide into hydroxide and oxy-hydroxide phases on the grain surfaces. Electrochromism in thus stabilized films is consistent with reversible changes between Ni hydroxide and oxy-hydroxide, in accordance with the Bode reaction scheme. An extension of this model is put forward to account for changes of $\mathrm{NiO}$ to $\mathrm{Ni}_{2} \mathrm{O}_{3}$. It was demonstrated that electrochromism is associated solely with proton transfer. Data on chemical diffusion coefficients are interpreted for polycrystalline $\mathrm{W}$ oxide and Ni oxide in terms of the lattice gas model with interaction. The later part of this review is of a more technological and applications oriented character and is based on the fact that EC devices with large optical modulation can be accomplished essentially by connecting W-oxide-based and Ni-oxide-based films through a layer serving as a pure ion conductor. Specifically, we treat methods to enhance the bleached-state transmittance by mixing the Ni oxide with other oxides characterized by wide band gaps, and we also discuss pre-assembly charge insertion and extraction by facile gas treatments of the films, as well as practical device manufacturing and device testing. Here the emphasis is on novel flexible polyester-foil-based devices. The final part deals with applications with emphasis on architectural "smart" windows capable of achieving improved indoor comfort jointly with significant energy savings due to lowered demands for space cooling. Eyewear applications are touched upon as well.

\section{Introduction}

Chromogenic materials are able to change their optical properties as a response to an external stimulus, ${ }^{1}$ such as irradiation by light (photochromic materials), change in temperature (thermochromic materials), the application of an electrical voltage (electrochromic materials), to

Department of Engineering Sciences, The Angström Laboratory, Uppsala University, P. O. Box 534, SE-75121 Uppsala, Sweden mention the most common types. Electrochromic (EC) materials, which this Feature Article is about, were brought to public attention some 35 years ago thanks to the seminal work on tungsten oxide films by $\mathrm{Deb}^{2,3}$ In essence, the optical absorption in the visible range changes widely as charge is inserted or extracted. Not surprisingly, these materials were immediately considered for application in information displays, but they did not stand up to the competition from the then rapidly developing liquid-crystalbased technology. 
Nevertheless electrochromism has remained an active area for basic and applied research, with large possibilities for uses in emerging technologies. The interest was boosted in the mid-1980s with the realization that electrochromism was of much interest in fenestration technology as a means to achieve energy efficiency in buildings, ${ }^{4}$ and the concept of the "smart" window ${ }^{5}$ - with variable transmittance of light and solar energy - was coined and captured the interest of researchers and the general public. EC materials have ever since then been considered a subset of the "solar energy materials".6,7 Recently, it has become clear that "smart" windows are able to combine two features that are often thought of as incompatible: energy efficiency (as a result of the curtailing of air conditioning) and indoor comfort (due to less glare and thermal discomfort). ${ }^{8-11}$ It is then hardly surprising that "smart" window technology is currently experiencing a pronounced market pull. ${ }^{12,13}$ Assets similar to those for architecture prevail in the automotive sector. ${ }^{14}$ Electrochromics-based technology is still in a state of development, and tunable EC photonic crystals ${ }^{15,16}$ and EC imaging ${ }^{17,18}$ represent two very new vistas.

Electrochromism is possible also in a number of organic materials (polymers), such as conducting polymers and viologens. A recent review of that field was given in ref. 19, and special mention should be made of polymer-based technology for EC-based automatically dimming rear-view mirrors $^{20}$ (based on 5,10-dihydro-5,10-dimethylphenazine monomers) which are now generally available for cars and trucks. Organic chromophores dispersed on a nanostructured inorganic substrate represent another option. ${ }^{21,22}$ A number of alternative chromogenic technologies that are more or less related to the ECs are available as well, ${ }^{23-25}$ including reversible electroplating ${ }^{26}$ and switchable mirrors comprising transition metal hydrides. ${ }^{27-37}$

\section{A. Prototype device}

Fig. 1 illustrates a standard EC construction that allows basic features and operating principles to be introduced conveniently. The design embodies five superimposed layers on one substrate or positioned between two substrates in a laminate configuration. The substrates are normally made of

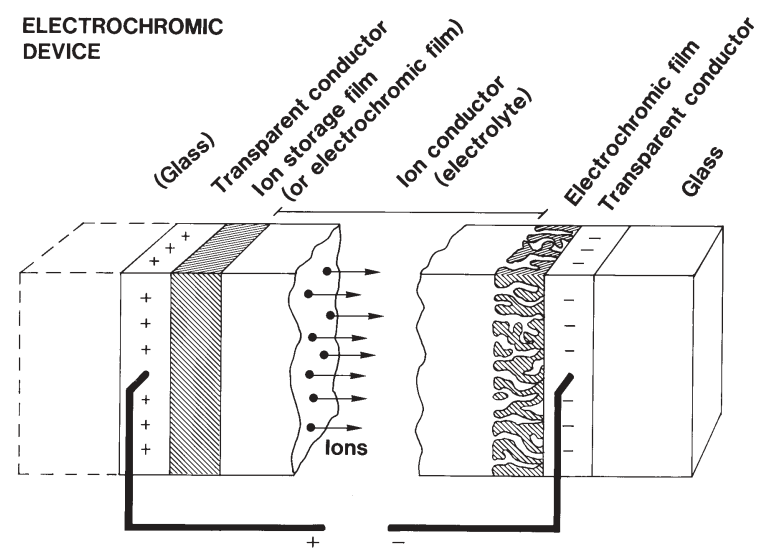

Fig. 1 Basic design of an electrochromic device, indicating transport of positive ions under the action of an electric field.

glass or flexible polyester foil. The central part of the five-layer construction is a pure ion conductor (i.e., electrolyte) that can be organic (an adhesive polymer) or inorganic (often based on an oxide film). The ions should be small in order to be mobile; protons $\left(\mathrm{H}^{+}\right)$or lithium ions $\left(\mathrm{Li}^{+}\right)$are normally preferred. This ion conductor is in contact with an EC film (tungsten oxide being a typical example; $c f$. section II below) capable of conducting electrons as well as ions. On the other side of the ion conductor is a film serving as ion storage, ideally with EC properties complementary to those of the first EC film (nickel oxide being a typical example; $c f$. section III below). This central three-layer structure is positioned between electrically conducting transparent films. The best material in terms of optical and electrical properties - or at least by far the most well-known one-is $\mathrm{In}_{2} \mathrm{O}_{3}: \mathrm{Sn}$ (referred to as indium tin oxide, or ITO). Films of $\mathrm{SnO}_{2}: \mathrm{F}$ are readily available on large area glass panes. ${ }^{38,39}$ Films of $\mathrm{SnO}_{2}: \mathrm{F}$ and $\mathrm{ZnO}: \mathrm{Al}$ are currently attracting much attention as a consequence of recent price rises on In. Surveys of the properties of these transparent conducting oxides have been given in refs. 40-42. Possibilities to enhance the properties of ITO by Ag addition have been explored. ${ }^{43}$ A recently discovered alternative to ITO, of much potential interest, is $\mathrm{TiO}_{2}: \mathrm{Nb}^{44}$ Options to replace the mentioned oxides with metal-based layers such as

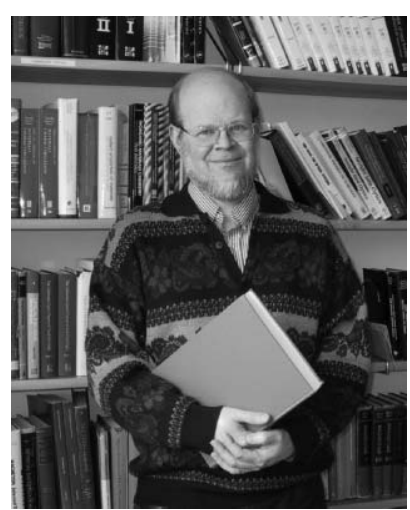

Gunnar A. Niklasson
Gunnar A. Niklasson has been Professor of Solid State Physics, particularly Solar Energy Materials, at Uppsala University since 1999. His research includes studies of the optical and electrical properties of disordered materials, with applications in the fields of energy efficient windows, solar energy absorbers, gas sensors and photo-catalysis. He has published some 200 articles, as well as about 10 review papers.

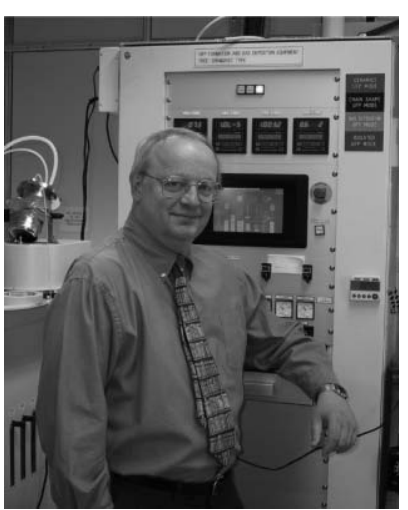

Claes G. Granqvist
Claes G. Granquist has been Professor of Solid State Physics at Uppsala University since 1993 and was formerly Professor at Gothenburg University. His research includes materials for energy efficiency and solar energy in the built environment, and nanomaterials for gas sensing and photo-catalysis. He has published some 600 articles, and 30 books and conference proceedings. He is a member of several academies and learned societies and has received several prizes and awards. 
Table 1 Survey of literature on thin films of EC oxides, beginning in 2002. The first column states the metal(s) on which the oxide is based. The entries are organized in analogy with the exposition in ref. 53. CVD denotes chemical vapour deposition

\begin{tabular}{|c|c|c|}
\hline Oxide type & Deposition technology & Reference \\
\hline \multirow[t]{8}{*}{$\mathrm{W}$} & Evaporation & $58-64$ \\
\hline & Laser ablation & 65 \\
\hline & Sputtering & $66-84$ \\
\hline & CVD & $85-90$ \\
\hline & Plasma enhanced CVD & 91,92 \\
\hline & Spray pyrolysis & $93-95$ \\
\hline & Sol-gel & $96-123$ \\
\hline & Electrodeposition & $49,50,124-131$ \\
\hline \multirow[t]{2}{*}{$\mathrm{W}+\mathrm{Mo}$} & CVD & $86,90,132-134$ \\
\hline & Electrodeposition & 135 \\
\hline \multirow[t]{2}{*}{$\mathrm{W}+\mathrm{V}$} & Sputtering & 136 \\
\hline & Sol-gel & 137 \\
\hline $\mathrm{W}+\mathrm{Nb}$ & Sol-gel & 137,138 \\
\hline $\mathrm{W}+\mathrm{Ta}$ & Laser ablation & 139 \\
\hline \multirow[t]{2}{*}{$\mathrm{W}+\mathrm{Ti}$} & Sol-gel & $140-142$ \\
\hline & Electrodeposition & 143 \\
\hline $\mathrm{W}+\mathrm{Au}$ & Sputtering & 80 \\
\hline $\mathrm{W}+\mathrm{Si}$ & Sol-gel & 140 \\
\hline $\mathrm{W}+\mathrm{P}$ & Sol-gel & $102,119,144$ \\
\hline $\mathrm{W}+$ polymer & Sol-gel & $105,145-147$ \\
\hline \multirow[t]{4}{*}{ Mo } & Evaporation & $148-150$ \\
\hline & Sputtering & 151,152 \\
\hline & CVD & $86,90,132,134,153-155$ \\
\hline & Electrodeposition & 156 \\
\hline \multirow[t]{4}{*}{$\mathrm{Ir}$} & Sputtering & 157 \\
\hline & Sol-gel & 158,159 \\
\hline & Electrodeposition & 160,161 \\
\hline & Anodization & 162 \\
\hline $\mathrm{Ir}+\mathrm{Mg}$ & Sputtering & 157 \\
\hline $\mathrm{Ir}+\mathrm{Ta}$ & Sputtering & 163 \\
\hline \multirow[t]{2}{*}{$\mathrm{Ti}$} & Sputtering & 164 \\
\hline & Nanotube & 165 \\
\hline \multirow[t]{5}{*}{$\mathrm{V}$} & Sputtering & $84,166-168$ \\
\hline & Plasma enhanced CVD & 169 \\
\hline & Sol-gel & $170-172$ \\
\hline & Electrodeposition & 173 \\
\hline & Polymer templating & 174,175 \\
\hline \multirow[t]{3}{*}{$\mathrm{V}+$ dopant } & Evaporation & 176 \\
\hline & Sol-gel & 170 \\
\hline & Electrodeposition & 177,178 \\
\hline $\mathrm{V}+$ polymer & Sol-gel & 179 \\
\hline \multirow[t]{6}{*}{$\mathrm{Ni}$} & Evaporation & 180,181 \\
\hline & Laser ablation & $182-185$ \\
\hline & Sputtering & $66,78,186-200$ \\
\hline & Spray pyrolysis & 201,202 \\
\hline & Sol-gel & $203-206$ \\
\hline & Electrodeposition & 207 \\
\hline $\mathrm{Ni}+\mathrm{Mg}$ & Sputtering & $208-211,214$ \\
\hline $\mathrm{Ni}+\mathrm{Al}$ & Sputtering & $208-211,214$ \\
\hline $\mathrm{Ni}+\mathrm{Si}$ & Sputtering & $208-211,214$ \\
\hline $\mathrm{Ni}+\mathrm{V}$ & Sputtering & $208-211,214$ \\
\hline $\mathrm{Ni}+\mathrm{Zr}$ & Sputtering & $208-211,214$ \\
\hline $\mathrm{Ni}+\mathrm{Nb}$ & Sputtering & $208-211,214$ \\
\hline $\mathrm{Ni}+\mathrm{Ag}$ & Sputtering & $208-211,214$ \\
\hline $\mathrm{Ni}+\mathrm{Ta}$ & Sputtering & $208-214$ \\
\hline $\mathrm{Ni}+\mathrm{W}$ & Sputtering & 185 \\
\hline $\mathrm{Ni}+\mathrm{Au}$ & Sputtering & 215 \\
\hline $\mathrm{Ni}+\mathrm{Cu}$ & Sol-gel & 216 \\
\hline \multirow[t]{2}{*}{$\mathrm{Nb}$} & Sputtering & 217 \\
\hline & Sol-gel & $138,218-222$ \\
\hline $\mathrm{Nb}+\mathrm{Mo}$ & Sol-gel & 222 \\
\hline
\end{tabular}

$\mathrm{ZnS} / \mathrm{Ag} / \mathrm{ZnS}$ (refs. 45,46 ) and even carbon nanotube layers ${ }^{47}$ have been mentioned.

When a voltage of the order of one volt is applied between the transparent electrical conductors, ions will be shuttled between the ion storage film and the EC film. The electrons extracted from or injected into the transparent conductors then alter the optical absorption. A reversal of the voltage, or short-circuiting, brings back the original properties. The coloration can be stopped at any intermediate level, and the device exhibits open-circuit memory so that the optical changes take place only when charge is moved. It is then apparent that the EC device can be viewed as an electrical battery with its charging state manifested as optical absorption. Transfer of battery-type work to the field of electrochromics has been attempted, ${ }^{48-52}$ but much remains to be done to fully exploit the analogies of the two technologies.

\section{B. Survey of recent work on inorganic electrochromic films}

EC materials and devices have been reviewed several times in the past, and the literature up to 1993 is covered in considerable detail in books by Granqvist $^{53}$ and Monk et $a l .{ }^{54}$ as well as elsewhere. ${ }^{55}$ Device-related work until 2002 has been reviewed more recently. ${ }^{56,57}$ Among the most recent literature, ${ }^{58-227}$ beginning in 2002 and listed in Table 1, we note work on films of the major EC oxides, based on W, Mo, $\mathrm{Ir}, \mathrm{Ti}, \mathrm{V}, \mathrm{Ni}$, and $\mathrm{Nb}$. Oxides of $\mathrm{W}, \mathrm{Mo}, \mathrm{Ti}$, and $\mathrm{Nb}$ colour under charge insertion and are referred to as cathodic EC materials, whereas oxides of Ir and $\mathrm{Ni}$ colour under charge extraction and are called anodic EC materials; V oxide is of an intermediate nature and displays features of weak cathodic and anodic coloration in different wavelength regions. Among inorganic non-oxides, we note that hexacyanometallates-i.e. compounds of the general type $\mathrm{M}_{k}\left[\mathrm{M}^{\prime}(\mathrm{CN})_{6}\right]_{l}$, where $\mathrm{M}$ and $\mathbf{M}^{\prime}$ are transition metal ions with different valencies - can exhibit pronounced anodic electrochromism; these materials are normally prepared by electrodeposition. ${ }^{228,229}$

The optical properties of oxide films based on $\mathrm{W}, \mathrm{Mo}, \mathrm{V}, \mathrm{Ni}$, and $\mathrm{Ru}$ can be altered also by exposure to oxidizing and reducing gases; this phenomenon is often referred to as "gasochromics" and may, possibly, lead to applications similar to those of some EC devices. ${ }^{82,230-239}$ Other effects with much similarity in principle are the photochromic, ${ }^{74,88,145,240-247}$ thermochromic, ${ }^{248,249}$ ion-bombardment-induced, ${ }^{250-253}$ and gamma-irradiation-induced ${ }^{254}$ ones, that are also seen in films based on oxides of $\mathrm{W}, \mathrm{Mo}$, and Ni. Some electrochromism has been observed in layers of CdSe nanocrystals. ${ }^{255,256}$ Electrochromism has been reported also in bulk samples of

Table 1 Survey of literature on thin films of EC oxides, beginning in 2002. The first column states the metal(s) on which the oxide is based. The entries are organized in analogy with the exposition in ref. 53. CVD denotes chemical vapour deposition (Continued)

\begin{tabular}{lll}
\hline Oxide type & Deposition technology & Reference \\
\hline $\mathrm{Rh}$ & Sol-gel & 223 \\
$\mathrm{Ta}+\mathrm{Zn}$ & Laser ablation & 224 \\
$\mathrm{Ta}+\mathrm{Pt}$ & Sputtering & 225 \\
$\mathrm{Sb}-\mathrm{Sn}$ & Laser ablation & 226 \\
\hline
\end{tabular}


nanostructured $\mathrm{W}$ oxide 257,258 and in $\mathrm{Nb}$ oxy-fluoride powder compacts. $^{259}$ The relevant literature is much larger than indicated above, though, and encompasses numerous investigations of films similar to those in Table 1 for sensing applications (of gases and liquids), thin film batteries, fuel cells, super-capacitors, (photo/electro)catalysis, photo-induced hydrophilicity, etc. $\mathrm{NiO}$ films have been widely studied for a variety of magnetic applications (such as spintronics). A survey of this vast literature is outside the scope of the present Feature Article, though.

One clear impression from the schematic survey of the most recent literature above is that much interest is currently focused on electrochromic $\mathrm{W}$ oxide and $\mathrm{Ni}$ oxide, and that sputtering and sol-gel deposition stand out as particularly relevant owing to their capability of yielding mixed oxide films.

\section{Outline of this Feature Article}

As noted above, EC materials and devices have been the subject of several earlier reviews. For better or worse, they have almost always had a "practical" focus on thin film manufacturing and device performance. The present Feature Article is different. Its main aim is to summarize recent advances in electrochromics with emphasis on materials chemistry (or applied physics) thereby laying a foundation for a deeper understanding of the fundamentals of the most important inorganic EC materials and hence cementing a solid basis for further progress regarding devices.

The Feature Article is organized as follows: sections II and III are devoted to in-depth presentations of results for $\mathrm{W}$ oxide and $\mathrm{Ni}$ oxide, respectively. The expositions revolve around recent, comprehensive work on thin films made by sputter deposition and follow a common format for the two materials: going from structural features, via thin film deposition, electronic band structure and optical properties, on to ion diffusion. Section IV then reports on device-related work on structures incorporating the former types of films, joined by a polymer electrolyte. The emphasis is on recent work on flexible foil-based devices. Section V, finally, covers some applications, in particular concerning the use of electrochromics in "smart" windows for buildings and automobiles.

\section{Tungsten oxide films}

Amorphous tungsten oxide $\left(\mathrm{a}-\mathrm{WO}_{3}\right)$ is a widely studied cathodic EC material, as apparent from the literature survey above, and almost all oxide-based EC devices employ $\mathrm{W}$ oxide. In fact, no serious contenders have appeared despite longstanding efforts to find such. Published research on $\mathrm{W}$ oxide films is very extensive; see, for example, the general reviews by Granqvist $^{53,56}$ and the review on charge transport by Monk. ${ }^{260}$ The designation "amorphous" implies that X-ray diffraction does not display any clear features, and hence local ordering, if any, persists only on length scales less than a few $\mathrm{nm}$. Considering the importance of $\mathrm{W}$ oxide for $\mathrm{EC}$ device technology, it is worthwhile to re-examine the interpretation of its physical properties in some detail, ${ }^{261}$ as will be done below. In order to gain a better understanding of the physics of the material, comparisons with the properties of polycrystalline tungsten oxide will be made throughout the presentation,

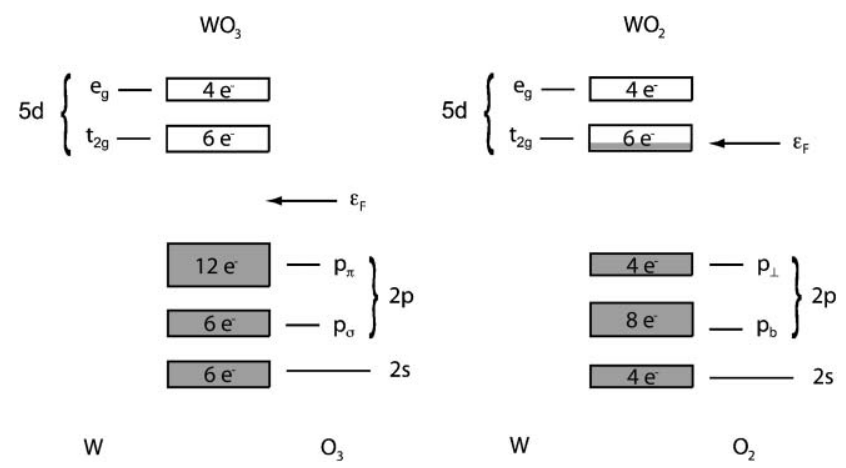

Fig. 2 Schematic band structures of $\mathrm{WO}_{3}$ (left-hand part) and $\mathrm{WO}_{2}$ (right-hand part), based on previous work in refs. 262 and 263. Tungsten and oxygen orbitals are indicated, using standard notation, as well as the location of the Fermi level $\left(\varepsilon_{\mathrm{F}}\right)$. The indicated numbers of electrons $\left(\mathrm{e}^{-}\right)$can be accommodated in the bands. Filled states are shaded.

which is based mainly on coatings produced by sputter deposition. This technology is notable for its up-scaling capability, and it hence stands out as being industrially viable even for large areas.

The history of induced colour changes in $\mathrm{W}$ oxides dates back to the days of Berzelius in the early 19th century, while electrochemical studies were initiated around $1930 .^{53}$ The optical properties of a- $\mathrm{WO}_{3}$ change from a transparent state to a coloured blue state upon electrochemical insertion of small cations such as $\mathrm{H}^{+}, \mathrm{Li}^{+}$, and $\mathrm{Na}^{+}$. The coloration is actually due to simultaneous insertion of charge-balancing electrons into the conduction band through an outer circuit, as evident from Fig. 2 (after Goodenough ${ }^{262}$ and Honig ${ }^{263}$ ). Electronic transitions between localized states close to the band edge give rise to an absorption process that can be interpreted in terms of intervalence transfer, as discussed in detail below. On the other hand, polycrystalline $\mathrm{WO}_{3}$ changes from a transparent state to a near-infrared absorbing one - and, subsequently, to a reflecting state- - upon insertion of ions and electrons. It has been shown that the absorbing state in the polycrystalline material is due to polaron absorption, ${ }^{264}$ while the reflecting state is due to free electrons in the conduction band. ${ }^{265-267}$

\section{A. Structural features}

Stoichiometric $\mathrm{WO}_{3}$ exhibits a monoclinic crystalline structure at room temperature and up to $\sim 300{ }^{\circ} \mathrm{C}$, with a density of $7.16 \mathrm{~g} \mathrm{~cm}^{-3}$. The structure of the crystalline material is based on corner-sharing $\mathrm{WO}_{6}$ octahedra. ${ }^{53}$ One may safely assume that the basic building blocks are similar in the amorphous structure, although bond lengths and bond angles exhibit considerable disorder. The bonds are mainly of ionic character, and stoichiometric $\mathrm{WO}_{3}$ can be pictured as being composed of $\mathrm{W}^{6+}$ and $\mathrm{O}^{2-}$ ions. However, the bonding is not completely ionic, and there is also a significant covalent part. $^{268,269}$ The valence band is largely composed of O $2 p$ orbitals, while the conduction band derives mainly from $\mathrm{W} 5 \mathrm{~d}$ orbitals. The Fermi level is positioned in the middle of the band gap, as shown in the left-hand part of Fig. 2. Each W ion is surrounded by six $\mathrm{O}$ ions, ideally forming an octahedron. 
Each $\mathrm{O}$ ion is bound to two $\mathrm{W}$ ions in a linear configuration, which can be represented as

$$
\mathrm{W}^{6+}-\mathrm{O}^{2-}-\mathrm{W}^{6+}
$$

In addition to the transparent oxide $\mathrm{WO}_{3}$, there exist a number of sub-stoichiometric so-called Magnéli phases of the forms $\mathrm{W}_{m} \mathrm{O}_{3 m-1}$ and $\mathrm{W}_{m} \mathrm{O}_{3 m-2}(m=1,2, \ldots)$ all the way down to $\mathrm{WO}_{2}{ }^{270}$ The sub-stoichiometric phases exhibit different colours, ranging from blue in the case of a slight sub-stoichiometry to brownish for $\mathrm{WO}_{2}{ }^{271}$ In these cases, the Fermi level is situated in the $\mathrm{W} 5 \mathrm{~d}$ band, as illustrated in the right-hand part of Fig. 2. The ideal amorphous structure is a continuous random network where all bonds are satisfied. ${ }^{272}$ In practice, however, various defects are present, i.e., dangling bonds, vacancies, and interstitials. Such a defect picture can be used to obtain a simplified understanding of the structural features associated with non-stoichiometric amorphous structures, as considered next.

We first regard sub-stoichiometric $\mathrm{W}$ oxide, in which case the most common defect is the oxygen vacancy. Vacancies can be neutral $\left(\square^{0}\right)$, singly charged $\left(\square^{+}\right)$, or doubly charged $\left(\square^{2+}\right)$ with respect to the unperturbed lattice. A neutral vacancy displays an electron configuration similar to that of the stoichiometric compound. However, it may be energetically advantageous to transfer one or both of its electrons to neighbouring ions. Oxygen vacancies in crystalline $\mathrm{WO}_{3}$ have recently been studied by ab initio computations. ${ }^{269,273,274}$ It is controversial whether the extra electrons occupy conduction band states ${ }^{269}$ or states localized at or near the vacancy. ${ }^{273,274}$ In addition, the relevance of these results to the amorphous structure is far from clear.

For the case of a- $\mathrm{WO}_{3}$, we instead adopt a simplified picture based on the predominantly ionic bonding. Considering the case where one of the electrons remains, i.e., the $\square^{+}$vacancy state, one can schematically depict the vacancy state occupied with one electron that forms a bond with one $\mathrm{W}^{6+}$ ion by

$$
\mathrm{W}^{5+} \square^{+}-\mathrm{W}^{6+}
$$

The other neighbouring tungsten ion then must be $\mathrm{W}^{5+}$. The extra electron transferred to the latter ion enters the conduction band of $\mathrm{W}$ oxide thereby giving rise to optical absorption.

The electrons may also be transferred to one or two neighbouring $\mathrm{W}$ ions, and the vacancy then becomes doubly charged. In the former case, one of the adjacent tungsten ions can be represented as $\mathrm{W}^{4+}$. It has been suggested by Bechinger et al. ${ }^{275,276}$ that such states are present in sub-stoichiometric W oxide, and that the optical absorption is due to transitions between $\mathrm{W}^{4+}$ and $\mathrm{W}^{5+}$. A problem with this model, however, is that the occurrence of $\mathrm{W}^{4+}$ species appears to be energetically unfavourable, ${ }^{277}$ and it seems to be more energetically advantageous to form a doubly charged vacancy and two $\mathrm{W}^{5+}$ ions. Structural rearrangements can easily occur as a consequence of the strong electron-phonon interaction in $\mathrm{W}$ oxide. The two $\mathrm{W}$ ions can move closer to one another and form a doubly charged $(\mathrm{W}-\mathrm{W})^{10+}$ complex, as illustrated schematically by

$$
\mathrm{W}^{6+}-\square^{0}-\mathrm{W}^{6+} \rightarrow(\mathrm{W}-\mathrm{W})^{10+}
$$

This process can be qualitatively seen as a realization of the Anderson electron pairing mechanism. ${ }^{278}$ Usually the large Coulomb repulsion between nearby localized electrons makes double occupancy of localized states unfavourable, but the electron-phonon interaction can mediate an attractive interaction between the electrons and the structural rearrangements can decrease the repulsive term. Band structure calculations by de Wijs and de Groot ${ }^{277,279}$ have identified the existence of such complexes and have shown that the extra electrons populate states lying deeply in the band gap. These states are obviously occupied by two electrons and are thus filled. It is easily realized that for $\mathrm{O} / \mathrm{W}$ ratios less than $2.5, \mathrm{~W}^{4+}$ states must also appear, which is in qualitative agreement with recent experimental results. ${ }^{280}$

Not only sub-stoichiometry is possible; $\mathrm{W}$ oxide produced in the presence of large oxygen content and at high sputtering power can be over-stoichiometric. ${ }^{281}$ Excess of oxygen in the material can be accommodated if hydroxyl bonds are present between adjacent oxygen atoms, as schematically shown by

$$
\mathrm{W}^{6+}-(\mathrm{O}-\mathrm{O})^{2-}-\mathrm{W}^{6+}
$$

In the defect picture, the extra $\mathrm{O}$ atoms may be viewed as interstitials. They may be neutral, or they may trap electrons and become singly or doubly charged, ${ }^{282}$ implying that only a schematic image of the bonds is given above. In reality, the sharing of electrons between the oxygen interstitial and its neighbours may certainly be of a more complex nature. ${ }^{282}$

There is no fundamental reason against vacancies and interstitials both being present in as-deposited $\mathrm{W}$ oxide films. In fact, different amounts of interstitials and vacancies in substoichiometric and stoichiometric films may well explain differences in optical and EC properties between films studied by different investigators.

The basis for the electrochromism in $\mathrm{W}$ oxide is proton or alkali ion intercalation into the material, as emphasized above. We denote by $x$ the intercalated ion/W atom ratio and, in order to be specific in the present discussion, take the intercalated species to be $\mathrm{Li}^{+}$. However the situation will be closely analogous for $\mathrm{H}^{+}, \mathrm{Na}^{+}$, or $\mathrm{K}^{+}$intercalation. A large number of $\mathrm{Li}^{+}$ions can be inserted into amorphous $\mathrm{W}$ oxide. The intercalation process is reversible up to $\mathrm{Li}^{+} / \mathrm{W}$ ratio of $\sim 0.7,{ }^{283}$ i.e., it is possible to extract the ions and repeat the intercalation cycle several times to this ratio. Irreversible intercalation - in which case not all ions can be extracted again from the oxide - can be performed for $x$ values up to $2 .^{283}$ In this limit, the electronic configuration would probably be similar to that of $\mathrm{WO}_{2}$ ( $c f$. right-hand part of Fig. 2). In practical EC devices $x$ is usually below 0.3 , though, since the optical absorption strength exhibits a maximum for $0.35<x$ $<0.5,{ }^{283,284}$ as discussed shortly in section II D.

The insertion of $\mathrm{Li}^{+}$into amorphous $\mathrm{W}$ oxide breaks up the continuous random network of $\mathrm{W}-\mathrm{O}-\mathrm{W}$, as illustrated by

$$
\mathrm{W}^{6+}-\mathrm{O}^{2-}-\mathrm{Li}^{+}\left(\mathrm{W}^{5+}\right)
$$

In our schematic chemical picture the $\mathrm{Li}^{+}$ion binds to an oxygen ion, while its outer electron is transferred to a neighbouring tungsten atom. $\mathrm{A} \mathrm{W}^{5+}$ site is then formed, analogously to the case of the singly charged vacancy discussed above. However, the 
lithium ion may also transfer an electron to a singly charged vacancy, thereby binding to that site. This process is interesting, since it does not change the number of $\mathrm{W}^{5+}$ states in the material. This is easily seen by comparison of $\mathrm{W}^{5+} \square^{+}-\mathrm{W}^{6+}$, which was given above, and

$$
\mathrm{W}^{6+}-\square^{0}-\mathrm{Li}^{+}\left(\mathrm{W}^{5+}\right)
$$

At high intercalation levels, two inserted $\mathrm{Li}^{+}$ions will be able to bind to oxygen ions connected to the same $\mathrm{W}$ site. This will lead to $\mathrm{W}^{4+}$ being present in the sample, and the number of such states will increase as $x$ goes up.

X-Ray photoemission spectroscopy (XPS) of core levels can be used to determine the relative fractions of different valence states for the metallic ions. It must be remembered, though, that XPS is a very surface sensitive technique, and the results may not always be representative of the bulk of the studied material. In the case of $\mathrm{W}$ oxide, considerable work has been carried out on the spin-orbit split W $4 \mathrm{f}$ spectrum, as reported before. ${ }^{53,285-290}$ Such spectra can be de-convoluted in order to obtain the fractions of $\mathrm{W}^{6+}, \mathrm{W}^{5+}$, and $\mathrm{W}^{4+}$ states close to the surface of the sample. The effect of proton intercalation was studied by Temmink et al. for evaporated films. ${ }^{291,292}$ The fraction of $\mathrm{W}^{5+}$ states was linearly dependent on $x$, at least up to $x \approx 0.3$, as expected for low intercalation levels. In addition, $\mathrm{W}^{4+}$ states were detected for $x>0.25$; however, they could not be reliably quantified due to uncertainties in the deconvolution. ${ }^{291,292}$ The latter type of species was also observed by Henningsson ${ }^{293}$ in deeply coloured polycrystalline films. Stolze et al. $^{280}$ studied W 4f states in sub-stoichiometric sputter deposited $\mathrm{W}$ oxide films. The $\mathrm{W}^{5+}$ signal increased at first continuously with increasing sub-stoichiometry, while the $\mathrm{W}^{4+}$ signal appeared rather abruptly at $\mathrm{O} / \mathrm{W}$ ratios of 2.6 to 2.5. Hence this study gave evidence for $\mathrm{W}^{4+}$ species only at small values of the $\mathrm{O} / \mathrm{W}$ ratio, specifically below 2.6 , but the data are uncertain owing to pronounced surface oxidation. ${ }^{280}$

Extended X-ray absorption fine-structure spectroscopy (EXAFS) is a technique for probing the local structure around an atomic species. ${ }^{272}$ It is element specific since it is based on the energy dispersive spectra above the X-ray absorption edges of the studied element. Small oscillations of the absorption as a function of energy appear in this region. They are due to interference between backscattered and outgoing electron waves, from which the local structure can be deduced. Fig. 3 shows radial distribution functions for the first coordination shell around $\mathrm{W}^{6+}$ and $\mathrm{W}^{5+}$ sites in evaporated amorphous $\mathrm{W}$ oxide films. ${ }^{294}$ The $\mathrm{W}^{5+}-\mathrm{O}$ distance is substantially larger in the proton intercalated sample. Similar effects have been found subsequently in $\mathrm{Li}^{+}$intercalated $\mathrm{W}$ oxide films prepared by sputtering and investigated by X-ray absorption spectroscopy. ${ }^{295,296}$ Ion/electron insertion is thus accompanied by a distortion of the local structure, which points to the importance of electron-phonon interactions in this material.

\section{B. Thin film deposition}

Amorphous $\mathrm{W}$ oxide is most commonly produced in thin film form. In the case of sputter deposition, amorphous films are obtained at substrate temperatures below $250{ }^{\circ} \mathrm{C}$. Crystalline features start to appear at higher temperatures, and good

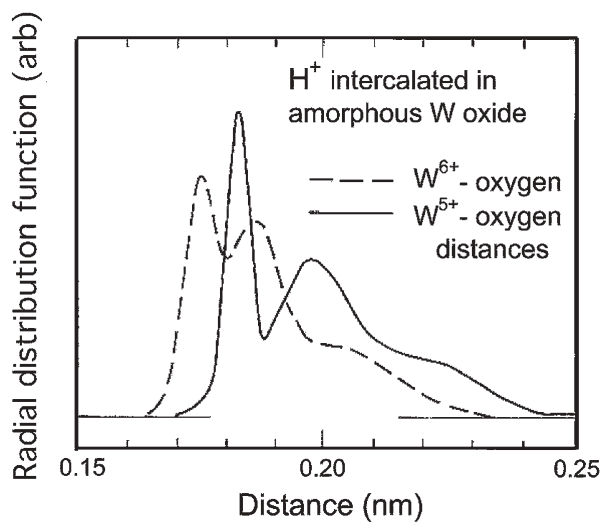

Fig. 3 Radial distribution function around $\mathrm{W}^{6+}$ and $\mathrm{W}^{5+}$ sites in evaporated proton intercalated amorphous tungsten oxide films, as obtained by EXAFS. Adapted from Kuzmin and Purans (ref. 294).

polycrystalline films can be obtained by deposition onto substrates heated to $350{ }^{\circ} \mathrm{C}{ }^{53,297}$ Below we present recent results - mainly from the authors' laboratory-obtained on W oxide films with a thickness of $\sim 300 \mathrm{~nm}$ deposited by reactive DC magnetron sputtering onto glass substrates coated with ITO having a resistivity of $60 \Omega$ square $^{-1}$. Detailed deposition conditions can be found in work by Berggren and Niklasson. ${ }^{283,298}$

The oxygen gas flow was varied during the sputter deposition in order to accomplish large changes in the stoichiometry. Data from a set of experiments by Lee et al. ${ }^{299}$ Stolze et al.,${ }^{280}$ and Berggren and Niklasson ${ }^{71,283}$ are shown in Fig. 4; other data were given in ref. 300. The results from Berggren's work were obtained by elastic recoil detection analysis (ERDA) and are in qualitative agreement with the earlier findings. It is seen that the $\mathrm{O} / \mathrm{W}$ ratio increases from 2 to 3 within a narrow range of $\mathrm{O}_{2}$ partial pressure during sputtering and then saturates around the stoichiometric composition. Water vapour incorporated into or adsorbed onto the films is a source of

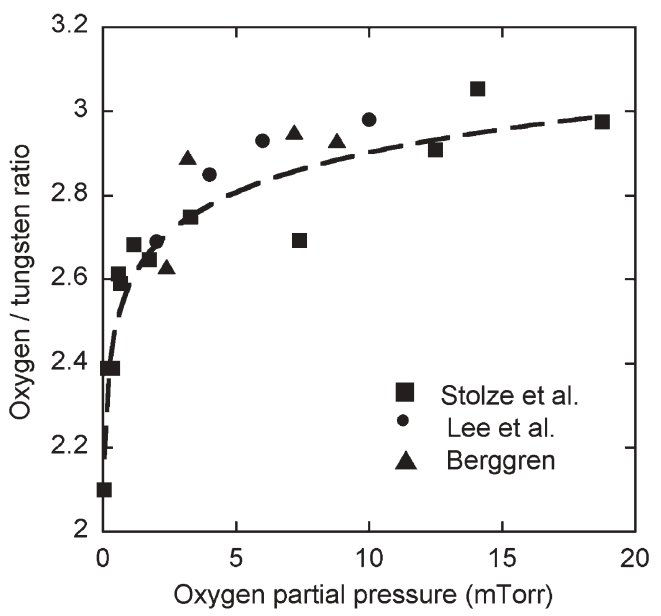

Fig. 4 Oxygen-to-tungsten ratio in sputter deposited tungsten oxide films vs. oxygen partial pressure during sputtering. Data were reproduced from Lee et al. (ref. 299), Stoltze et al. (ref. 280), and Berggren and Niklasson (refs. 71 and 283). The dashed curve was drawn for convenience. 
uncertainty, but this was corrected for by Stolze et al. ${ }^{280}$ who combined $\mathrm{O} / \mathrm{W}$ determination using wavelength dispersive X-ray analysis with measurement of hydrogen content by nuclear reaction analysis (NRA). For Berggren's films, the water content was negligible because of the low background pressure prior to deposition; the hydrogen content was $\sim 1$ atom $\%$, as found by ERDA. Over-stoichiometric films have been reported in some prior investigations; ${ }^{281}$ those films were deposited at lower pressures and higher powers than in our work.

The densities of our $\mathrm{W}$ oxide films were found to be smaller the closer they were to stoichiometry. For example $\mathrm{WO}_{2.63}$ had a density of $\sim 7.2 \mathrm{~g} \mathrm{~cm}^{-3}, \mathrm{WO}_{2.89}$ had $\sim 5.7 \mathrm{~g} \mathrm{~cm}^{-3}$, while $\mathrm{WO}_{2.93}$ was porous with a density of $\sim 5.0 \mathrm{~g} \mathrm{~cm}^{-3}$. Films with an $\mathrm{O} / \mathrm{W}$ ratio above $\sim 2.75$ were visually transparent. For lower ratios, a progression was observed from pale purple to blue, blue-gray, brown, and, finally, very dark brown. ${ }^{283}$

As-deposited films were intercalated by $\mathrm{Li}^{+}$in an electrolyte of lithium perchlorate in propylene carbonate. The samples were employed as the working electrode in a three-electrode electrochemical cell, and a specific amount of charge was inserted by applying a constant current over a given time. Data on the latter films will be reported on below.

\section{Electronic band structure}

XPS is by far the most used method to study the electronic valence band density of states (DOS) today. It gives a qualitative picture of the occupied electron states, and by performing measurements as a function of intercalation level it is possible to see which states are occupied by the inserted electrons. A number of XPS studies on W oxide have been published. ${ }^{53}$ Fig. 5 shows XPS spectra of evaporated W oxide

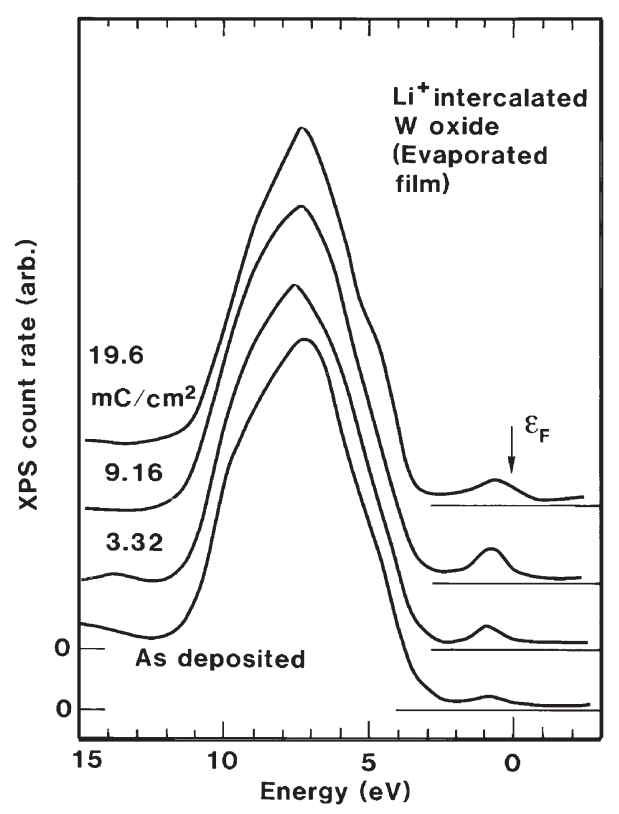

Fig. 5 XPS spectra of the valence band and the occupied part of the conduction band for evaporated tungsten oxide films in the asdeposited state and after intercalation of $\mathrm{Li}^{+}$ions to the shown amounts of charge. The Fermi level is indicated by a vertical arrow. Adapted from Hashimoto and Matsuoka (refs. 301 and 302). films intercalated to different values of $x$ from work by Hashimoto and Matsuoka. ${ }^{301,302}$ Similar results have been obtained by others. ${ }^{303}$ It is seen that a broad band lies between 11 and $3 \mathrm{eV}$ below the Fermi level. It is generally agreed that this feature is the valence band dominated by $\mathrm{O} 2 \mathrm{p}$ states. The intensity goes towards zero at higher energy, but then a narrow peak appears just below the Fermi level. This peak increases with the amount of ion intercalation. The reason for this feature is probably that the electrons that are inserted together with the ions occupy the lower part of the conduction band. The minimum between the two peaks corresponds to the band gap. It is difficult to resolve any details in the XPS spectra, such as the existence of localized gap states or the shape of the conduction band. To do this, one has to employ other techniques, as considered next.

The establishment of a link between the electrochemical properties and the electronic DOS would increase the understanding of EC effects considerably. This is so because the intercalation process is kinetically limited by the diffusion of the ions into or out of the material, and a variety of electrochemical techniques are available for the characterization of ion dynamics. ${ }^{304}$ However, the optical properties of EC materials are dependent on the electronic band structure, i.e., the energy levels and the character of the states occupied by the inserted or extracted electrons. A recent investigation by Strømme et al. ${ }^{305}$ has shown that the fine structure in the electrode potential curves of $\mathrm{W}$ oxide (and $\mathrm{Ti}$ oxide) films displays a striking resemblance to features in the computed electronic DOS. This similarity is restricted to disordered or amorphous materials, and it is believed that the crucial factor is whether the electron states are extended or localized. Only in the latter case does the electronic contribution dominate the potential curves. The technique also implicitly assumes the validity of the rigid-band model during intercalation, which is not always a good approximation. ${ }^{306}$ For $\mathrm{W}$ oxide, the rigidband approximation seems to be adequate, though. ${ }^{268,307}$

We now present chronopotentiometry data-i.e., results of measurements of the potential $U$ of an electrode during ion intercalation at a very low constant current-for amorphous W oxide films and demonstrate how information can be obtained on the conduction band DOS. This analysis assumes that electronic effects influence the potential curves much more than a possible dispersion of ionic site energies. The lattice gas model $^{308}$ — wherein the potential curves are interpreted in terms of entropic effects and ion interaction - has been very successful for crystalline materials, but its application to amorphous materials is questionable. ${ }^{305}$

The derivative $-\mathrm{d} x / \mathrm{d} U$, obtained from chronopotentiometry, is a measure of the number of electrons and ions inserted into the film per unit energy. Hence it can be directly compared to the computed electronic DOS. We refer to $-\mathrm{d} x / \mathrm{d} U$ as the "electrochemical density of states" (EDOS). Zero of the energy scale was put at the equilibrium potential of the pure oxide. The energy scale in the computations was adjusted in order to achieve a good fit of the most prominent peaks of the DOS to the experimental data. Fig. 6 shows a comparison of experimental EDOS and computed DOS (per spin state) for the case of electron (and $\mathrm{Li}^{+}$) insertion into the conduction band of amorphous W oxide films. ${ }^{305}$ The computed DOS for 


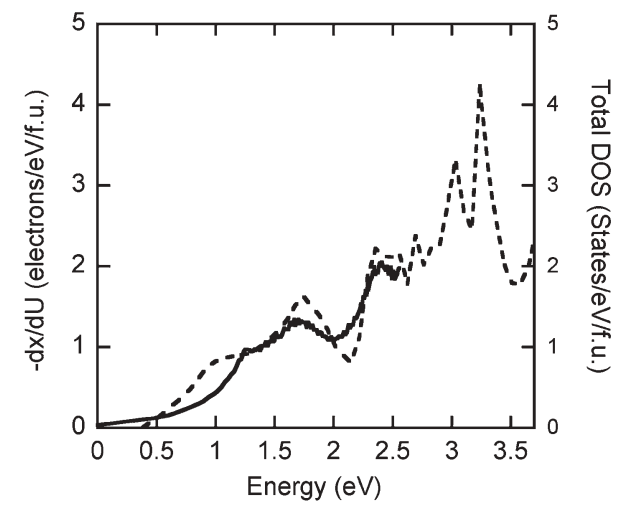

Fig. 6 Electrochemical density of states $(-\mathrm{d} x / \mathrm{d} U)$ for an amorphous tungsten oxide film (full line; left-hand scale) and fitted density of states (DOS) obtained from band structure calculations for monoclinic $\mathrm{WO}_{3}$ (dashed line; right-hand scale) vs. energy. Data are given per formula unit (f.u.). Zero energy was taken to be at the experimental band edge. Each state can be occupied by two electrons of opposite spin in the computed total DOS. Adapted from ref. 305.

monoclinic $\mathrm{WO}_{3}$ displays a remarkably good agreement with the chronopotentiometry data. However, it must be noticed that the computed DOS should be multiplied by a factor of two in order to account for both spin states. Additional measurements with smaller, pulsed currents have also been performed; ${ }^{309}$ they displayed higher values of the EDOS, of the order of the computed DOS when considering spin degeneracy, but at the expense of a more limited energy range and noisy data. These latter results show that the charge carriers in the material exhibit very slow relaxations, and that the chronopotentiometry measurements do not fully correspond to steady state conditions. It is thus clear that kinetic effects influence the measured EDOS to a significant degree.

Next we present evidence that the electronic states, probed by the experiment reported on in Fig. 6, are localized. ${ }^{309}$ To that end we combine the chronopotentiometry measurements with electrical conductivity data recorded between $77 \mathrm{~K}$ and room temperature for slightly sub-stoichiometric amorphous W oxide films intercalated with $\mathrm{Li}^{+}{ }^{310}$ The conductivity was found to be temperature dependent and follow the variable range hopping relation given by $^{311,312}$

$$
\sigma(t)=\sigma_{0} \exp \left(-t_{0} / t\right)^{1 / 4}
$$

where $\sigma(t)$ is the temperature dependent electrical conductivity and $\sigma_{0}$ is a pre-factor. The quantity $t_{0}$ is related to the DOS at the Fermi level, denoted $N\left(\varepsilon_{\mathrm{F}}\right)$, and to the electron localization radius $\alpha_{\mathrm{e}}^{-1}$ by the relation

$$
t_{0}=C \alpha_{\mathrm{e}}^{3} /\left[k_{\mathrm{B}} N\left(\varepsilon_{\mathrm{F}}\right)\right]
$$

$C$ is a numerical factor, of the order 5 to $20,{ }^{312}$ and $k_{\mathrm{B}}$ is Boltzmann's constant. We used the fully relaxed EDOS and results from the conductivity measurements (with $C \approx 10$ ) to estimate the electron localization radius for the conduction band states in films consisting of $\mathrm{Li}_{x} \mathrm{WO}_{2.89}$ and $\mathrm{Li}_{x} \mathrm{WO}_{2.93}$ $(x<0.53)$. Fig. 7 shows $\alpha_{\mathrm{e}}^{-1}$ as a function of $x$ for amorphous $\mathrm{W}$ oxide films at different intercalation levels ${ }^{309}$

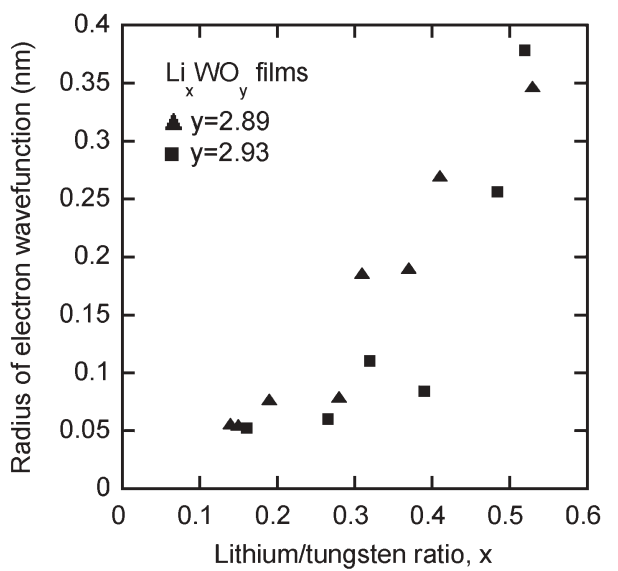

Fig. 7 Localization radius of electron wave function $v s$. Li/W ratio for amorphous tungsten oxide films comprised of $\mathrm{WO}_{2.89}$ and $\mathrm{WO}_{2.93}$.

$(\sim 0.13<x<\sim 0.53)$. The radius of the electron wave function increases continuously during $\mathrm{Li}^{+}$intercalation, and the rise appears to be steeper at higher intercalation levels. The localization radius seems to be slightly smaller for the film represented by $\mathrm{WO}_{2.93}$ than for the film represented by $\mathrm{WO}_{2.89}$ at the same value of $x$. This suggests that electrons in substoichiometric $\mathrm{W}$ oxide films become less localized as the oxygen deficiency is enhanced. The electron localization can be due to electron-phonon interaction (i.e., polaronic localization) $)^{313}$ as well as to disorder. ${ }^{272}$ The localization radius for polarons in crystalline $\mathrm{W}$ oxide has been estimated to $\sim 0.6 \mathrm{~nm},{ }^{264}$ and therefore we suggest that the disorder in the amorphous state is the main reason for the results in Fig. 7.

\section{Optical properties}

The electrons inserted together with the intercalated ions occupy the lower part of the conduction band, and hence the optical band gap should increase upon intercalation. Indeed, this effect has been observed repeatedly. ${ }^{314-316}$ The band gap shift for evaporated films is small, though; it is of the order of 0.1 to $0.25 \mathrm{eV}$ for $x \approx 0.15$. A substantially higher band gap increase, as large as $\sim 0.4 \mathrm{eV}$, was recently found for electrodeposited amorphous $\mathrm{W}$ oxide films. ${ }^{127}$ Fig. 6 shows that the EDOS exhibits a low energy tail extending into the band gap, which should give rise to substantial band gap changes already at small intercalation levels. The experimentally observed band gap shifts are probably due to the Burstein-Moss effect. ${ }^{317,318}$ However, the shifts are in many cases balanced by many-body interactions due to electron-ion and electron-electron scattering, ${ }^{319-322}$ which may explain the small magnitude of the effect. Distortion of $\mathrm{WO}_{6}$ octahedra is another conceivable reason for band gap shifts.

Optical absorption at energies below that of the band gap is associated with transitions between localized states in the case of non-magnetic materials. ${ }^{323}$ Electron states can become localized due to a disordered structure of the material, and strong electron-phonon interaction also promotes localization. However, electron-phonon interaction can lead to localization also in crystalline compounds. We first consider the case of crystalline $\mathrm{W}$ oxide, for which polaronic effects can be 
estimated quantitatively. The strength of the electron-phonon coupling is expressed by the Fröhlich coupling constant, ${ }^{324}$ viz.

$$
a_{\mathrm{F}}=\left(e^{2} / 2 h \varepsilon_{\mathrm{V}}\right)\left(\varepsilon_{\infty}{ }^{-1}-\varepsilon_{0}{ }^{-1}\right)\left(m / 2 E_{\mathrm{LO}}\right)^{1 / 2}
$$

where $e$ is the electron charge, $h$ is Planck's constant, $m$ is the effective mass, $E_{\mathrm{LO}}$ is the energy of a longitudinal optical (LO) phonon, $\varepsilon_{\mathrm{v}}$ is the dielectric constant of vacuum, and $\varepsilon_{\infty}$ and $\varepsilon_{0}$ are the high-frequency and low-frequency dielectric constants, respectively. The coupling constant involve nothing but quantities that are measurable, at least in principle, and hence it is possible to determine for which materials polaronic effects should be of importance. For practical purposes, the highfrequency and low-frequency dielectric constants can be taken from data pertaining to the optically visible and $\mathrm{MHz}-\mathrm{GHz}$ frequency ranges, respectively. Specific values of the parameters were obtained from the available literature: $\mathrm{m} / \mathrm{m}_{\mathrm{e}}=$ $2.9,{ }^{325} \varepsilon_{\infty} \approx 4$ to $5,{ }^{326}$ and $\varepsilon_{0} \approx 30,{ }^{327}$ where $m_{\mathrm{e}}$ is the free electron mass. For sputter deposited films the values of $\varepsilon_{\infty}$ span a large range, probably as a consequence of structural differences. The value of $m$ is also very uncertain since it was derived from computations of the electronic band structure specifically for the monoclinic phase. The LO phonon energy was obtained from p-polarized infrared reflectance measurements at oblique incidence on thin films deposited onto reflecting substrates. ${ }^{261}$ It was found that polycrystalline $\mathrm{WO}_{3}$ exhibits two strong LO phonons with energies being 50 and $123 \mathrm{meV}$, and it is not clear how these quantities should be weighted in eqn (3). The usual practice ${ }^{328}$ has been to use $70 \mathrm{meV}$ without justification, which is close to the value of $75 \mathrm{meV}$ obtained from the average

$$
E_{\mathrm{LO}}{ }^{-0.5}=E_{\mathrm{LO} 1}{ }^{-0.5}+E_{\mathrm{LO} 2}{ }^{-0.5}
$$

over the two LO modes. With the data quoted above one arrives at values of $\sim 4$ to 5 for the polaron coupling constant. The general conclusion is then clear despite the uncertainties: the electron-phonon interaction in $\mathrm{W}$ oxide is very strong thereby leading to self-trapping of the charge carriers. The localization radius as well as the polaron binding energy $E_{\mathrm{p}}$ can also be obtained from the parameters above, as outlined by Larsson et al. ${ }^{264}$ The electron becomes localized in a polaron state with a radius of 0.5 to $0.6 \mathrm{~nm}$. The polaronic ground state is at the bottom of a potential well and extends to 0.1 to $0.2 \mathrm{eV}$ below the conduction band.

Fig. 8 compares the optical absorption coefficient $\alpha$ as a function of photon energy for nearly stoichiometric polycrystalline and amorphous $\mathrm{W}$ oxide films produced by sputtering. ${ }^{261}$ In order to obtain a measure of the "absorption efficiency" upon $\mathrm{Li}^{+}$and electron insertion, the absorption coefficient was divided by the $\mathrm{Li}^{+} / \mathrm{W}$ ratio. For the polycrystalline films, we have verified that $\alpha$ is almost proportional to $x$ as long as $x$ remains below $\sim 0.07$, and a similar trend exists for amorphous films. ${ }^{284}$ In both cases, $\alpha$ displays a distinct peak in the near-infrared region. It is observed that the maximum absorption coefficient, when normalized by $x$, is significantly higher for the polycrystalline $\mathrm{W}$ oxide films. These films exhibit a peak centered at 0.6 to $0.7 \mathrm{eV}$, and the amorphous films have a peak at 1.2 to $1.3 \mathrm{eV}$. For the polycrystalline case,

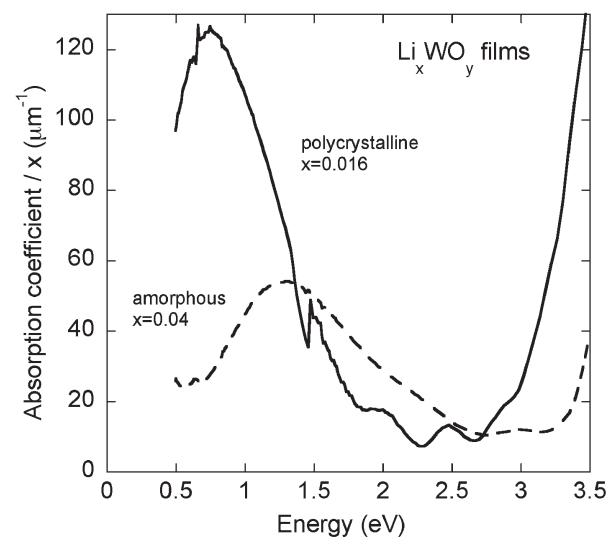

Fig. 8 Optical absorption coefficient divided by Li/W ratio $x$ for polycrystalline (full curve) and amorphous (dashed curve) nearstoichiometric tungsten oxide films $v s$. photon energy.

the peak maximum is close to $4 E_{\mathrm{p}}$, as estimated from polaron theory. ${ }^{264}$ Nanocrystalline $\mathrm{W}$ oxide films produced from nanoparticles display an absorption spectrum close to the one for polycrystalline $\mathrm{WO}_{3}$ in Fig. $8 .^{329}$ Similar polaronic absorption peaks have been previously observed in substoichiometric crystals and were then interpreted in terms of small-polaron theory. ${ }^{328}$

The different behaviours of the optical absorption for amorphous and polycrystalline films may point at differences in absorption mechanisms that are presently not well understood. In the case of amorphous $\mathrm{W}$ oxide, it was found that the localization radius of the electron states is much smaller than in the crystalline case. Hence the main localization mechanism appears to be disorder, but the electron-phonon interaction certainly influences the optical properties as well. Two pictures have been put forward for the optical absorption in amorphous $\mathrm{W}$ oxide. Theories of small-polaron absorption ${ }^{328}$ give qualitative agreement with experiments, but it is necessary to take effects of the electronic DOS into account in order to achieve quantitative agreement. ${ }^{284}$ The energy difference between initial and final polaron states gives rise to a shift of the absorption peak to higher energies. For obtaining a good curve fit, it is sufficient to assume a simple Gaussian DOS. ${ }^{284,330}$ Another picture, based on intervalence charge transfer absorption, was introduced in early work by Faughnan et al. $^{331}$ The optical absorption process was then modeled as ensuing from charge transfer of electrons from $\mathrm{W}^{5+}$ to $\mathrm{W}^{6+}$ sites.

The fact that $\alpha$ is proportional to $x$ at not too large intercalation levels makes it meaningful to characterize the electrochromism in films by a coloration efficiency (CE) defined by $\Delta(\alpha d) / \Delta Q$, where $\Delta Q$ is the charge exchange effecting a certain change in the optical density. Specifically, it is practical to make use of information from cyclic voltammetry and spectrophotometry. ${ }^{332}$ The results for the films reported on here have CEs that are consistent with literature data. ${ }^{53}$

As discussed above, only $\mathrm{W}^{6+}$ is present in stoichiometric $\mathrm{W}$ oxide, while intercalated films also can have $\mathrm{W}^{5+}$ states. The "site-saturation" model of Denesuk and Uhlmann ${ }^{333}$ assumes that $\alpha$ is proportional to the number of available electronic 

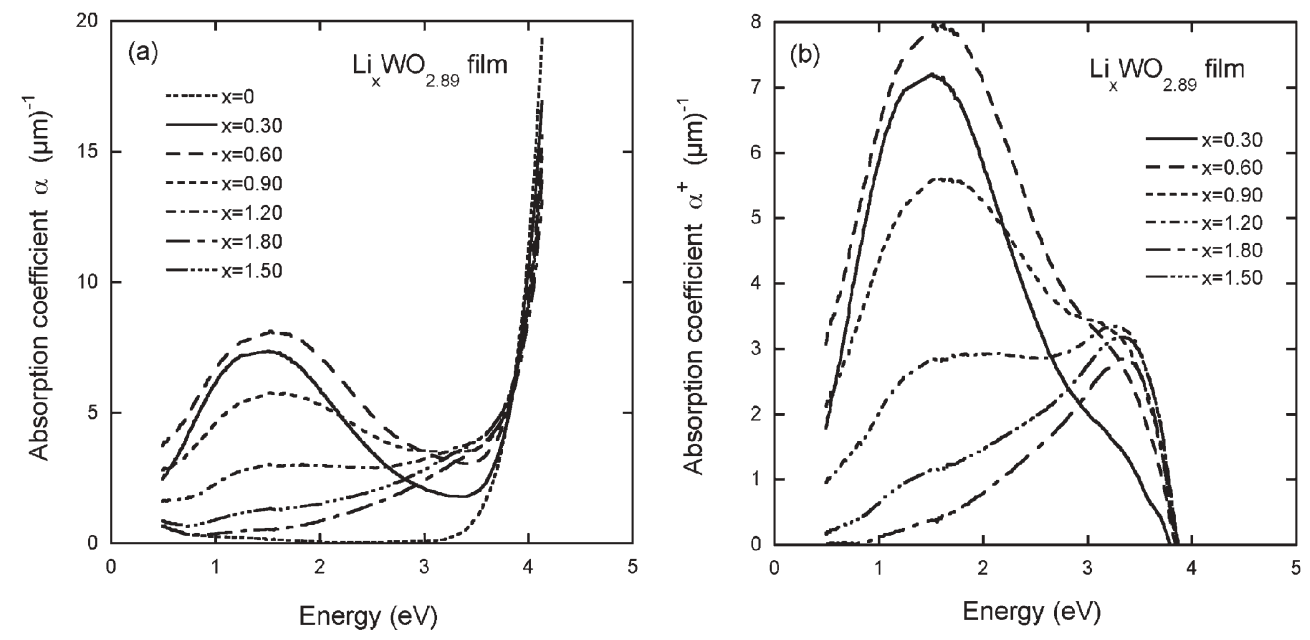

Fig. 9 (a) Absorption coefficient $\alpha$ vs. energy for a sub-stoichiometric amorphous $\mathrm{WO}_{2.89}$ film intercalated to the shown Li/W ratios $x$. (b) The corresponding absorption coefficient $\alpha^{+}$when the absorption $\alpha$ for the un-intercalated film, with data given in (a), has been subtracted.

transitions from a $\mathrm{W}^{6+}$ ion to a $\mathrm{W}^{5+}$ ion. This number can be found by multiplying the probabilities $P$ for $\mathrm{W}^{6+}(i . e ., 1-x)$ and $\mathrm{W}^{5+}$ (i.e., $x$ ) and is given by ${ }^{333}$

$$
\mathrm{W}^{6+} \leftrightarrow \mathrm{W}^{5+}: P=\left(x-x^{2}\right)
$$

An identical relation was applied recently to describe the intercalation process, ${ }^{334,335}$ it was found from considerations of dissipation and feedback leading to a "quadratic logistic" equation. The model predicts that the maximum of the total absorption should be at $x=0.5$ for stoichiometric films.

The notions underlying the site saturation model are interesting, and we next discuss how they can be extended to account for optical absorption in sub-stoichiometric and $\mathrm{Li}^{+}$ intercalated $\mathrm{W}$ oxide films, specifically reviewing recent work by Berggren. ${ }^{283}$ Reflectance $R$ and transmittance $T$ were measured by spectrophotometry on sputter deposited films, backed by glass substrates pre-coated with conducting ITO, having different compositions and a wide range of intercalation levels in the $0 \leqslant x \leqslant 2$ interval. The energy dependent absorption coefficient $\alpha(E)$ was calculated between 0.5 and $4 \mathrm{eV}$ from the expression ${ }^{336}$

$$
\alpha(E)=d^{-1} \ln \{[1-R(E)] / T(E)\}
$$

where $d$ is film thickness.

Fig. 9(a) displays absorption coefficients of $\mathrm{a} \mathrm{Li}^{+}$containing $\mathrm{WO}_{2.89}$ film at various intercalation levels as a function of energy. ${ }^{283,298}$ Qualitatively similar results were obtained for films comprised of $\mathrm{WO}_{2.63}, \mathrm{WO}_{2.89}$, and $\mathrm{WO}_{2.93}$. The steeply rising magnitude of $\alpha$ above $3.5 \mathrm{eV}$ is due to inter-band transitions across the fundamental band gap of $\mathrm{W}$ oxide as well as to contributions from the ITO coating and the glass substrate. The absorption in the as-deposited film $(x=0)$ is close to zero, and the slight increase towards low energies is due to absorption in the ITO. We now concentrate on the optical sub-band gap absorption in $\mathrm{W}$ oxide. To analyze this contribution, we subtract the absorption coefficient for the non-intercalated film from that of the intercalated ones. The result is shown in Fig. 9(b), where it is denoted $\alpha^{+}$. This absorption coefficient has a maximum at $\sim 1.5 \mathrm{eV}$, and it displays an initial increase as the intercalation level increases. Then the peak reaches saturation and finally decreases. The decrease takes place at the same time as another peak appears at higher energy. This behaviour continues until the new peak at $\sim 3.3 \mathrm{eV}$ takes over most of the absorption. The new peak is responsible for the brown colour when the intercalation level corresponds to $x>0.7$. Attempts to model the spectra in Fig. 9(b) with two Gaussian peaks did not lead to satisfactory results. However, a superposition of three Gaussians provided good fits for all intercalation levels. Two of the peaks were fixed at the positions observed in Fig. 9(b)-viz., $1.4 \mathrm{eV}$ (peak 1) and $3.37 \mathrm{eV}$ (peak 3)-while the position of the remaining peak (denoted 2) was found to vary between 2.45 and $2.70 \mathrm{eV}$. Fig. 10 yields the integrated strengths of the Gaussian peaks as a function of $x$ for the $\mathrm{WO}_{2.89}$ film. ${ }^{298}$ Similar results were obtained for the other samples. It is seen that peak 1 is the highest and has its maximum at $x \approx 0.5$. The peak increases in magnitude as the oxygen deficiency goes up. Peak 3, fixed at $3.37 \mathrm{eV}$, rises continuously as the intercalation level increases and is highest for the film composed of $\mathrm{WO}_{2.63}$. Peak 2, whose position was allowed to vary during the fitting, is pronounced and it seems to be at a maximum for $0.5<x$ $<1$. It was sometimes difficult to separate peaks 2 and 3 .

What is the cause of these three absorption peaks? The "site saturation" model can be extended to take into account transitions between three kinds of sites, namely those corresponding to $\mathrm{W}^{4+}, \mathrm{W}^{5+}$, and $\mathrm{W}^{6+}$, as discussed by Berggren. ${ }^{283}$ Furthermore, a generalization of the model is possible to the case where each site can be "empty" or "filled" not only with one "electron" but also with two. Starting with empty states $(x=0)$, most of the states will be singly occupied in the beginning. "Electron transitions" between "empty" and singly occupied states are then most common. As more single states are "filled" there will be an increased probability that also doubly occupied states will be formed. Analytical expressions 


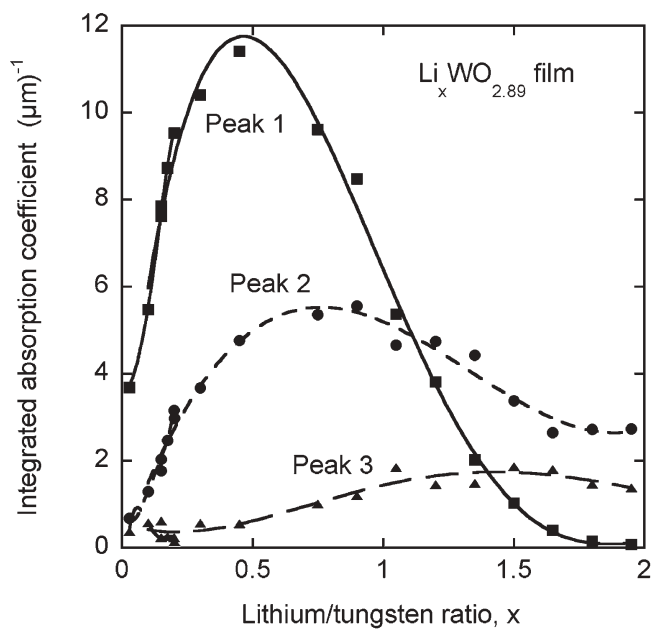

Fig. 10 Integrated absorption coefficient $v s$. Li/W ratio $x$ of three superimposed Gaussian peaks at energies of $1.4 \mathrm{eV}$ (peak 1), $3.37 \mathrm{eV}$ (peak 3), and 2.45 to $2.70 \mathrm{eV}$ (peak 2). These peaks emerged from a fit to the absorption coefficients shown in Fig. 9(b), as discussed in the main text. The curves were drawn solely for convenience.

for the possible electronic transitions can be found and are given by 283,298

$$
\begin{gathered}
\mathrm{W}^{6+} \leftrightarrow \mathrm{W}^{5+}: P=2 x(2-x)^{3} \\
\mathrm{~W}^{5+} \leftrightarrow \mathrm{W}^{4+}: P=2 x^{3}(2-x) \\
\mathrm{W}^{6+} \leftrightarrow \mathrm{W}^{4+}: P=x^{2}(2-x)^{2}
\end{gathered}
$$

for the number of transitions as a function of the intercalation ratio. These functions are depicted in Fig. 11. The qualitative behaviour displays significant similarities with the experimental results in Fig. 10, especially if one remembers that the absorption strength per transition might be different for the three cases.

It is of interest to compare the previous results with data for sub-stoichiometric films, and Fig. 12 displays optical

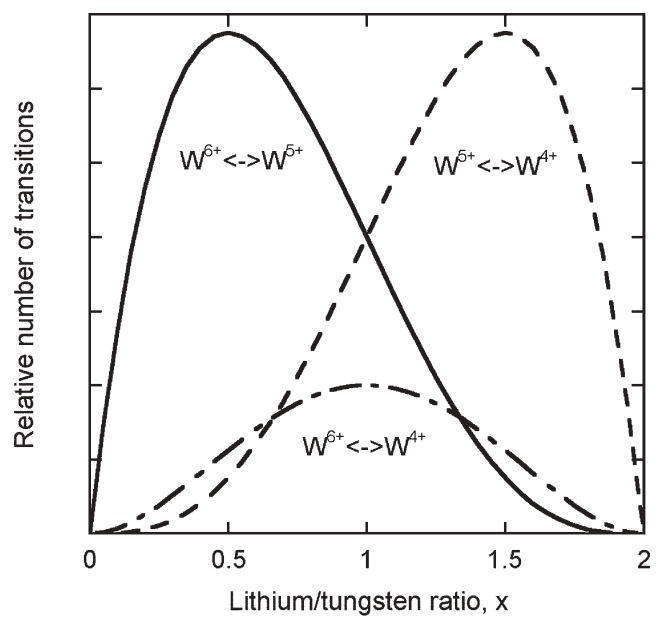

Fig. 11 Relative number of transitions of the types $\mathrm{W}^{6+} \leftrightarrow \mathrm{W}^{5+}, \mathrm{W}^{5+}$ $\leftrightarrow \mathrm{W}^{4+}$, and $\mathrm{W}^{6+} \leftrightarrow \mathrm{W}^{4+}$ vs. Li/W ratio $x$, as given by the analytical expressions in eqn $(7 \mathrm{a}-\mathrm{c})$.

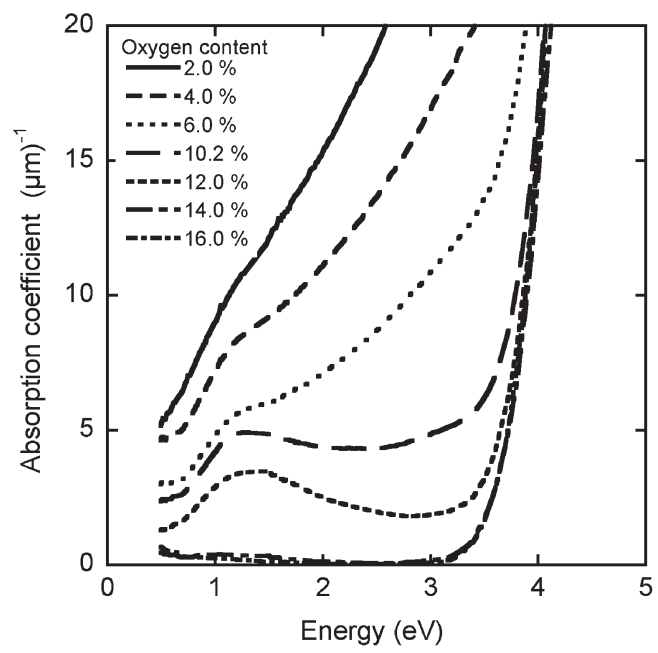

Fig. 12 Absorption coefficient vs. energy for as-deposited substoichiometric tungsten oxide films prepared by sputter deposition with the shown oxygen admixtures in the argon gas.

absorption coefficients of various samples produced by deposition with low $\mathrm{O}_{2} / \mathrm{Ar}$ flow ratios in the sputter gas. ${ }^{283}$ The films deposited with $\mathrm{O}_{2} / \mathrm{Ar}$ values of 16 and $12 \%$ consisted of $\mathrm{WO}_{2.89}$ and $\mathrm{WO}_{2.63}$, respectively. Films with $\mathrm{O} / \mathrm{W}$ ratios above $\sim 2.75$ were transparent, while lower oxygen contents gave rise to an absorption peak very similar to the one produced by $\mathrm{Li}^{+}$intercalation. A difference is that the tail close to the band gap was higher for the sub-stoichiometric films and increased as the $\mathrm{O} / \mathrm{W}$ ratio decreased. The most oxygen deficient films in Fig. 12 have an almost featureless absorption, increasing steeply with energy, and were visibly brown. This could be due to the process represented by eqn ( $7 \mathrm{~b}$ ) above or, possibly, to the occurrence of metallic tungsten particles in the oxide.

\section{E. Ion diffusion}

This section reports on measurements of ion transport by the galvanostatic intermittent titration technique ${ }^{337}$ (GITT) applied to polycrystalline and amorphous $\mathrm{W}$ oxide films. Prior to the GITT measurement, all films were found to be stable under electrochemical cycling. Ions were intercalated by applying a constant current over a limited time $\tau$, and the voltage was then allowed to relax to its steady-state value. The procedure was repeated in order to carry out measurements at different intercalation levels.

The chemical diffusion coefficient $\tilde{D}$ was calculated from the voltage response to the current step and the relaxation after the current pulse using a relation based on the semi-infinite diffusion approximation according to ${ }^{337}$

$$
\tilde{D}=\left[4 d^{2} /(\pi \tau)\right]\left(\Delta U_{\mathrm{s}} / \Delta U_{\mathrm{t}}\right)^{2}
$$

where $\Delta U_{\mathrm{s}}$ is the change of the steady state potential and $\Delta U_{\mathrm{t}}$ is the change in potential during the application of the current pulse, after correcting for ohmic drop. The semi-infinite approximation used in this model is valid when

$$
\tau \ll d^{2} / \tilde{D}
$$




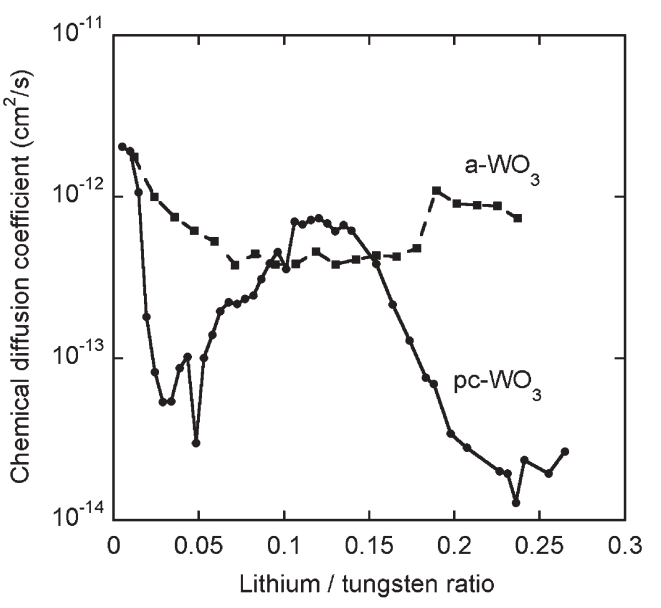

Fig. 13 Chemical diffusion coefficients from ref. $338 v$ s. Li/W ratio for polycrystalline ( $\mathrm{pc}$; circles) and amorphous (a; squares) tungsten oxide films. Individual data points are joined by straight lines.

All voltage responses showed a linear dependence on the square root of time, as expected for semi-infinite diffusion. ${ }^{338}$ Values for the chemical diffusion coefficients of the $\mathrm{W}$ oxide films were extracted by use of eqn (8). Specifically, the intercalation current was $2 \mu \mathrm{A} \mathrm{cm}^{-2}$ and it was applied for $240 \mathrm{~s}$. After each step the sample was allowed to relax until the voltage change was less than $1 \mathrm{mV} \mathrm{min}^{-1}$; this value was taken to represent the steady state.

The chemical diffusion coefficient of $\mathrm{Li}^{+}$in amorphous and polycrystalline $\mathrm{W}$ oxide films is presented in Fig. 13 as a function of $\mathrm{Li}^{+} / \mathrm{W}$ ratio. The results were discussed in detail by Strømme Mattsson. ${ }^{338}$ Clearly the amorphous and crystalline samples exhibit diffusion coefficients with very different behaviours as a function of potential, although the overall magnitudes are similar. The curve for polycrystalline $\mathrm{W}$ oxide displays two minima at steady state potentials of 2.75 and $2.55 \mathrm{~V}$ (corresponding to $x \approx 0.03 \pm 0.01$ and $x \approx 0.3$, respectively). ${ }^{339}$ The diffusion coefficient drops by almost two orders of magnitude at the minima.

The appearance of a distinct minimum in the diffusion coefficient $v s$. potential can be understood as the result of a phase transition during intercalation. The depths of the minima are associated with the crystallinity, and well-crystallized films exhibit deeper minima upon extraction and insertion of charge. Ideally, $\tilde{D}$ approaches zero as a discontinuity at the phase transition. This phenomenon can be reconciled with the lattice gas model with interactions. ${ }^{340}$ The chemical diffusion coefficient and the chemical potential $\mu$ for the Frumkin-type isotherm in this model are given by ${ }^{340,341}$

$$
\begin{gathered}
\tilde{D}=U(1-X) X(\partial \mu / \partial X) \\
\mu=\mu^{\circ}+R_{g} t \ln [X /(1-X)]+R_{g} \operatorname{tg} X
\end{gathered}
$$

where $X$ is the fraction of ions inserted due to the step current, $U$ is the mobility at $X=0, \mu^{\circ}$ is the standard value of the chemical potential, $R_{g}$ is the gas constant and $g$ is the interaction energy (divided by $k_{\mathrm{B}} t$ ) between the sites and includes the Coulombic interaction and the strain field in the lattice. $g$ is negative for attractive interaction and positive for repulsive interaction. Combining eqn (10) and (11), it can be shown that

$$
\tilde{D}=\tilde{D}_{X=0}+g \tilde{D}_{X}=0(1-X) X
$$

A fit of eqn (12) to the minimum in the diffusion coefficient around $2.75 \mathrm{~V}$ indicated attractive interactions between the inserted ions with $g$ close to $-4 .{ }^{338}$ The as-deposited polycrystalline $\mathrm{W}$ oxide films exhibit a monoclinic structure. During $\mathrm{Li}^{+}$intercalation, they first become tetragonal and then cubic at the minima seen in Fig. 12. ${ }^{339,342}$ The diffusion coefficient for the amorphous film displays a smoother behaviour with $\tilde{D}$ slightly decreasing as $x$ increases (i.e., as the potential drops). No indications of phase transitions are observed, as expected for an amorphous structure.

This section is concluded by a comparison of the electronic and ionic conductivities of $\mathrm{W}$ oxide films. We make an estimate by assuming that the chemical diffusion coefficient is not significantly different from the ionic one. A diffusion coefficient of $10^{-12} \mathrm{~cm}^{2} \mathrm{~s}^{-1}$ corresponds to an ion mobility of $4 \times 10^{-11} \mathrm{~cm}^{2} \mathrm{~V}^{-1} \mathrm{~s}^{-1}$ and, for realistic intercalation levels, an ionic conductivity of $\sim 3 \times 10^{-8} \mathrm{~S} \mathrm{~cm}^{-1}$. The electronic conductivities of polycrystalline and amorphous $\mathrm{W}$ oxide films, deposited under the conditions stated in section II B, have been measured by low-frequency dielectric spectroscopy. As-deposited films exhibited conductivities close to $10^{-7} \mathrm{~S} \mathrm{~cm}^{-1}$, with little difference between amorphous and polycrystalline samples. ${ }^{343}$ Upon intercalation, the electronic conductance of $\mathrm{W}$ oxide films can increase by orders of magnitude. ${ }^{310}$ Hence it is clear that electronic conduction dominates over ionic conduction in $\mathrm{W}$ oxide, although both are significant. Thus $\mathrm{W}$ oxide is indeed a mixed conductor, as EC materials should be.

\section{F. Concluding remarks on sputter deposited W oxide films}

Many physical properties of $\mathrm{W}$ oxide films are currently well understood. In particular this is so for films produced by sputter deposition, which is a technique of major interest for applications which we return to in section IV below. The W oxide needs to have an amorphous structure in order to exhibit good EC characteristics. Polycrystalline films also exhibit considerable optical modulation, but mostly in the nearinfrared spectral region. We have presented a conceptual picture of the structural characteristics of amorphous W oxide, based on the notions of defects in the ideal amorphous state.

The most important recent results on amorphous $\mathrm{W}$ oxide concern their electronic structure and optical properties. It is possible to obtain the conduction band density of states (up to $2.5 \mathrm{eV}$ from the band edge) from a simple electrochemical chronopotentiometry experiment. It has been shown that the electronic states are localized far up in the conduction band. When ions are intercalated into $\mathrm{W}$ oxide, the chargecompensating electrons enter these localized states. Hence the optical absorption underlying the EC effect would be best described as due to transitions between occupied and empty localized conduction band states.

A fully quantitative theory of such transitions is not yet at hand. However, one can profitably model the optical absorption in a more phenomenological way as due to a 
superposition of possible transitions between the charge states of the $\mathrm{W}$ ions $(6+, 5+$, and 4+). This model shows good agreement with experiments in a very wide range of $\mathrm{Li}^{+}$ concentrations in the films and represents a major step forward concerning a physical understanding of the optical properties.

\section{Nickel oxide films}

The most commonly used anodic oxide-based EC materials are Ni oxide ${ }^{344-347}$ and Ir oxide. ${ }^{348}$ They are able to change from a transparent state to a neutral coloured one upon extraction of protons or insertion of $\mathrm{OH}^{-}$ions. Charge-balancing electrons are simultaneously extracted from the valence band. The films are probably a mixture of oxide and hydroxide components in the bleached state, since a reservoir of protons seems to exist in the films. Due to the high cost and limited supply of Ir, the use of $\mathrm{Ni}$ oxide is favoured at least for large scale applications. These materials have been less widely studied than $\mathrm{W}$ oxide. However, the research has soared in recent years - especially for Ni-oxide-based films - as seen from the references given in the Introduction. Generally speaking, the physical understanding of the properties of anodic EC materials is on a less advanced level than for $\mathrm{W}$ oxide (discussed in section II above). Below we review the properties of Ni-oxide-based materials with special emphasis on a recent thorough study in the authors' laboratory of $\mathrm{Ni}-\mathrm{V}$ oxide thin films. ${ }^{349-351}$

A variety of mixed oxides have also been studied lately in an attempt to improve the EC properties of anodically colouring materials. A number of mixed Ni-based oxides with enhanced modulation between the transparent and the coloured state have been discovered. ${ }^{208-211}$ The optical properties of these novel materials will be treated from a device perspective in more detail in section IV. Intercalation of $\mathrm{Li}^{+}$into Ni-oxidecontaining films has been researched several times, ${ }^{352-356}$ but it seems that the optical properties are not modulated to any large extent. ${ }^{357,358}$ This means that electrochromic Ni oxide films only can be used in devices where the optical modulation depends on proton/electron transport. One reason is that the oxygen-rich compounds $\mathrm{NiOOH}$ and $\mathrm{Ni}_{2} \mathrm{O}_{3}$ are strongly absorbing for visible light. It should be mentioned for completeness that reversible charging and discharging under $\mathrm{Li}^{+}$exchange has been discovered recently; here it seems that the $\mathrm{Li}^{+}$insertion is accompanied by the formation of metallic $\mathrm{Ni}$ dispersed in a matrix of $\mathrm{Li}_{2} \mathrm{O} .^{359}$

\section{A. Structural features}

The electrochromism in Ni-oxide-based materials probably involves several Ni-containing phases. In this section we review the basic properties of $\mathrm{Ni}$ oxides, ${ }^{360}$ hydroxides, and oxyhydroxides and how they can be transformed into one another upon proton or $\mathrm{OH}^{-}$exchange. In particular, we extend the well established Bode reaction scheme ${ }^{361,362}$ to high levels of proton exchange.

Nickel monoxide, $\mathrm{NiO}$, exhibits a cubic $\mathrm{NaCl}$ structure with a lattice parameter of $0.4173 \mathrm{~nm}^{363}$ Single crystalline Ni monoxide has a density of $6.67 \mathrm{~g} \mathrm{~cm}^{-3} .{ }^{363}$ It is not possible to make stoichiometric $\mathrm{NiO}$ crystals, since they always exhibit an excess of oxygen. ${ }^{364}$ The extra oxygen cannot be placed inside

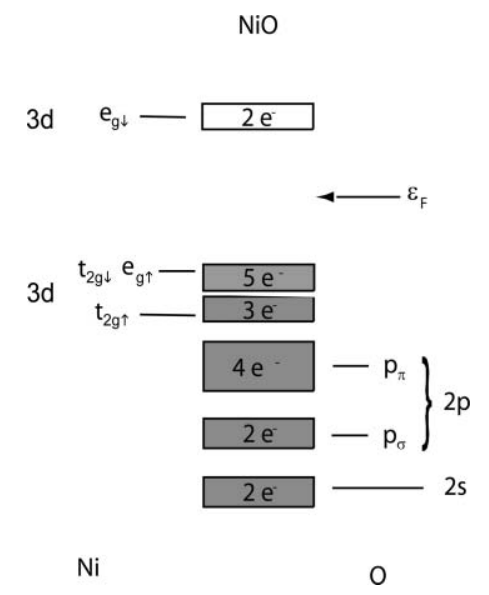

Fig. 14 Schematic band structure of $\mathrm{NiO}$, based on previous work in refs. 262, 263, and 367. Nickel and oxygen orbitals as well as majority and minority spin states are indicated using standard notation, together with the Fermi level $\left(\varepsilon_{\mathrm{F}}\right)$. The indicated number of electrons $\left(\mathrm{e}^{-}\right)$can be accommodated in the bands. Filled states are shaded.

the $\mathrm{NaCl}$ structure; instead vacancies related to $\mathrm{Ni}^{2+}$ are created, thus giving a p-type conduction character. ${ }^{365,366} \mathrm{~A}$ schematic band diagram is depicted in Fig. 14 (after Goodenough, ${ }^{262}$ Honig, ${ }^{263}$ and Hugel and Belkhir ${ }^{367}$ ). The upper part of the valence band consists of $\mathrm{Ni} 3 \mathrm{~d}$ states starting at $\sim 2 \mathrm{eV}$ below the Fermi level. In reality, these states overlap with a wide $\mathrm{O} 2 \mathrm{p}$ band at $\sim 4$ to $8 \mathrm{eV}$ from the Fermi level; ${ }^{360}$ the $\mathrm{Ni} 3 \mathrm{~d}$ and $\mathrm{O} 2 \mathrm{p}$ states are almost completely hybridized. ${ }^{368}$ There is a splitting between the Ni $3 \mathrm{~d}$ levels with different spin directions. $^{367,369}$ The optical band gap is $\sim 4 \mathrm{eV} ;{ }^{370}$ it may arise from the separation between the minority spin $t_{2 g}$ and $e_{g}$ bands. ${ }^{369}$ The conduction band consists of unoccupied Ni $3 \mathrm{~d}$ $\left(\mathrm{e}_{\mathrm{g}}\right)$ states with an admixture of $\mathrm{O} 2 \mathrm{p}$ states; $4 \mathrm{~s}$ and $4 \mathrm{p}$ bands are present at higher energies. ${ }^{368,371}$

Ni hydroxide has a hexagonal structure that consists of a packing of hydroxyl ions with $\mathrm{Ni}^{2+}$ occupying alternate rows of octahedral sites. $^{372}$ The $\mathrm{Ni}$ hydroxide exists in two modifications, $\alpha$ and $\beta$. Their only difference is the quantity of water needed for stabilization; the $\alpha$ phase occurs at low content of water and the $\beta$ phase at high content. ${ }^{373}$ The $\mathrm{Ni}(\mathrm{OH})_{2}$ structure of the $\alpha$ form comprises a stacking of the $\mathrm{Ni}(\mathrm{OH})_{2}$ layers with a large interlayer separation $(\sim 0.76 \mathrm{~nm})$, whereas the $\beta-\mathrm{Ni}(\mathrm{OH})_{2}$ has the same structure except that the interlayer separation is much smaller $(\sim 0.46 \mathrm{~nm}) .{ }^{372}$ These two phases can be further de-hydrated (oxidized) to the corresponding $\gamma$ and $\beta$ oxy-hydroxides for the $\alpha$ and $\beta$ phases, respectively, as proposed by Bode et al. ${ }^{361,362}$ The reaction scheme is usually presented as

$$
\begin{array}{ccc}
\beta-\mathrm{Ni}(\mathrm{OH})_{2} & \leftrightarrow & \beta-\mathrm{NiOOH}+\mathrm{H}^{+}+\mathrm{e}^{-} \\
\uparrow & & \uparrow \\
\alpha-\mathrm{Ni}(\mathrm{OH})_{2} & \leftrightarrow & \gamma-\mathrm{NiOOH}+\mathrm{H}^{+}+\mathrm{e}^{-}
\end{array}
$$

Contraction is observed upon dehydration. A poorly crystallized phase of $\mathrm{Ni}$ hydroxide, characterized by the coexistence of $\alpha$ and $\beta$ phases, has also been identified. ${ }^{374}$ The densities of the pure phases differ considerably and have been reported to be 2.6 to $2.8 \mathrm{~g} \mathrm{~cm}^{-3}$ and 3.65 to $4.15 \mathrm{~g} \mathrm{~cm}^{-3}$ for the $\alpha$ and $\beta$ 
structures, respectively. ${ }^{361-363,375,376}$ An elucidation of the Bode scheme has been given recently. ${ }^{377}$

$\mathrm{Ni}$ hydroxide is an n-type semiconductor with a band gap of $\sim 3.6$ to $3.9 \mathrm{eV}$, while the oxy-hydroxide phase is a p-type semiconductor with a band gap of $\sim 1.7$ to $1.8 \mathrm{eV}^{378}$ Additional absorption close to $1.5 \mathrm{eV}$ has also been observed for the Ni oxy-hydroxide. ${ }^{378}$ The electronic structure of the hydroxide exhibits features similar to those of $\mathrm{NiO}$, which is to be expected since they have the same nature of the charge transfer between $\mathrm{Ni} 3 \mathrm{~d}$ and $\mathrm{O} 2 \mathrm{p}$ states. ${ }^{379}$

The Bode reaction scheme illustrated in reaction (13) above does not involve $\mathrm{NiO}$, and hence it cannot explain how nickel in the $\mathrm{NiO}$ phase can change its valency from $2+$ to $3+$ upon coloration. However, this reaction scheme can be extended in order to include such a possibility. ${ }^{349,350}$ It is known that excess oxygen in $\mathrm{NiO}$ produces a $\mathrm{Ni}^{2+}$ vacancy, which leads to the creation of a hole on two adjacent $\mathrm{Ni}^{2+}$ ions, thus producing $\mathrm{Ni}^{3+}$ ions. ${ }^{380}$ A similar situation is encountered upon extraction of two protons from $\mathrm{Ni}$ hydroxide. The condition of charge neutrality leads to the creation of two $\mathrm{Ni}^{3+}$ ions, and the superoxide $\mathrm{Ni}_{2} \mathrm{O}_{3}$ is formed from $\mathrm{Ni}$ oxide and hydroxide. This reaction is included in the extended Bode scheme in reaction (14) below, involving both proton extraction from the proton-containing $\mathrm{Ni}(\mathrm{OH})_{2}$ phase and valence change of $\mathrm{Ni}$ atoms belonging to the $\mathrm{NiO}$ phase. The extraction of $\mathrm{H}^{+}$causes a transformation from $\mathrm{Ni}(\mathrm{OH})_{2}$ to $\mathrm{NiOOH}$, and the extraction of another $\mathrm{H}^{+}$is compensated for by creation of a hole on the $\mathrm{Ni}^{2+}$ in the $\mathrm{NiO}$ unit, viz.

$$
\begin{aligned}
& \beta \text {-Ni(OH })\left._{2}\right|_{\text {bleached }} \\
& \uparrow \\
& \alpha-\left.\mathrm{Ni}(\mathrm{OH})_{2}\right|_{\text {bleached }} \leftrightarrow \gamma-\left.\mathrm{NiOOH}\right|_{\text {coloured }}+\mathrm{H}^{+}+\mathrm{e}^{-} \\
& \mathrm{NiO}+\alpha-\left.\left.\mathrm{Ni}(\mathrm{OH})_{2}\right|_{\text {bleached }} \leftrightarrow \mathrm{Ni}_{2} \mathrm{O}_{3}\right|_{\text {coloured }}+2 \mathrm{H}^{+}+2 \mathrm{e}^{-}
\end{aligned}
$$

The compounds on the left-hand side are optically transparent, while those on the right-hand side are absorbing. The transformation from one to the other thus gives rise to the characteristic electrochromism of hydrated Ni-oxide-based materials.

Alternatively, $\mathrm{OH}^{-}$groups may contribute to the ion intercalation in $\mathrm{Ni}$ oxide and hydroxide according to the reactions $^{381,382}$

$$
\begin{gathered}
\mathrm{Ni}(\mathrm{OH})_{2}+\mathrm{OH}^{-} \leftrightarrow \mathrm{NiOOH}+\mathrm{H}_{2} \mathrm{O}+\mathrm{e}^{-} \\
\mathrm{NiO}+\mathrm{OH}^{-} \leftrightarrow \mathrm{NiOOH}+\mathrm{e}^{-}
\end{gathered}
$$

Indeed, some experimental evidence has been presented in favour of this possibility. ${ }^{383}$ Below we will describe the results of carefully designed experiments by which it is possible to distinguish between $\mathrm{H}^{+}$and $\mathrm{OH}^{-}$exchange.

\section{B. Thin film deposition}

Magnetron sputtering has frequently been used for deposition of $\mathrm{Ni}$ oxide coatings. $\mathrm{DC}$ and $\mathrm{RF}$ reactive sputtering from metallic targets give films with similar properties, in particular good electrochromism and good stability under extended electrochemical cycling. Magnetron sputtering is an industrially viable technique with excellent capacity for large scale, large area manufacturing, but the magnetism of the $\mathrm{Ni}$ target poses technical problems and it is more advantageous to deposit Ni-oxide-based films from non-magnetic targets. A widely available non-magnetic alloy is nickel-vanadium containing $7 \% \mathrm{~V}$. In order to ensure the technological relevance of the present Feature Article, we concentrate below on the properties of hydrated $\mathrm{Ni}-\mathrm{V}$ oxide coatings produced by sputtering. However, it should be noted that the deposition process and the physical properties are similar to those of pure $\mathrm{Ni}$ oxide as well as other Ni-oxide-based films. In particular, the optical properties and the electrochromism of the $\mathrm{Ni}-\mathrm{V}$ oxide films are close to those of pure Ni oxide.

A non-magnetic $\mathrm{Ni}(93 \%)-\mathrm{V}(7 \%)$ alloy was hence used as sputter target. The deposition was conducted in a reactive atmosphere of $\mathrm{Ar}+\mathrm{O}_{2}$ or $\mathrm{Ar}+\mathrm{O}_{2}+\mathrm{H}_{2}$ onto ITO-coated unheated glass substrates. The gas pressure was typically $30 \mathrm{~m}$ Torr and the film thickness was $\sim 200 \mathrm{~nm}$. The deposition process could be characterized by three regions; ${ }^{209,210,349}$ they are depicted in Fig. 15, showing film deposition rate $r$ and luminous transmittance $T_{\text {lum }}$ as a function of $\mathrm{O}_{2} / \mathrm{Ar}$ ratio. $T_{\text {lum }}$ was obtained by averaging the spectral transmittance over the sensitivity of the human eye. At low oxygen content, corresponding to region (1), films with close-to-metallic reflectance were deposited. In region (2), the films were transparent with $T_{\text {lum }}$ being as high as $74 \%$. Finally, dark brown films were deposited at high oxygen content, corresponding to region (3). Films from region (2) possess the best EC properties. From a sputtering point of view, regions (1), (2), and (3) correspond to metallic, partly oxidised, and completely oxidised target surfaces, respectively. A stable set point for thin film production was found to occur just before the abrupt change in the deposition rate from region (2) to (3). In region (3), the target tends to oxidise after a long period of sputtering. The deposition rate can be increased by applying a higher power to the target, since the quantity of sputtered metal then increases. In this case, the curves in Fig. 15 will shift to the right, as the quantity of oxygen needed to deposit the oxide must increase in order to equilibrate the excess of metal.

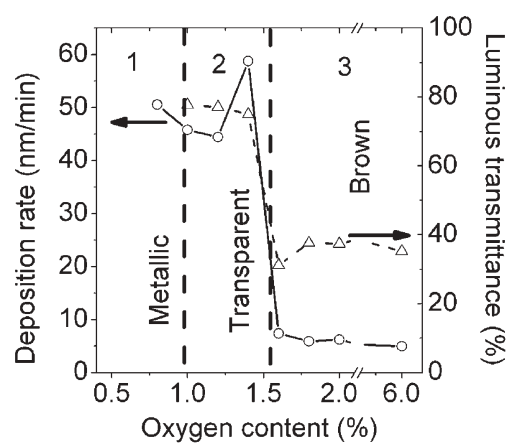

Fig. 15 Deposition rate and luminous transmittance in the asdeposited state of $\mathrm{Ni}-\mathrm{V}$ oxide vs. $\mathrm{O}_{2}$ content in the sputtering atmosphere. Three intervals are indicated corresponding to nearly metallic (1), transparent (2), and dark brown (3) films. The thickness was $\sim 200 \mathrm{~nm}$ for all films. Arrows indicate the applicable vertical scale. 
Addition of $\mathrm{H}_{2}$ to the gas mixture lowers $r$ and increases the transmittance in the as-deposited state by approximately $10 \%$. The films are brown at high hydrogen content (above 16\%); this probably follows from the lower deposition rate, implying that more oxygen atoms per metal arrive at the substrate. Optimum EC performance was observed at a low (2 to $12 \%$ ) amount of $\mathrm{H}_{2}$ in the gas mixture.

The percentage values of $\mathrm{O}_{2}$ and $\mathrm{H}_{2}$ in the gas mixture are relative numbers and depend on the characteristics of the equipment and the target. In general, the optimum relative amounts of these gases correspond to a value just before the target is oxidized and a decrease in the sputter rate is observed. In the case of sputtering from a pure Ni target, for example, the optimum $\mathrm{O}_{2} / \mathrm{Ar}$ ratio in region (2) is approximately $4.7 \%$.

Elemental compositions were determined by Rutherford backscattering spectrometry (RBS). However, the hydrogen content could not be determined with this method. Defining the composition as $\mathrm{Ni}_{1-p} \mathrm{~V}_{p} \mathrm{O}_{q}$, the three regions in Fig. 15 correspond to $p \approx 0.11$ and $q \leqslant 0.71$ for region (1), $0.05 \leqslant$ $p \leqslant 0.10$ and $1.45 \leqslant q \leqslant 1.75$ for region (2), and $p \approx 0.11$ and $q \approx 2.07$ for region (3). As pointed out before, films with optimum electrochromism were found in region (2); the densities of the films with good EC properties were $~ 3.6$ to $4.2 \mathrm{~g} \mathrm{~cm}^{-3}$.

The hydrated $\mathrm{Ni}-\mathrm{V}$ oxide films on ITO were used as working electrodes in a three-electrode electrochemical cell. Specifically, the electrolyte was a $1 \mathrm{M} \mathrm{KOH}$ solution and the film was cycled between $-0.65 \mathrm{~V}$ and $0.65 \mathrm{~V}$ vs. an $\mathrm{Ag} / \mathrm{AgCl}$ reference electrode. The $\mathrm{Ni}-\mathrm{V}$ oxide films had to be run through 10 to 20 colour-bleach cycles before the inserted and extracted charge became completely reversible. The stabilized films were then taken out in their fully bleached and coloured states in order to carry out ex-situ X-ray diffraction and other physical measurements.

X-Ray diffraction was used to study the structure of asdeposited and electrochemically coloured and bleached films deposited under the conditions of region (2). Clear evidence was found for a nano-crystalline phase. The diffraction patterns were characteristic of cubic $\mathrm{Ni}$ oxide (bunsenite), and the grain sizes were estimated to lie in the 10 to $25 \mathrm{~nm}$ range. As-deposited and electrochemically cycled films showed the same structural characteristics. No evidence was found for crystalline phases containing vanadium or hydrogen. A recent study $^{384}$ based on EXAFS provided clear evidence that $\mathrm{V}$ ions substitute $\mathrm{Ni}$ ions in the NiO-type structure and are distributed without clear evidence for clustering. In transparent films the $\mathrm{V}$ ions are at the centres of oxygen octahedra, and they shift by about $0.04 \mathrm{~nm}$ to off-centre positions upon coloration. ${ }^{384}$

\section{Electronic bandstructure}

The electronic bandstructure of $\mathrm{NiO}$ has been extensively studied by a number of computational and experimental techniques; early work has been summarized several times. ${ }^{365,369,385}$ Computations are cumbersome and often controversial. However, significant advances have been made and many experimental results can now be reproduced by $a b$ initio calculations. ${ }^{386-388}$ The electronic structure of non-stoichiometric $\mathrm{Ni}$ oxide has also been studied recently, ${ }^{389}$ but its relevance for the electrochromic hydrated material is not clear.

Ni-oxide-based EC films colour under proton extraction or $\mathrm{OH}^{-}$insertion. Charge compensating electrons are simultaneously extracted from the valence band of the compound. In order to provide a deeper insight into the underlying science, it is hence of much interest to detect changes in the occupied electronic states during the exchange of ions. One of the most convenient techniques to study the occupied states is XPS, as noted in section II. Chronopotentiometry cannot be used in the case of Ni-based oxides, because any information on the electronic states would be obscured by a number of phase transitions as protons are extracted. We return to these phase transitions in section III E below. The present section reviews a recent thorough XPS study of $\mathrm{Ni}-\mathrm{V}$ oxide thin films by Avendaño et $a l .{ }^{351}$ The films were prepared by sputter deposition under conditions of region (2), as described above. Data were taken by use of synchrotron radiation; the photon energy was varied from 50 to $1500 \mathrm{eV}$. The end of the beam line was equipped with a high-resolution hemispherical electron analyser with an energy resolution $E / \Delta E$ from $10^{3}$ to $10^{4}$. The photon flux on the sample was in the range of $10^{11}$ to $10^{13} \mathrm{~s}^{-1}$. Measured spectra were normalized with respect to the $\mathrm{Ni} 2 \mathrm{p}$ core states, and the binding energy (BE) calibration was done by setting the $\mathrm{BE}$ of adventitious carbon to $285 \mathrm{eV} .^{390}$

XPS measurements were carried out for core states of $\mathrm{Ni}, \mathrm{O}$, and $\mathrm{V}$, as well as for the states forming the top of the valence band. The measurements were performed on as-deposited, bleached, and coloured hydrated $\mathrm{Ni}-\mathrm{V}$ oxide films. The measurements for the coloured and bleached conditions were performed during the same run, on different halves of the same film. We first discuss the core state spectra, since they contain important information on the phases and compounds present in the films.

$\mathrm{Ni} 2 \mathrm{p}_{3 / 2}$ states in $\mathrm{NiO}$ exhibit a double peak at BEs between 852 and $860 \mathrm{eV}$. For a perfect $\mathrm{NiO}$ crystal, the ratio between the lower BE peak (centred at $\sim 854.8 \mathrm{eV}$ ) and the higher BE peak (centred at $\sim 856.1 \mathrm{eV}$ ) is $4 / 3 .{ }^{391} \mathrm{Ni}$ atoms in the $3+$ valency state give an XPS peak centred at $\sim 855.7 \mathrm{eV}$, i.e., between the two peaks of the NiO. In the measured XPS signal, the contribution of the $3+$ states causes the double peak to appear with an intensity ratio different than $4 / 3$. The two peaks overlap strongly in the spectra, but the change in the peak shape is consistent with more $\mathrm{Ni}^{3+}$ ions in the coloured film than in the bleached one.

The $\mathrm{O} 1 \mathrm{~s}$ states in oxide phases such as $\mathrm{NiO}$ and $\mathrm{Ni}_{2} \mathrm{O}_{3}$ exhibit single peaks centred at $\sim 529.7 \mathrm{eV}$ (refs. 391 and 392) and $531.4 \mathrm{eV},{ }^{393}$ respectively. In the hydrogen-containing phases based on $\mathrm{Ni}(\mathrm{OH})_{2}$ and $\mathrm{NiOOH}$, the $\mathrm{O}$ 1s peak is located at $\sim 531.3 \mathrm{eV}$ (refs. 394-396) and $531.7 \mathrm{eV},{ }^{397}$ respectively. All of these peaks overlap in the measured spectra, but the intensity redistribution within the measured line can be used to obtain evidence for phase transformations taking place upon coloration and bleaching.

Fig. 16 shows $\mathrm{O} 1 \mathrm{~s}$ states for stabilised hydrated Ni-oxidebased films in the coloured and bleached conditions. Spectra were taken with two incident photon energies. Spectra for the bleached film are consistent with a mixture of optically transparent $\mathrm{NiO}$ and $\mathrm{Ni}(\mathrm{OH})_{2}$ phases. The spectra of the 


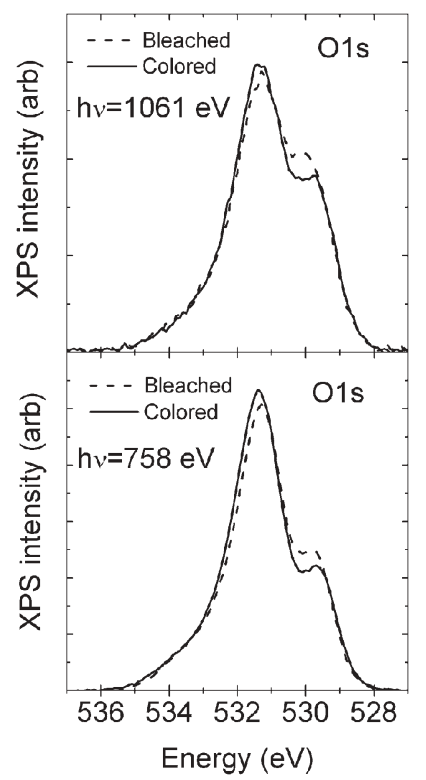

Fig. 16 XPS spectra for O 1s core states of stabilized hydrated Ni-V oxide films in coloured and bleached conditions. Photon energies of $1061 \mathrm{eV}$ and $758 \mathrm{eV}$, with energy pass of $40 \mathrm{eV}$ and energy step $0.1 \mathrm{eV}$, were used.

coloured film must have additional contributions from $\mathrm{NiOOH}$ and/or $\mathrm{Ni}_{2} \mathrm{O}_{3}$, but these overlap with the Ni hydroxide signal at $\sim 531.5 \mathrm{eV}$. However, it is observed that the $\mathrm{NiO}$ peak at $529.7 \mathrm{eV}$ decreases in intensity during coloration, while the other peak increases. This clearly indicates that the $\mathrm{NiO}$ phase plays a role in the coloration process. All of the spectra in Fig. 16 have higher intensity at $758 \mathrm{eV}$ than at $1061 \mathrm{eV}$. The analyzed surface layer is thinner at lower photon energy; therefore the results imply that the outermost surfaces of the grains are more oxygen-rich than the bulk. Approximately $35 \%$ more oxygen was detected at the photon energy $758 \mathrm{eV}$ than at $1061 \mathrm{eV}$.

The $\mathrm{O} / \mathrm{Ni}$ ratio at the surface was calculated by subtraction of the XPS background and subsequent integration of the spectra for the $\mathrm{Ni} 2 \mathrm{p}$ states, divided by the corresponding values obtained for the $\mathrm{O} 1 \mathrm{~s}$ states. The $\mathrm{O} / \mathrm{Ni}$ ratio for asdeposited films increased by $\sim 9 \%$ after five colour-bleach cycles. In addition, for as-deposited films the peak at lower BE $(529.7 \mathrm{eV})$ was stronger than the other one. The reduction in intensity upon going from the as-deposited to the stabilized bleached condition can be attributed to transformation of the hydrated Ni oxide to hydroxide. Such a transformation may involve excess oxygen, present in the films from the beginning, together with protons and/or $\mathrm{OH}^{-}$introduced during electrochemical cycling.

For the stabilized films, the difference between the $\mathrm{O} / \mathrm{Ni}$ ratio for the bleached and coloured conditions was less than $1 \%$, implying that there was no significant transport of oxygen upon cycling. This result is important since it disproves the interchange of hydroxyl groups during coloration and points at intercalation of protons being the only important process. Hence reaction (14), where $\mathrm{NiO}$ reacts with the hydroxide and produces $\mathrm{Ni}_{2} \mathrm{O}_{3}$ upon proton extraction, is fully consistent with the spectra presented in Fig. 16.

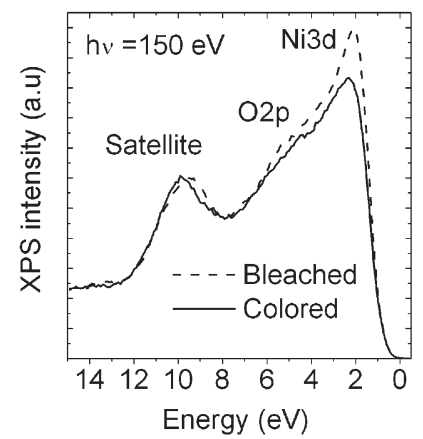

Fig. 17 XPS spectra for Ni 3d and O 2p states of stabilized hydrated $\mathrm{Ni}-\mathrm{V}$ oxide films in coloured and bleached conditions. The $\mathrm{V} 3 \mathrm{~d}$ and $\mathrm{Ni} 3 \mathrm{~d}$ states are overlapping. A photon energy of $150 \mathrm{eV}$, with energy pass of $10 \mathrm{eV}$ and energy step $0.1 \mathrm{eV}$, was used.

Fig. 17 shows the top of the valence band for stabilized hydrated $\mathrm{Ni}-\mathrm{V}$ oxide films under coloured and bleached conditions. The valence band consists of $\mathrm{Ni} 3 \mathrm{~d}$ states close to the band edge together with a broad $\mathrm{O} 2 \mathrm{p}$ band at $\sim 2$ to $6 \mathrm{eV}$ from the edge. In addition, a satellite can be seen at $\sim 10 \mathrm{eV}$. The position of the Ni $3 \mathrm{~d}$ peak is shifted by $\sim 0.6 \mathrm{eV}$ towards higher energy for the coloured film, as compared to its location in the bleached one. A depopulation of the valence band in the coloured state with respect to the bleached state is observed, indicative of a valence change from $2+$ to $3+$ upon coloration. Interestingly, no significant shift of the band edge could be observed, and the decrease of the occupied electron states takes place over a very broad energy range. The reason for these features is not known at present. We note finally that valence changes in the vanadium additive are possible in principle, but ongoing work of ours shows beyond doubt that they play a very insignificant role in the electrochromism.

\section{Optical properties}

The EC properties of $\mathrm{Ni}-\mathrm{V}$ oxide films are strongly affected by the amount of $\mathrm{O}_{2}$ in the sputter plasma. The nearly metallic films, deposited with sputter parameters in region (1), did not exhibit any optical modulation. The initially transparent films in region (2), however, displayed pronounced electrochromism with a bleached-state value of $T_{\text {lum }}$ exceeding $80 \%$ and a coloured-state transmittance strongly decreasing within a narrow range of $\mathrm{O}_{2}$ flow. An increase of the $\mathrm{O}_{2}$ content of the sputtering gas in this intermediate range also yielded a significant enhancement of the charge capacity. Optimum performance was found at $\mathrm{O}_{2}$ concentrations somewhat below $1.5 \%$, as seen in Fig. 15. Larger $\mathrm{O}_{2}$ flows - corresponding to region (3) - led to as-deposited absorbing films with weak optical modulation and decreased charge capacity.

Transmittance and reflectance spectra were recorded for asdeposited, coloured, and bleached films. Data for the coloured and bleached films were obtained at maximum reversible optical contrast. The absorption coefficient $\alpha(E)$ was calculated from $T(E)$ and $R(E)$ using eqn (6). Data for bleached and coloured films are shown in Fig. 18. The optical spectra resemble earlier ones for $\mathrm{Ni}$ oxide. ${ }^{53,346,347}$ Spectra for the bleached film did not exhibit any structure in the studied energy range. The absorption above $3.7 \mathrm{eV}$ is due to the ITO 


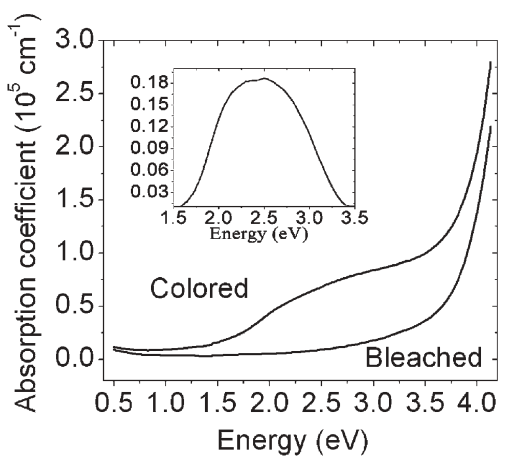

Fig. 18 Absorption coefficient vs. photon energy in the visible and near-infrared regions for coloured and bleached $\mathrm{Ni}-\mathrm{V}$ oxide films. The inset shows extracted data on the broad peak in the coloured state.

base layer. By plotting $\ln (\alpha)$ vs. photon energy one obtains a linear dependence between 3.5 and $3 \mathrm{eV}$ for the bleached film. This behaviour is referred to as an Urbach tail ${ }^{398}$ it is due to excitations between localized states in the band gap and the band edges. Logarithmic band edges have been reported ${ }^{399,400}$ before for hydrated $\mathrm{V}$ pentoxide, and hence the Urbach tail in the $\mathrm{Ni}-\mathrm{V}$ oxide films may be due to states associated with the $\mathrm{V}$ ions.

The coloured film exhibited broad absorption from 1.5 to $3.7 \mathrm{eV}$. The increase of the absorption in the coloured film is caused by charge transfer from $\mathrm{Ni}^{2+}$ to $\mathrm{Ni}^{3+}$ produced during the extraction of protons, as discussed in section III C. Previous results ${ }^{401}$ on films made by sputtering showed more pronounced structure in the absorption spectra, associated with oxygen excess in the Ni oxide. The inset in Fig. 18 shows the absorption coefficient extracted from the present optical spectra after subtraction of a base line.

The NiO phase is polycrystalline, and it is therefore interesting to compare the optical absorption with the polaron theory that was so successful in the case of polycrystalline W oxide. For Ni oxide, most of the pertinent parameters can be obtained from the literature. Thus $\varepsilon_{\infty}=5.4, \varepsilon_{0}=12$, and $E_{\mathrm{LO}}=$ $0.076 \mathrm{eV}^{402}$ In addition $\mathrm{m} / \mathrm{m}_{\mathrm{e}}$ is 1.66 (longitudinal) and 0.68 (transverse) in the valence band. ${ }^{325}$ These values lead to a polaron coupling constant in the range of 1.1 to 1.75 and to a polaron binding energy of the order of only $0.02 \mathrm{eV}$. The predicted peak absorption would then overlap with the longitudinal optical phonons far out in the infrared range. It is probable that the absorbing Ni oxy-hydroxide - conceivably being very disordered - gives the main contribution to the optical absorption in Fig. 18.

In the infrared range, electrochromic $\mathrm{Ni}-\mathrm{V}$ oxide films exhibit strong phonon absorption both in the bleached and the coloured states, although the details differ. ${ }^{350}$ The absence of a significant free-electron component suggests that the states in the valence band in Fig. 17 are actually localized. Hence the optical absorption in Fig. 18 might be modelled, more appropriately, on a premise of transitions between localized states. It should be noted that the absorption peak is situated in the region where the contributions of charge transfer absorption from $\mathrm{Ni}^{2+}$ to $\mathrm{Ni}^{3+}$ have been predicted. ${ }^{401} \mathrm{We}$ return to the optical properties of $\mathrm{Ni}$-oxide-based films, from a device perspective, in section IV A below.

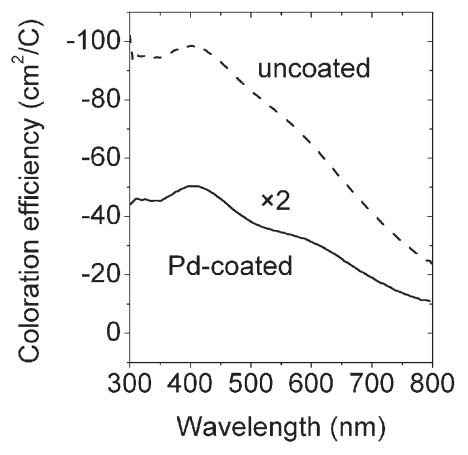

Fig. 19 Spectral coloration efficiency for $\mathrm{Ni}-\mathrm{V}$ oxide films. The curve for the film coated by a $25 \mathrm{~nm}$ thick layer of Pd (solid line) is multiplied by a factor of two.

Coloration efficiency (CE) is a convenient parameter for comparing the performance of EC films, as emphasized in section II $\mathrm{D}$ where this parameter was defined. The $\mathrm{CE}$ is very high for Ni-oxide-based films sputter deposited under conditions corresponding to region (2). Spectral CE is depicted in Fig. 19 for a hydrated $\mathrm{Ni}-\mathrm{V}$ oxide film as well as for a similar film coated by a thin Pd layer. This top layer serves as a membrane that only allows $\mathrm{H}^{+}$to penetrate to the underlying film. ${ }^{403}$ Thus all other ions-such as $\mathrm{OH}^{-}$and $\mathrm{K}^{+}$-were filtered out. It should be noted, for completeness, that the Pd layer did not display any optical modulation in the pertinent voltage range. The difference in the magnitude of the CEs in Fig. 19 ensues from the additional absorption in the $\mathrm{Pd}$ coating. The wavelengths where the $\mathrm{CE}$ displays peaks are the same in the cases of Pd coated and uncoated films. A decrease of the $\mathrm{CE}$ towards increasing wavelengths can be observed in both cases. The similarities in the main features of the CEs for $\mathrm{Pd}$ coated and uncoated films strongly suggest that the modulation of the optical absorption in the Ni-oxide-based film is exclusively due to the insertion/extraction of hydrogen.

\section{E. Ion diffusion}

Ion transport properties were investigated by the GITT technique ${ }^{337}$ applied to films of $\mathrm{Ni}-\mathrm{V}$ oxide and pure $\mathrm{Ni}$ oxide deposited under conditions of region (2). ${ }^{350}$ Prior to the GITT measurement, all films were stabilized by having undergone 70 colour-bleach cycles in $1 \mathrm{M} \mathrm{KOH}$. Specifically, the sequential current steps in GITT were $0.08,0.16,0.24,0.32$, and $0.40 \mathrm{~mA}$, in cycles of nine; the currents were applied for $20 \mathrm{~s}$, and the voltage was recorded during a relaxation time of $3580 \mathrm{~s}$; the steady-state voltage was taken to be the one when the change was less than $0.08 \mathrm{mV}$ during $10 \mathrm{~s}$.

We first compare the ion transport in hydrated $\mathrm{Ni}-\mathrm{V}$ oxide and $\mathrm{Ni}$ oxide films in order to study the possible influence of the $\mathrm{V}$ on the electrochemical properties. Fig. 20 presents data on chemical diffusion coefficient and quasi-steady-state voltage (SSV) for a pure hydrated $\mathrm{Ni}$ oxide film made by sputtering from a magnetic target of $99.9 \% \mathrm{Ni}$ in an atmosphere of $\mathrm{Ar}+\mathrm{O}_{2}+\mathrm{H}_{2}$. Data for a $\mathrm{Ni}-\mathrm{V}$ oxide film, deposited at the same power and pressure, are shown in Fig. 21. In both cases it is seen that $\tilde{D}$ exhibits two deep minima at about -0.1 and $0.23 \mathrm{~V}$. The SSV displays plateaus at these potentials, although the relation of SSV to the extracted $\mathrm{H}^{+} / \mathrm{Ni}$ ratio exhibits 

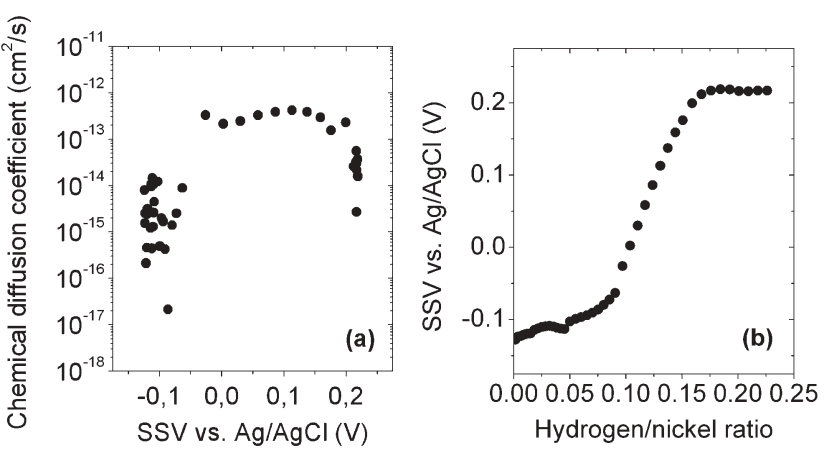

Fig. 20 Chemical diffusion coefficient of $\mathrm{H}^{+} v s$. steady-state voltage (SSV) (a) and SSV vs. atomic fraction of hydrogen (with respect to Ni) (b) deintercalated from an optimized $\mathrm{Ni}$ oxide film.
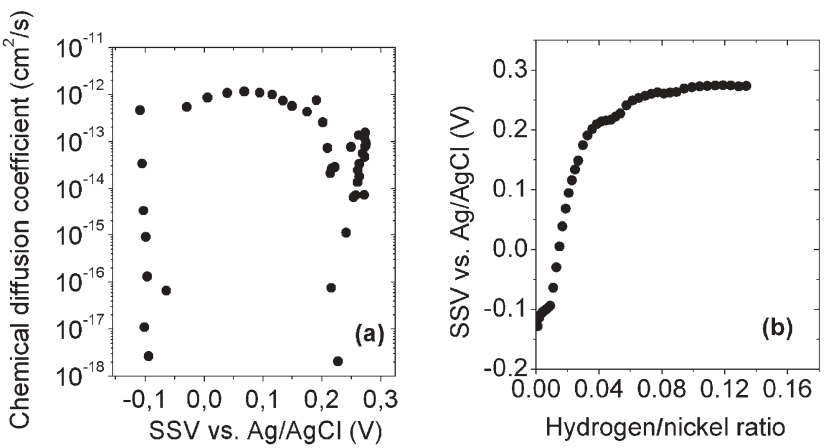

Fig. 21 Chemical diffusion coefficient of $\mathrm{H}^{+}$vs. steady-state voltage (SSV) (a) and SSV vs. atomic fraction of hydrogen (with respect to Ni) (b) deintercalated from an optimized $\mathrm{Ni}-\mathrm{V}$ oxide film. Pertinent experimental parameters are given in the main text.

differences. It seems that the hydrated $\mathrm{Ni}$ oxide film contains more hydrogen in the bleached state than the hydrated Ni-V oxide film.

The similarities between the data reported in Fig. 20 and 21 show that, effectively, the minima for $\tilde{D}$ ensue solely from the base material, i.e., the hydrous $\mathrm{Ni}$ oxide. We next interpret the two well-defined plateaus at -0.1 and $0.23 \mathrm{~V}$ which in both cases correspond to distinct minima in $\tilde{D}$. The appearance of a sharp minimum in the diffusion coefficient vs. potential can be understood as the result of a phase transition ${ }^{340}$ - as pointed out in section II E above - in the present case occurring during the extraction of protons from the hydrated Ni-oxide-based films. The amplitude of the minima of $\tilde{D}$ is associated with the crystallinity, and well-crystallized films exhibit deep minima upon extraction and insertion of charge. It is possible to identify the phases involved in the de-intercalation process by comparing the potentials at which the minima of $\tilde{D}$ appear with the optical properties. At the first minimum the film is still transparent, but the second one is located where the absorption starts to rise.

We suggest that the first minimum in Fig. 20 and 21 corresponds to the transition from $\beta-\mathrm{Ni}$ hydroxide to $\alpha-\mathrm{Ni}$ hydroxide, and that the second one stems from a transition from $\alpha$-Ni hydroxide to $\gamma-\mathrm{Ni}$ oxy-hydroxide. It is well known that the $\mathrm{Ni}$ oxy-hydroxide phases have higher absorption than the Ni hydroxide phases. ${ }^{53}$ The proposed phase transitions only involve proton exchange, which in the case under study is the dominating process governing the coloration. The assignment is fully consistent with the Bode reaction scheme given in section III A.

Accurate measurements of the initial quantity of hydrogen in the films are not available, and hence it is only possible to make a qualitative analysis of the data presented in Fig. 20 and 21. At the two apparent phase changes, $\tilde{D}$ decreases by four to five orders of magnitude at the actual transition. This means that the model of the Frumkin-type isotherm that was introduced in section II E- in which the electron exchange is slow enough that quasi-equilibrium conditions may be assumed - is an excellent approach for a qualitative analysis. ${ }^{341}$ When $\tilde{D}$ approaches zero at the phase change, the "critical" value of $g$ will be close to -4 , which means that the net force between the ions is attractive. ${ }^{341}$

We finally consider the electronic conductivity of electrochromic Ni oxide. Bleached films exhibit very low conductivity, of the order of $10^{-11} \mathrm{~S} \mathrm{~cm}^{-1}$, but the conductivity increases rapidly as the $\mathrm{Ni}$ oxide is coloured. ${ }^{404}$ Under deep coloration, the electronic conductivity is of the same order of magnitude as for as-deposited $\mathrm{W}$ oxide. Ni oxide is hence a mixed conductor, but with a much lower electronic conductivity than for $\mathrm{W}$ oxide.

\section{F. Concluding remarks on sputter deposited Ni-V oxide films}

There is an excess of oxygen in the as-deposited films, in combination with low density (high porosity) and small grain size. The grain surface is richer in oxygen than the bulk. Independently of the colour, there are always $\mathrm{Ni}$ atoms in valence states $2+$ and $3+$ in the films. The number of $\mathrm{Ni}^{3+}$ ions increases upon coloration.

A $\mathrm{NiO}$ structure was found by X-ray diffraction for films in all colour conditions, while the presence of other Ni-based phases - such as $\mathrm{Ni}(\mathrm{OH})_{2}, \mathrm{Ni}_{2} \mathrm{O}_{3}$, and $\mathrm{NiOOH}$ - was inferred from other data. This indicates that the coloration process is a surface phenomenon, most likely occurring in the outer parts of the grains.

In the beginning of an electrochemical cycling sequence, a number of cycles are required for the charge capacity to reach its maximum value and stabilize. XPS results are consistent with a transformation of the over-stoichiometric hydrated $\mathrm{Ni}$ oxide to hydroxide and oxy-hydroxide phases on the grain surfaces. The amount of oxygen in the films increases by $\sim 25 \%$ by intercalation of $\mathrm{OH}^{-}$groups occurring simultaneously with intercalation of protons from the electrolyte. GITT results ${ }^{350}$ suggest crystallization of the hydroxide and oxy-hydroxide phases during the initial intercalation cycles. After the charge capacity has been stabilized, experiments with Pd coated films, together with XPS results, showed that the electrochemical coloration occurs solely by proton intercalation, with the oxygen content in the films being equal under bleached and coloured conditions.

Upon proton extraction, GITT measurements were consistent with the Bode scheme in reaction (13). However, the Bode model does not explain the $2+$ to $3+$ valence change for nickel belonging to the $\mathrm{NiO}$ phase upon coloration, as observed by XPS (Fig. 16). An extension of the Bode scheme was suggested to account for these results; see section III B.

Approximately three monolayers have been estimated as the depth resolution for the $\mathrm{Ni} 2 \mathrm{p}$ and $\mathrm{O} 1$ s core levels when the 
photon energy is $1061 \mathrm{eV}$. Because the coloration is a surface effect and the bulk remains $\mathrm{NiO}$ independently of the film being bleached or coloured, one can argue that - after the transformation of the $\mathrm{Ni}(\mathrm{OH})_{2}$ to $\mathrm{NiOOH}$ - the change of the $\mathrm{NiO}$ to $\mathrm{Ni}_{2} \mathrm{O}_{3}$ may take place at the interface between the $\mathrm{NiO}$ and the $\mathrm{Ni}$ oxy-hydroxide. Owing to the fact that the electrochromism is basically a surface phenomenon, there is also a possibility that surface-related states - such as those for oxygen-reduced $\mathrm{NiO}\left(\begin{array}{lll}1 & 0 & 0\end{array}\right)$ - - lead to optical absorption due to in-gap states, which in this case appear to be related to surface metallicity. ${ }^{405}$

\section{Devices based on tungsten oxide and nickel oxide}

After having examined the fundamental properties of $\mathrm{W}$ oxide and $\mathrm{Ni}$ oxide films in sections II and III, respectively, we turn to devices incorporating such films. Rigid, glass-based devices of this kind have been reported on in a number of studies, ${ }^{66,195,406-417}$ and recently work on flexible polyesterfilm-based devices has been carried out in the authors' laboratory. ${ }^{70,418-420}$ Devices for emittance control have been discussed as well. ${ }^{417,421-424}$

With regard to device-related aspects, we first note that an optimization of the bleached-state transmittance and the colour rendering are of very great importance for practical applications, especially in the field of architecture. ${ }^{425,426} \mathrm{~W}$ oxide films are able to attain a highly transparent state, and the mixing with other oxides, such as Mo oxide and V oxide, is well known to produce a more or less neutral colour. ${ }^{53,137}$ The colour properties of Ni-oxide-based EC films have received less interest until a recent comprehensive investigation was done by Avendaño et al. ${ }^{211}$ (which expanded some earlier work $^{208}$ ). The results of this investigation are summarized in section IV A below. Colour properties of Au-containing Ni oxide films have received some attention as well. ${ }^{192}$ The colour of electrochromic Ir-oxide-based films has attracted interest recently too. ${ }^{157,427}$ Below we also cover aspects of device manufacturing with regard to thin film deposition and preassembly charge balancing in section IV B and device assembly and initial tests in section IV C.

\section{A. Optical properties of Ni-oxide-based films: bleached-state transmittance and colour}

Films of Ni-based oxides were deposited using standard DC and $\mathrm{RF}$ reactive magnetron co-sputtering from targets of $\mathrm{Mg}, \mathrm{Al}, \mathrm{Si}, \mathrm{Ni}, \mathrm{Zr}, \mathrm{Nb}, \mathrm{Ag}, \mathrm{Ta}, \mathrm{Ni}(61.5 \%)-\mathrm{Al}(38.5 \%)$, and $\mathrm{Ni}(93 \%)-\mathrm{V}(7 \%)$, following procedures outlined in section III B and described in detail by Avendaño et al. ${ }^{209,211,428}$ Unheated glass substrates, pre-coated with ITO having a resistance of $60 \Omega$ square $^{-1}$, were used for optical and electrochemical investigations as before, whereas polished carbon substrates were used for compositional analysis using RBS. Atomic ratios $\mathrm{Mg} / \mathrm{Ni}=0.80$ and $\mathrm{Al} / \mathrm{Ni}=0.59 \pm 0.03$ led to optimized $\mathrm{EC}$ properties. ${ }^{211}$ These compositions correspond to non-magnetic or weakly-magnetic sputter targets, which is advantageous with regard to manufacturing. The $\mathrm{Ni}-\mathrm{Mg}$-oxide-based system has been studied in detail, and it appears that $\mathrm{Ni}_{p} \mathrm{Mg}_{1-p} \mathrm{O}$ as well as $\mathrm{Ni}_{p} \mathrm{Mg}_{1-p}(\mathrm{OH})_{2}$ form solid solutions as a consequence of the similarities of the ionic radii for $\mathrm{Ni}^{2+}$ and $\mathrm{Mg}^{2+} .429-431$
Cyclic voltammograms were recorded by use of a threeelectrode electrochemical cell in a $1 \mathrm{M} \mathrm{KOH}$ solution. After some initial voltammetric cycles to stabilize the EC performance, spectral transmittance $T(\lambda)$ and reflectance $R(\lambda)$ were measured in the $300<\lambda<800 \mathrm{~nm}$ range with the films in their fully bleached and coloured states. In general, the shapes of the voltammograms changed depending on the specific additive to Ni oxide, but the main features characteristic of the pure oxide tended to prevail. The charge capacity - and hence the magnitude of the electrochromism - is influenced by the potentiodynamic range, particularly the potential for full coloration, $E_{\mathrm{col}}$. Similar charge capacities (from 15 to $20 \mathrm{mC} \mathrm{cm}^{-2}$ ) could be obtained provided that $E_{\mathrm{col}}$ was varied by 0.05 to $0.1 \mathrm{~V}$ when additives were present. This shift is insignificant for EC device applications.

It is of particular interest to be able to maximize the bleached-state transmittance in EC devices, as pointed out above. To that end we evaluated the spectral absorptance $A(\lambda)$ for Ni-oxide-based films from $A(\lambda)=1-T(\lambda)-R(\lambda)$. Fig. 22 shows that a significant decrease of $A(\lambda)$ occurred at short wavelengths for additives $\mathrm{Mg}, \mathrm{Al}, \mathrm{Si}, \mathrm{Zr}, \mathrm{Nb}$, and $\mathrm{Ta}$, whereas films containing $\mathrm{V}$ or $\mathrm{Ag}$ did not show any improvement in their optical properties compared to those of pure $\mathrm{Ni}$ oxide. Similar results for $\mathrm{Mg}$ additives have been reported also by others. ${ }^{432}$ The addition of $\mathrm{Fe}$ or $\mathrm{Zn}$ makes the band gap smaller. ${ }^{433,434}$ The increase of the bleached-state transmittance did not have any detrimental effect on the coloration efficiency. In fact, a CE even somewhat larger than that shown for $\mathrm{Ni}-\mathrm{V}$ oxide in Fig. 19 could be observed for $\mathrm{Ni}-\mathrm{Al}$ oxide films. $^{211}$

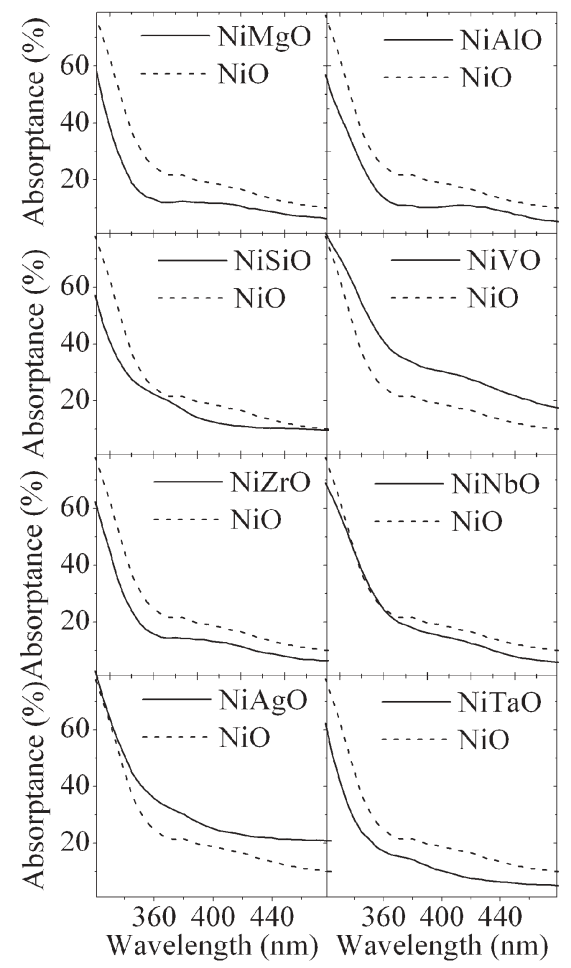

Fig. 22 Spectral absorptance of electrochromic Ni-oxide-based films in their bleached states. The designation NiMO (with $\mathrm{M}$ being $\mathrm{Mg}, \mathrm{Al}$, $\mathrm{Si}, \mathrm{V}, \mathrm{Zr}, \mathrm{Nb}, \mathrm{Ag}$, or $\mathrm{Ta}$ ) indicates that $\mathrm{M}$ is present in the oxide but does not specify the amount. 
The strong absorptance at $\lambda<350 \mathrm{~nm}$ is due to the semiconductor band gap, which appears to be widened as a consequence of the addition of $\mathrm{Mg}, \mathrm{Al}, \mathrm{Si}, \mathrm{Zr}, \mathrm{Nb}$, or $\mathrm{Ta}$ and narrowed by the addition of $\mathrm{V}$ or $\mathrm{Ag}$. Alternatively, the additives may affect optical absorption caused by defects such as vacancies, over-stoichiometry, grain boundaries, etc. Thermodynamically stable $\mathrm{Ni}$ oxide is a p-type conductor due to excess oxygen ${ }^{365,366}$ as pointed out in section III A. It is then plausible that the p-type conductivity and the residual optical absorption in the bleached state originate from the same electron states, and this may explain why films of pure $\mathrm{Ni}$ oxide cannot be made completely colourless. When Al is added, for example, it can act as a donor of electrons and fill electron (hole) states, thereby reducing the residual absorption. The addition of $\mathrm{V}$, on the other hand, may provide acceptor states whose effect would be to enhance the residual absorption.

We next consider the colour of electrochromic Ni-oxidebased films. Quantitative assessments of colour can be performed in several different ways; here we employ the CIE colorimetric system. ${ }^{435,436}$ The purpose of colorimetric analysis is to give colour specifications for observers with normal vision in terms of tri-stimulus values or chromaticity coordinates. The ideal observer's colour matching functions are denoted $\bar{x}, \bar{y}$, and $\bar{z}$, and represent red, green, and blue primaries, respectively. One can describe any colour as an additive mixture of these. The $\bar{y}$ curve is chosen so that it coincides with the luminous efficiency of the light-adapted eye, and hence it can be used to evaluate $T_{\text {lum }}$. The CIE 1964 tristimulus values corresponding to a certain colour stimulus $\Psi(\lambda)$ are obtained from

$$
X_{\mathrm{CIE}}=\frac{\int \bar{X}(\lambda) \Psi(\lambda) \mathrm{d} \lambda}{\int \bar{Y}(\lambda) S(\lambda) \mathrm{d} \lambda}
$$

and analogously for $Y_{\mathrm{CIE}}$ and $Z_{\mathrm{CIE}}$. The colour stimulus of present interest is $\Psi(\lambda)=S(\lambda) T(\lambda)$ where $S(\lambda)$ is the relative spectral irradiance function. Chromaticity coordinatesdenoted $x, y$, and $z$-are then obtained from

$$
x=X_{\mathrm{CIE}} /\left(X_{\mathrm{CIE}}+Y_{\mathrm{CIE}}+Z_{\mathrm{CIE}}\right)
$$

and correspondingly for $y$ and $z$. These formulae lead to the chromaticity diagram shown in the lower parts of the various panels of Fig. 23. Any colour can be represented as a point within the shown boundary. The chromaticity coordinates for a colourless (achromatic) material are $x=y=z=0.333$.

The chromaticity coordinates were calculated for four different standard illuminants representing a chosen set of light sources. Illuminant D65 signifies the average North sky daylight at $6500 \mathrm{~K}$, illuminant A represents a tungsten halogen incandescent light source at $2856 \mathrm{~K}$ (typical home or store accent lighting), illuminant F11 pertains to a commercial rareearth-phosphor narrow-band fluorescent light source at $4000 \mathrm{~K}$ (used in Europe and the Pacific Rim for typical office or store lighting), and illuminant F2 represents a commercial wideband-fluorescent cool white light source at $4150 \mathrm{~K}$ (typical office or store lighting in the USA).
Fig. 23 shows chromaticity coordinates for the optimized Ni-oxide-based thin films reported on in Fig. 22 under CIE standard illuminants D65, A, F11, and F2. For illuminant D65, the data pertaining to the bleached state lie very close to the point representing colourlessness. The data for the coloured state are rather scattered, with the chromaticity depending on the specific additive. Also the trajectories in colour space between the bleached and coloured states are different for each of the additives. Another characteristic of the bleached state is that the dominant wavelengths are short so that the eye has low sensitivity. The chromaticity coordinates for the incandescent light (illuminant A) indicate a light yellow colour in the bleached state and a yellow-green colour in the dark state. The data points for the bleached state appear less dispersed than the corresponding points for D65. For fluorescent lights, F11 for narrow-band fluorescent and F2 for cool white fluorescent light sources, the data are similar
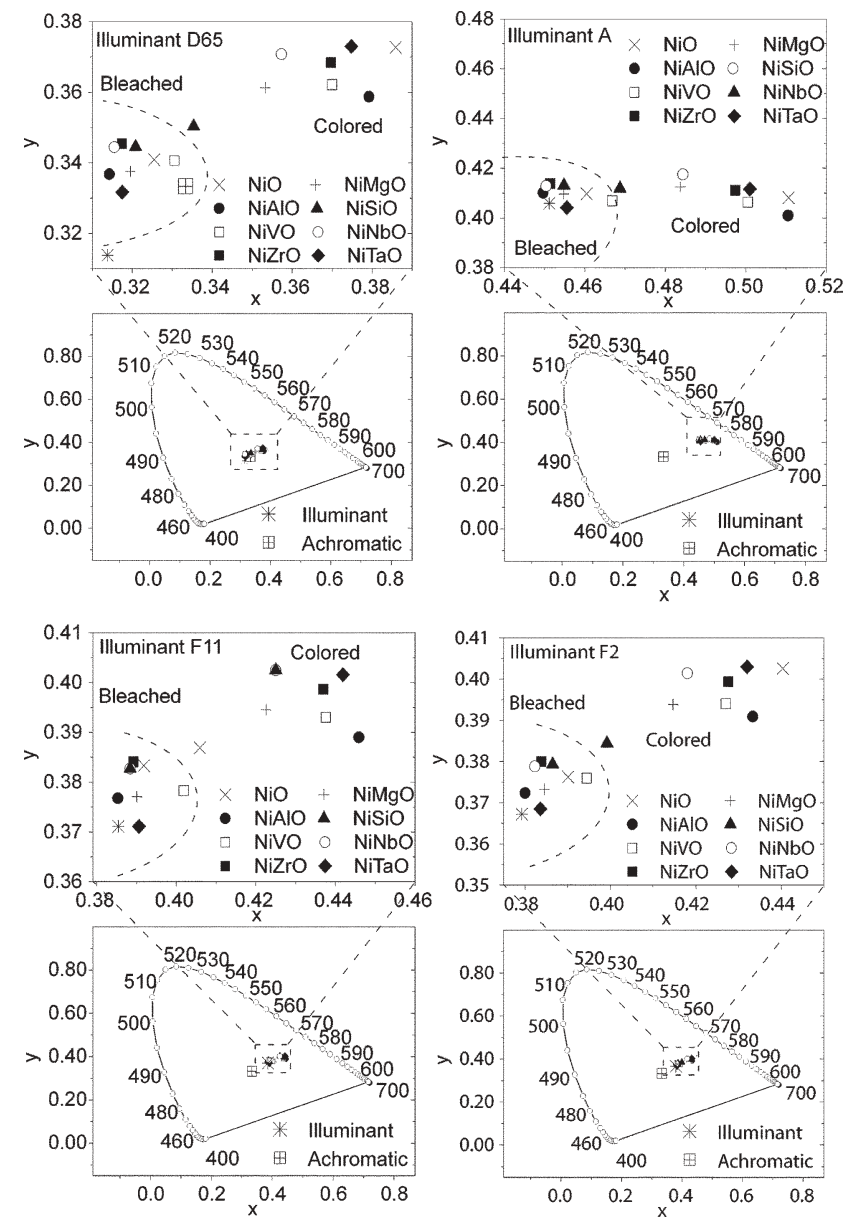

Fig. 23 CIE chromaticity diagrams representing the colour of optimized electrochromic Ni-oxide-based films in fully bleached and coloured states under daylight illumination (CIE D65), incandescent illumination (CIE A), narrow-band fluorescent illumination (CIE F11), and cool white fluorescent illumination (CIE F2). Coordinates signifying the illuminant as well as colourlessness (i.e., the achromatic point) are plotted as references. The upper part of each panel is a magnification of the central region of the lower part. The designation NiMO (with $\mathrm{M}$ being $\mathrm{Mg}, \mathrm{Al}, \mathrm{Si}, \mathrm{V}, \mathrm{Zr}, \mathrm{Nb}$, or Ta) indicates that $\mathrm{M}$ is present in the oxide but does not specify the amount. 


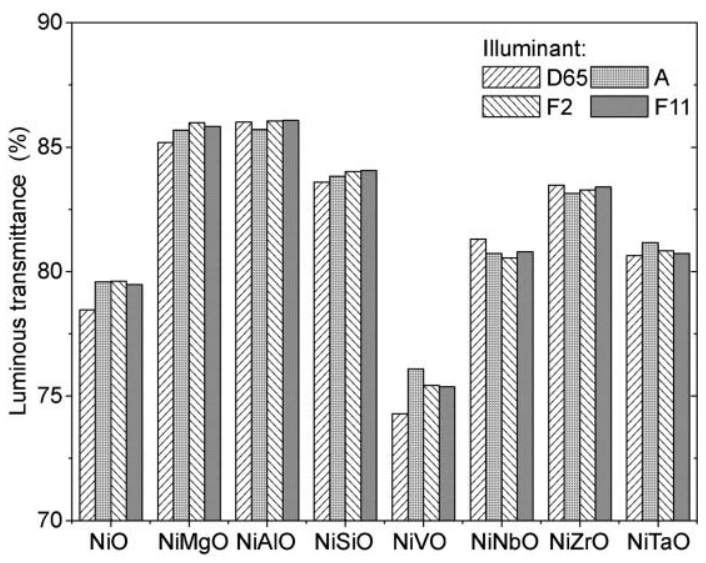

Fig. 24 Luminous transmittance $Y_{\mathrm{CIE}}$ (equal to $T_{\text {lum }}$ ) for the Ni-oxide-based films reported on in Fig. 23 exposed to four different CIE standard illuminants. The designation NiMO (with $\mathrm{M}$ being $\mathrm{Mg}$, $\mathrm{Al}, \mathrm{Si}, \mathrm{V}, \mathrm{Zr}, \mathrm{Nb}$, or $\mathrm{Ta}$ ) indicates that $\mathrm{M}$ is present in the oxide but does not specify the amount.

and dispersed as regards the coloured states. The films show a green-yellow colour in the bleached state.

Fig. 24 shows $Y_{\mathrm{CIE}}$, which corresponds to the luminous transmittance. The results are entirely consistent with those in Fig. 22. Films of $\mathrm{Ni}$ oxide mixed with $\mathrm{Mg}$ and $\mathrm{Al}$ show a $T_{\text {lum }}$ as large as $85 \%$, whereas films containing $\mathrm{Si}$ and $\mathrm{Zr}$ yield $T_{\text {lum }} \mathrm{s}$ up to $\sim 83 \%$. For additives of $\mathrm{Nb}$ or $\mathrm{Ta}, T_{\text {lum }}$ can be $\sim 80 \%$. The case of the $\mathrm{V}$ admixture is different, though, and shows that $T_{\text {lum }}$ does not exceed $75 \%$, i.e., lying $\sim 4 \%$ below the value for pure $\mathrm{Ni}$ oxide. Generally speaking, the luminous transmittance shows a rather weak dependence on the specific illuminant.

\section{B. Deposition and pre-assembly charge balancing}

This section reports on a new flexible EC foil device with sufficient optical modulation range, dynamics, and durability for practical uses. ${ }^{70}$ The device embodies a film of $\mathrm{W}$ oxide made by sputtering in the presence of hydrogen, another film of $\mathrm{Ni}-\mathrm{V}$ oxide made by sputtering and post-deposition treatment in ozone, and a polymer laminate.

DC magnetron sputtering was performed as reported in sections II B and III B. The substrates were of $0.175 \mathrm{~mm}$ thick polyester (PET) pre-coated with ITO typically having a resistance per square of $60 \Omega$. Substrates were roughly $30 \times$ $10 \mathrm{~cm}^{2}$ in size. Sputtering took place in $\mathrm{Ar}+\mathrm{O}_{2}+\mathrm{H}_{2}$ with optimized mixing ratio as before.

From a manufacturing point of view, it is preferable to be able to deposit the films under conditions that make them ready for device lamination, or to have convenient processes for making the as-deposited films ready for this. In the case of W oxide, it is possible to carry out the deposition in $\mathrm{Ar}+\mathrm{O}_{2}+$ $\mathrm{H}_{2}$ according to principles delineated by Giri and Messier. ${ }^{437}$ The hydrogen produces a blue colour for the as-deposited films, and the key issue with regard to optimizing the gas mixture is to incorporate hydrogen into the film without creating oxygen deficiency.

In practice, the optimization of the $\mathrm{W}$ oxide films can be made by measuring their colour in the as-deposited state.

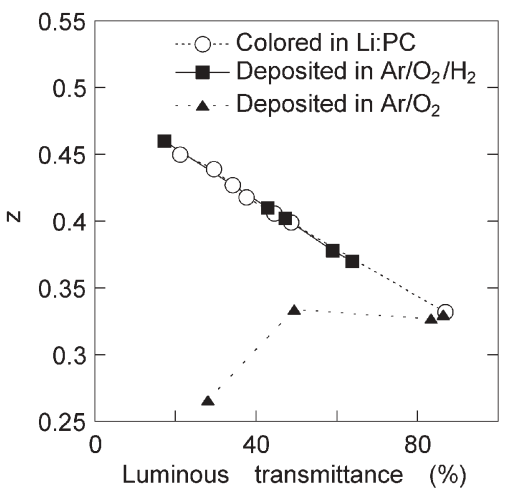

Fig. 25 Chromaticity coordinate $z$, corresponding to blue light, vs. luminous transmittance for $300 \mathrm{~nm}$ thick tungsten oxide films of three types: deposited in $\mathrm{Ar}+\mathrm{O}_{2}$ and then coloured by charge insertion from an electrolyte of $\mathrm{LiCiO}_{4}$ in propylene carbonate (PC), as deposited in $\mathrm{Ar}+\mathrm{O}_{2}$ with different oxygen contents, and as deposited in $\mathrm{Ar}+\mathrm{O}_{2}+$ $\mathrm{H}_{2}$ with different hydrogen contents. The colour specifications were made by integration of spectrophotometrically recorded transmittance. Symbols denote evaluated data and lines were drawn for convenience.

Fig. 25 compares the chromaticity coordinate $z$, corresponding to blue light, ${ }^{436}$ with the variation of the luminous transmittance for films deposited in $\mathrm{Ar}+\mathrm{O}_{2}$ and $\mathrm{Ar}+\mathrm{O}_{2}+\mathrm{H}_{2}$. Data for a "standard" film deposited in $\mathrm{Ar}+\mathrm{O}_{2}$ and coloured electrochemically by $\mathrm{Li}^{+}$incorporation are shown as a reference. As-deposited films, produced in $\mathrm{Ar}+\mathrm{O}_{2}$, displayed a decrease in transmittance when the $\mathrm{O}_{2}$ partial pressure was lowered. It can be seen from Fig. 25 that these under-oxidized films exhibit a colour that is very different from the one in the electrochemically coloured films. When sputtering was done in $\mathrm{Ar}+\mathrm{O}_{2}+\mathrm{H}_{2}$, however, the transmittance of the as-deposited films was decreased when the $\mathrm{H}_{2}$ partial pressure was increased. Such films showed the same colour rendering as the electrochemically treated films for transmittance levels down to about $20 \%$ in $300 \mathrm{~nm}$ thick films. The evolution of $z$ at still lower transmittance levels is most likely associated with oxygen deficiency. Fig. 26 illustrates the spectral transmittance for a film that is ready for integration in a device.

The Ni-V oxide films are transparent in the as-deposited state and require pre-treatment prior to device lamination. Charge insertion via an electrochemical procedure is possible, in principle, but obviously unwieldy and not suited for practical fabrication. An alternative method for charging was

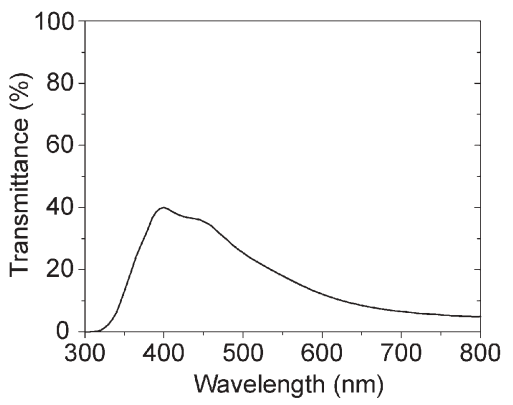

Fig. 26 Spectral transmittance of a $300 \mathrm{~nm}$ thick tungsten oxide film produced by sputtering in $\mathrm{Ar}+\mathrm{O}_{2}+\mathrm{H}_{2}$ under conditions making it ready for device lamination. 


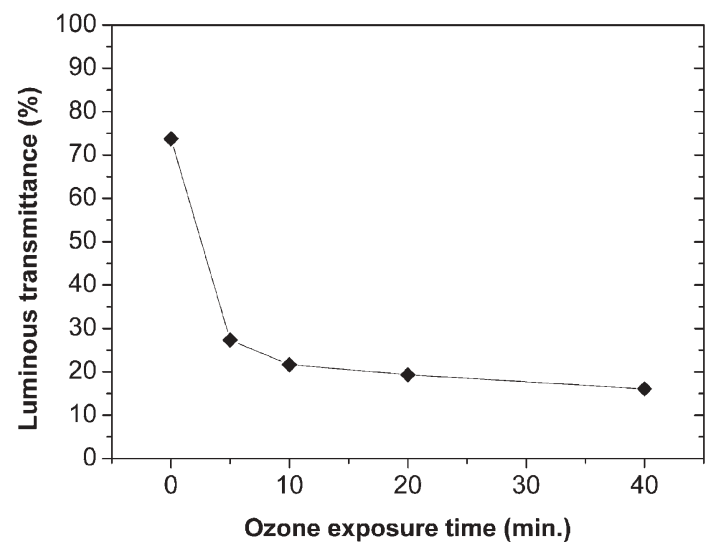

Fig. 27 Luminous transmittance $v s$. post-deposition ozone exposure time for $220 \mathrm{~nm}$ thick $\mathrm{Ni}-\mathrm{V}$ oxide films produced by sputtering in $\mathrm{Ar}+\mathrm{O}_{2}+\mathrm{H}_{2}$.

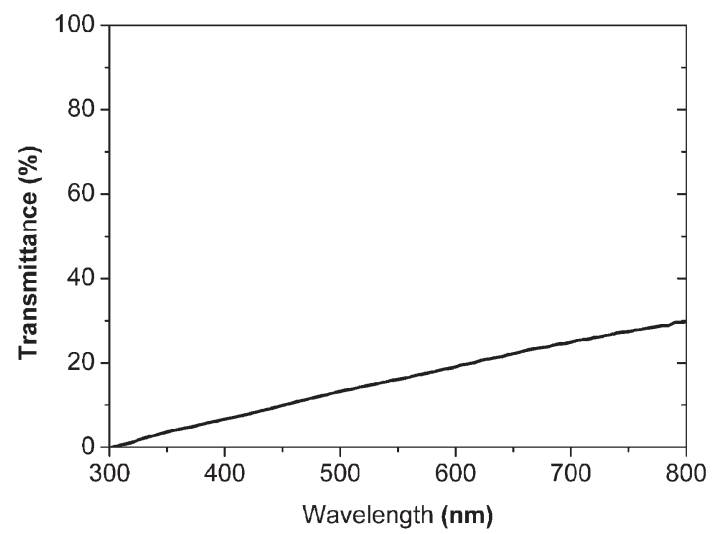

Fig. 28 Spectral transmittance of a $220 \mathrm{~nm}$ thick Ni-V oxide film produced by sputtering in $\mathrm{Ar}+\mathrm{O}_{2}+\mathrm{H}_{2}$ and post-treated in ozone under conditions making it ready for device lamination.

developed recently by Azens et al. ${ }^{438}$ Essentially, this new method employs exposure to ozone obtained by ultraviolet irradiation of the film in the presence of oxygen. The reaction paths involved in ozone treatment have been discussed recently. ${ }^{439}$ Fig. 27 displays the decrease of the luminous transmittance as a function of time when a conventional ozone photo-reactor was used to treat a $220 \mathrm{~nm}$ thick $\mathrm{Ni}-\mathrm{V}$ oxide film. The transmittance drops by some $50 \%$ during a few minutes, and a further decrease takes place for extended exposure times. Fig. 28 illustrates the typical spectral transmittance for a $\mathrm{Ni}-\mathrm{V}$ oxide film prior to device lamination.

\section{Device assembly and initial tests}

Polyester-based foils - one with a $\mathrm{W}$ oxide film coloured by sputtering in the presence of $\mathrm{H}_{2}$ (cf. Fig. 26) and another with a $\mathrm{Ni}-\mathrm{V}$ oxide film coloured by post-deposition ozone exposure (cf. Fig. 28) - were laminated together by a PMMA-based electrolyte related to the type described by Wixwat et al..$^{40}$ using roll-pressing at $80{ }^{\circ} \mathrm{C}$. The edges of the double foil were then sealed, electrical contacts were attached, and the EC device was ready for testing and use. Cycling between coloured and bleached states took place using trapezoidal voltage pulses

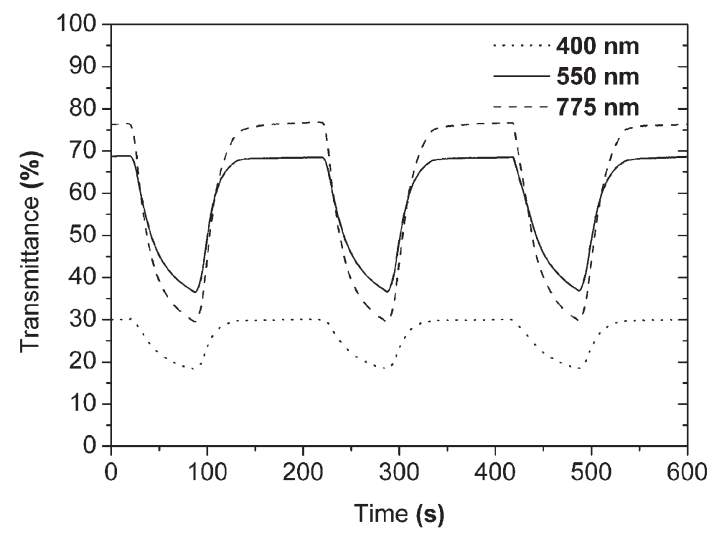

Fig. 29 Transmittance at three wavelengths $v s$. time for electrochromic switching of a laminated device as described in the main text.

between -1.6 and $+1.5 \mathrm{~V}$, respectively. The precise voltage range was adjusted automatically to compensate for varying temperatures.

Fig. 29 shows the transmittance at three different wavelengths for cycling with one full colour-bleach cycle each $200 \mathrm{~s}$. The optical modulation is pronounced, especially for midluminous and red light. Most of the changes take place within a few tens of seconds after application of the pulse, but the coloration has not reached saturation even after several minutes. Fig. 30 reports on the transmittance in fully coloured and bleached states after cycling in the same way as in Fig. 29. The foils are seen to switch between a high level of about $70 \%$ and a low level of 35 to $40 \%$ at a mid-luminous wavelength, which is in agreement with the data in Fig. 29. The span between the coloured and bleached states is shown to remain practically unchanged for 5000 cycles. This by no means represents the maximum achievable number of cycles, though. Lower transmittance levels, down to $25 \%$ or less in the coloured state, could be reached for longer coloration times.

The devices have open-circuit memory, which is an asset since electrical power must be drawn only to effect changes in the optical properties. Fig. 31 illustrates the mid-luminous transmittance for a device coloured to a transmittance equal to $20 \%$. It is found that the transmittance has increased only marginally after a time as long as $160 \mathrm{~h}$.

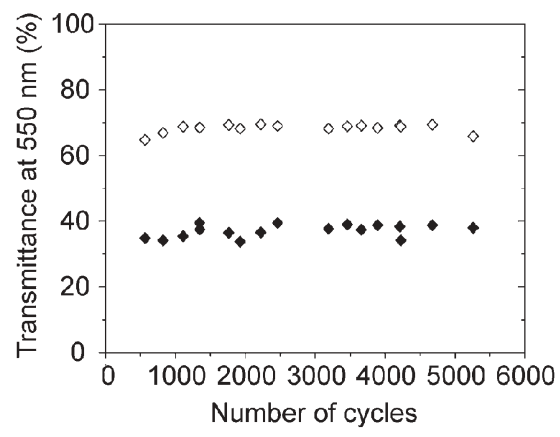

Fig. 30 Transmittance at a wavelength of $550 \mathrm{~nm} v$ s. number of colour-bleach cycles for a laminated electrochromic foil device in coloured and bleached states. 


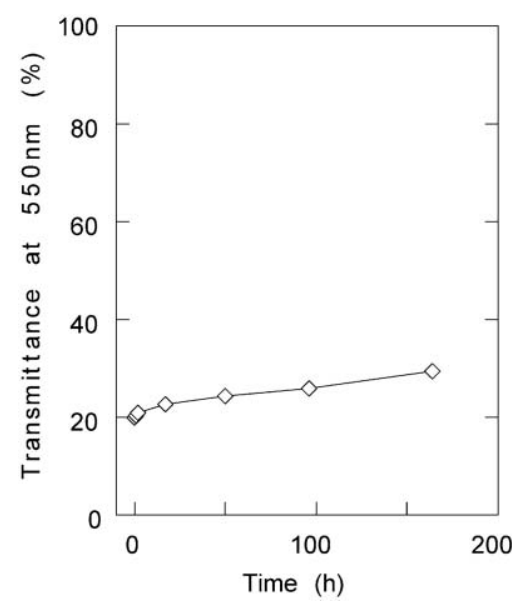

Fig. 31 Transmittance at a wavelength of $550 \mathrm{~nm} \mathrm{vs}$. time for a laminated electrochromic foil device kept under open-circuit conditions.

\section{Some applications aspects}

The work reported in section IV above demonstrated techniques to produce EC devices - in particular flexible EC foils - with sufficient optical modulation range, dynamics, and durability for making them interesting with regard to a number of important applications. The largest and most challenging of these, and also probably the most difficult one, is "smart" windows 5 for uses in buildings and automobiles. Detailed technical information on practical EC devices is rarely found in the literature; however, some examples of devices were reported in recent work by Kubo et al. ${ }^{441,442}$ and Schütt $e t a l{ }^{443}$ and a computational feasibility study for EC windows in vehicles was presented by Jaksic and Salahifar. ${ }^{14}$ It is important to realize that the "smart" windows can fulfil different goals: they can provide improved indoor comfort by being able to prevent glare and thermal discomfort for the users of the building or automobile, and simultaneously they can provide large energy savings through a lowered cost for air cooling; they are therefore perfectly in tune with the notion of "intelligent buildings". ${ }^{444}$ Specifically, EC foils may be of much interest for membrane architecture ${ }^{445,446}$ by being able to regulate energy flows and lighting in large constructions with very little embedded energy. The "smart" windows technology is thus able to yield environmental benefits, and in this context it is important to have environmental assessments regarding EC glazing production, as reported recently by Syrrakou et al. ${ }^{447}$ Economics aspects of the technology have been modeled ${ }^{448}$ as well as diverse applications issues ${ }^{449-451}$ including net energy performance of EC skylights. ${ }^{9}$

The order of magnitude of the energy savings possible with "smart" windows technology is considered next, following previous work at the authors' laboratory. ${ }^{8,10,11}$ The solar energy falling onto a vertical surface per year is set to $1000 \mathrm{kWh} \mathrm{m}^{-2}$. This can serve as a nominal value, whereas more correct numbers for South-facing/North-facing/horizontal surfaces are 850/350/920, 1400/450/1700, and 1100/560/ $1800 \mathrm{kWh} \mathrm{m}^{-2}$ for Stockholm (Sweden), Denver (USA), and Miami (USA), respectively. Half of this, $500 \mathrm{kWh} \mathrm{m}^{-2}$, is visible light. This number is used below since infrared radiation can be reflected off - at least in principle - by use of known technology that does not require variable transmittance. If the transparency can be altered between 7 and $75 \%$ which is by no means unlikely given further electrochromics technology development - the difference between having the window constantly coloured and constantly bleached is $340 \mathrm{kWh} \mathrm{m}^{-2}$. The stated range of optical modulation can be accomplished already today, but at the expense of slow dynamics and some degradation..$^{10,11}$ The next issue is then to contemplate when the "smart" window should be coloured and when it should be bleached. With physical presence as the overriding control strategy, the question is when a room is in use - or, more precisely, the fraction of the solar energy that enters when nobody is present. Considering that a normal (office) room is empty during vacations, holidays and weekends, early mornings and late afternoons (when the sun is near the horizon), etc., it is surely a conservative estimate that $50 \%$ of the energy enters the room when there is no one to look through the window. Hence this estimate yields that $170 \mathrm{kWh} \mathrm{m}^{-2}$ is the amount of energy saved annually by adopting the given control strategy.

Is this energy savings significant or not? To answer this question, we note that $17 \%$ is a typical value for today's best thin-film solar cells and sub-modules. ${ }^{452}$ Thus these solar cells would be able to generate $170 \mathrm{kWh} \mathrm{m}^{-2}$ in the example given above. Of course the analogy between energy savings in "smart" windows and energy generation in solar cells is not tied to the choice of the incident solar energy being $1000 \mathrm{kWh} \mathrm{m}^{-2}$ but applies generally irrespective of the orientation of the surface under examination. The "smart" window saves thermal energy, but if the cooling machineoperating with an efficiency of $300 \%$, say - runs on electricity generated with an efficiency of 33\% then the analogy becomes perfect. This latter consideration implies that one employs a "national scenario" for the energy, with a "Coefficient-ofPerformance" ("COP-factor") equal to unity.

Building simulations were carried out recently with the object of providing realistic estimates of the energy savings inherent in the "smart" windows technology. Initial results are presently being published by Roos et al. ${ }^{453,454}$ Specifically, calculations for a standard office module with well defined size, window area, lighting demand, occupancy, equipment, etc., showed that the energy savings potential was considerable for the cooling load. The studied office block was oriented with one façade facing South and one facing North and the simulations were performed with climate data applicable to Rome (Italy), Brussels (Belgium), and Stockholm (Sweden). When using "smart" windows instead of conventional static solar control windows, the energy for space cooling, on an annual basis, could be reduced by as much as 40 to $50 \%$. The amount of saved energy is obviously climate dependent. In moderately warm climates, such as Brussels and Stockholm, the number of days with very high outdoor temperature is relatively small but the energy required for balancing excessive solar energy inflow nevertheless is substantial, and an interesting result of the simulations was that the cooling power could be reduced so that air conditioning may be completely avoided when "smart" windows were used. In this 
case, the additional cost for "smart" windows can be more than compensated for by the elimination of an air conditioning system. The method for controlling the "smart" windows is of obvious importance and has been the subject of some recent studies. ${ }^{455-462}$

Potential applications in energy efficient buildings and automobiles have provided the main impetus for research and development on electrochromics for several years. However, there are numerous other applications as well, especially with regard to foil-type EC devices. These can be applied, for example, in ski goggles and visors for motorcycle helmets. These visors can be coloured to a chosen degree in the day and bleached in the night. It is especially important that the driving and riding safety can be significantly improved by having the visor bleach before entering tunnels or other dark spaces. Another aspect with a bearing on safety is that facial warming can be significantly limited by absorption in the visor. ${ }^{463}$

\section{Acknowledgements}

Many persons have contributed to the results presented in this Feature Article. In particular we wish to thank Drs Lars Berggren and Esteban Avendaño for their dedicated work as Ph.D. students; their results form the bases of much of sections II and III, respectively. Dr Andris Azens contributed, in particular, to many of the results reported in section IV.

\section{References}

1 Large-Area Chromogenics: Materials and Devices for Transmittance Control, ed. C. M. Lampert and C. G. Granqvist, SPIE Opt. Eng. Press, Bellingham, USA, 1990, vol. IS4.

2 S. K. Deb, Appl. Opt., Suppl., 1969, 3, 192.

3 S. K. Deb, Philos. Mag., 1973, 27, 801.

4 J. S. E. M. Svensson and C. G. Granqvist, Sol. Energy Mater., 1984, 11, 29.

5 J. S. E. M. Svensson and C. G. Granqvist, Sol. Energy Mater., 1985, 12, 391.

6 C. G. Granqvist, Adv. Mater., 2003, 15, 1789.

7 C. G. Granqvist, in Encyclopedia of Energy, ed. C. J. Cleveland, Elsevier, Oxford, UK, 2004, vol. 3, p. 845.

8 C. G. Granqvist, Int. Glass Rev., 2001, (2), 67.

9 J. H. Klems, Energy Build., 2001, 33, 93.

10 C. G. Granqvist, Smart Mater. Bull., 2002, (10), 9.

11 A. Azens and C. G. Granqvist, J. Solid State Electrochem., 2003, 7, 64 .

12 M. R. LaPointe and G. M. Sottile, Proc. Soc. Photo-Opt. Instrum. Eng., 2001, 4458, 112

13 G. M. Sottile, Mater. Sci. Eng., B, 2005, 119, 240.

14 N. I. Jaksic and C. Salahifar, Sol. Energy Mater. Sol. Cells, 2003, 79, 409.

15 T. Sumida, Y. Wada, T. Kitamura and S. Yanagida, Chem. Lett., 2002, 31, 180.

16 S.-L. Kuai, G. Bader and P. V. Ashrit, Appl. Phys. Lett., 2005, 86, 221110.

17 N. Kobayashi, M. Nishimura and H. Ohtomo, Electrochim. Acta, 2005, 50, 3886.

18 N. Kobayashi and M. Nishimura, Sol. Energy Mater. Sol. Cells, 2006, 90, 538.

19 A. A. Argun, P.-H. Aubert, B. C. Thompson, I. Schwendeman, C. L. Gaupp, J. Hwang, N. J. Pinto, D. B. Tanner, A. G. MacDiarmid and J. R. Reynolds, Chem. Mater., 2004, 16, 4401

20 H. J. Byker, Electrochim. Acta, 2001, 46, 2015.

21 U. Bach, D. Corr, D. Lupo, F. Pichot and M. Ryan, Adv. Mater., $2002, \mathbf{1 4}, 845$.
22 H. Pettersson, T. Gruszecki, L.-H. Johansson, M. O. M. Edwards, A. Hagfeldt and T. Matuszczyk, Displays, 2004, 25, 223.

23 H. Hagenström, in Proc. 4th Int. Conf. on Coatings on Glass, ed. C.-P. Klages, H. J. Gläser and M. A. Aegerter, FraunhoferInstitut für Schicht- und Oberflächentechnik, Braunschweig, Germany, 2002, p. 21.

24 C. M. Lampert, Sol. Energy Mater. Sol. Cells, 2003, 76, 489.

25 C. M. Lampert, Mater. Today, 2004, (3), 28.

26 S. C. de Oliveira, L. C. de Morais, A. A. da Silva Curvelo and R. M. Torresi, J. Electrochem. Soc., 2003, 150, E578.

27 J. Isidorsson, I. A. M. E. Giebels, E. S. Kooji, N. J. Koeman, J. H. Rector, A. T. M. van Gogh and R. Griessen, Electrochim. Acta, 2001, 46, 2179.

28 A.-M. Janner, P. van der Sluis and V. Mercier, Electrochim. Acta, 2001, 46, 2173.

29 P. van der Sluis and V. M. M. Mercier, Electrochim. Acta, 2001, 46, 2167.

30 B. Farangis, P. Nachimuthu, T. J. Richardson, J. L. Slack, B. K. Meyer, R. C. C. Perera and M. D. Rubin, Solid State Ionics, 2003, 165, 309.

31 T. J. Richardson, Solid State Ionics, 2003, 165, 305.

32 I. Aruna, B. R. Mehta, L. K. Malhotra and S. M. Shivaprasad, Adv. Mater., 2004, 16, 169.

33 I. A. M. E. Giebels, J. Isidorsson and R. Griessen, Phys. Rev. B, 2004, 69, 205111

34 E. Johansson, C. Chacon, C. Zlotea, Y. Andersson and B. Hjörvarsson, J. Phys.: Condens. Matter, 2004, 16, 7649.

35 W. Lohstroh, R. J. Westerwaal, B. Noheda, S. Enache, I. A. M. E. Giebels, B. Dam and R. Griessen, Phys. Rev. Lett., 2004, 93, 197404.

36 J. L. M. van Mechtelen, B. Noheda, W. Lohstroh, R. J. Westerwaal, J. H. Rector, B. Dam and R. Griessen, Appl. Phys. Lett., 2004, 84, 3651.

37 S. Enache, T. Leeuwerink, A. F. Th. Hoekstra, A. Remhof, N. J. Koeman, B. Dam and R. Griessen, J. Alloys Compd., 2005, $397,9$.

38 C. G. Granqvist, in Materials Science for Solar Energy Conversion Systems, ed. C. G. Granqvist, Pergamon, Oxford, UK, 1991, p. 106.

39 C. G. Granqvist and A. Hultåker, Thin Solid Films, 2002, 411, 1.

40 D. S. Ginley and C. Bright, MRS Bull., 2000, 25(8), 15.

41 P. P. Edwards, A. Porsch, M. O. Jones, D. V. Morgan and R. M. Perks, Dalton Trans., 2004, (19), 2995.

42 T. Minami, Semicond. Sci. Technol., 2005, 20, S35.

43 J. Lu, A. Hultåker, G. A. Niklasson, C. G. Granqvist and E. Olsson, Thin Solid Films, 2005, 479, 107.

44 Y. Furubayashi, T. Hitosugi, Y. Yamamoto, K. Inaba, G. Kinoda, Y. Hirose, T. Shimada and T. Hasegawa, Appl. Phys. Lett., 2005, 86, 252101.

45 G. Leftheriotis, S. Papaefthimiou and P. Yanoulis, Sol. Energy Mater. Sol. Cells, 2000, 61, 107.

46 S. Papaefthimiou, G. Leftheriotis and P. Yanoulis, Electrochim. Acta, 2001, 46, 2145

47 Z.-C. Wu, Z.-H. Chen, X. Du, J. M. Logan, J. Sippel, M. Nikolou, K. Kamaras, J. R. Reynolds, D. B. Tanner, A. F. Hebard and A. G. Rinzler, Science, 2004, 305, 1273.

48 C. Marcel and J.-M. Tarascon, Solid State Ionics, 2001, 143, 89.

49 L.-C. Chen, Y.-H. Huang, K.-S. Tseng and K.-C. Ho, J. New Mater. Electrochem. Syst., 2002, 5, 203.

50 L.-C. Chen, K.-S. Tseng, Y.-H. Huang and K.-C. Ho, J. New Mater. Electrochem. Syst., 2002, 5, 213.

51 K.-H. Heckner and A. Kraft, Solid State Ionics, 2002, 152-153, 899.

52 P. Knauth and H. L. Tuller, J. Am. Ceram. Soc., 2002, 85, 1654.

53 C. G. Granqvist, Handbook of Inorganic Electrochromic Materials, Elsevier, Amsterdam, The Netherlands, 1995, reprinted 2002.

54 P. M. S. Monk, R. J. Mortimer and D. R. Rosseinsky, Electrochromism: Fundamentals and Applications, VCH, Weinheim, Germany, 1995.

55 P. R. Somani and S. Radhakrishnan, Mater. Chem. Phys., 2002, 77, 117.

56 C. G. Granqvist, Sol. Energy Mater. Sol. Cells, 2000, 60, 201.

57 C. G. Granqvist, E. Avendaño and A. Azens, Thin Solid Films, 2003, 442, 201. 
58 P. Losier and P. V. Ashrit, J. Mater. Sci. Lett., 2003, 22, 1095.

59 A. Lusis, J. Kleperis and E. Pentjušs, J. Solid State Electrochem., 2003, 7, 106.

60 E. Ozkan, S.-H. Lee, C. E. Tracy, J. R. Pitts and S. K. Deb, Sol Energy Mater. Sol. Cells, 2003, 79, 439.

61 J. García-Cañadas, I. Mora-Seró, F. Fabregat-Santiago, J. Bisquert and G. Garcia-Belmonte, J. Electroanal. Chem. 2004, 565, 329.

62 J. García-Cañadas, F. Fabregat-Santiago, I. Porqueras, C. Person, J. Bisquert and G. Garcia-Belmonte, Solid State Ionics, 2004, 175, 521 .

63 A. Siokou, S. Ntais, S. Papaefthimiou, G. Leftheriotis and P. Yianoulis, Surf. Sci., 2004, 566-568, 1168.

64 R. Sivakumar, M. Jayachandran and C. Sanjeeviraja, Mater. Chem. Phys., 2004, 87, 439.

65 H. Qiu, Y. F. Lu and Z. H. Mai, J. Appl. Phys., 2002, 91, 440.

66 K.-S. Ahn, Y.-C. Nah, Y.-E. Sung, K.-Y. Cho, S.-S. Shin and J.-K. Park, Appl. Phys. Lett., 2002, 81, 3930.

67 Y.-S. Huang, Y.-Z. Zhang, Z.-T. Zeng and X.-F. Hu, Appl. Surf. Sci., 2002, 202, 104.

68 W. J. Lee, Y. K. Fang, J.-J. Ho, C.-Y. Chen, S.-F. Chen, R.-Y. Tsai, D. Huang and F. C. Ho, J. Mater. Sci.: Mater. Electron., 2002, 13, 751 .

69 F. van Driel, F. Decker, F. Simone and A. Pennisi, J. Electroanal. Chem., 2002, 537, 125.

70 A. Azens, G. Gustavsson, R. Karmhag and C. G. Granqvist, Solid State Ionics, 2003, 165, 1.

71 L. Berggren and G. A. Niklasson, Solid State Ionics, 2003, 165, 51

72 F.-P. Dai, S.-Y. Lu, B.-X. Feng, S.-R. Jiang and C. Chen, Acta Phys. Sin., 2003, 52, 1003.

73 Y.-C. Nah, K.-S. Ahn and Y.-E. Sung, Solid State Ionics, 2003, 165, 229.

74 J. Scarminio, Sol. Energy Mater. Sol. Cells, 2003, 79, 357.

75 E. Washizu, A. Yamamoto, Y. Abe, M. Kawamura and K. Sasaki, Solid State Ionics, 2003, 165, 175.

76 H.-N. Cui, S. Jia, L.-J. Meng and V. Texeira, Microchim. Acta, 2004, 145, 19.

77 H. Kamal, A. A. Akl and K. Abdel-Hady, Physica B, 2004, 349, 192.

78 E. Avendaño, L. Berggren, G. A. Niklasson, C. G. Granqvist and A. Azens, Thin Solid Films, 2006, 496, 30

79 L. Berggren and G. A. Niklasson, Sol. Energy Mater. Sol. Cells, 2005, 85, 573 .

80 K. W. Park, Electrochim. Acta, 2005, 50, 4690.

81 H. Sadiki, J. F. Pierson, C. Rousselot, N. Martin and G. Terwagne, Surf. Coating Technol., 2005, 200, 232.

82 M. Stolze, D. Gogova and L.-K. Thomas, Thin Solid Films, 2005, 476, 185.

83 T.-S. Yang, Z.-R. Lin and M.-S. Wong, Appl. Surf. Sci., to be published.

84 S. J. Yoo, J. W. Lim and Y.-E. Sung, Sol. Energy Mater. Sol. Cells, 2006, 90, 477.

85 L. Meda, R. C. Breitkopf, T. E. Haas and R. U. Kirss, Thin Solid Films, 2002, 402, 126.

86 K. Gesheva, A. Szekeres and T. Ivanova, Sol. Energy Mater. Sol. Cells, 2003, 76, 563.

87 J. Scarminio, M. A. Bica de Moraes, R. C. E. Dias, F. P. Rouxinol and S. F. Durrant, Electrochem. Solid-State Lett., 2003, 6, H9.

88 C. S. Blackman and I. P. Parkin, Chem. Mater., 2005, 17, 1583.

89 Z. Dimitrova and D. Gogova, Mater. Res. Bull., 2005, 40, 333.

90 F. Hamelmann, K. Gesheva, T. Ivanova, A. Szekeres, M. Abrashev and U. Heinzmann, J. Optoelectron. Adv. Mater., 2005, 7, 393.

91 M. Seman and C. A. Wolden, J. Vac. Sci. Technol., A, 2003, 21, 1927.

92 M. Seman and C. A. Wolden, Sol. Energy Mater. Sol. Cells, 2004, 82, 517.

93 P. S. Patil, J. Solid State Electrochem., 2002, 6, 284.

94 M. Regragui, M. Addou, A. Outzourhit, E. El Idrissi, A. Kachouane and A. Bougrine, Sol. Energy Mater. Sol. Cells, 2003, 77, 341

95 R. Sivakumar, A. M. E. Raj, B. Subramanian, M. Jayachandran, D. C. Trivendi and C. Sanjeeviraja, Mater. Res. Bull., 2004, 39, 1479 .
96 C. O. Avellaneda, K. Dahmouche and L. O. S. Bulhões, Mol. Cryst. Liq. Cryst., 2002, 374, 113.

97 A. Hauch, A. Georg, U. Opara Krašovec and B. Orel, J. Electrochem. Soc., 2002, 149, H159.

98 U. Opara Krašovec, A. Šurca Vuk and B. Orel, Sol. Energy Mater. Sol. Cells, 2002, 73, 21.

99 E. Ozkan, S.-H. Lee, P. Liu, C. E. Tracy, F. Z. Tepehan, J. R. Pitts and S. K. Deb, Solid State Ionics, 2002, 149, 139.

100 P. Varshney, M. Deepa, N. Sharma and S. A. Agnihotry, Solid State Ionics, 2002, 152-153, 877.

101 C. O. Avellaneda and L. O. S. Bulhões, Solid State Ionics, 2003, 165,59 .

102 C. O. Avellaneda and L. O. S. Bulhões, J. Solid State Electrochem., 2003, 7, 183.

103 S. Badilescu and P. V. Ashrit, Solid State Ionics, 2003, 158, 187.

104 P. K. Biswas, N. C. Pramanik, M. K. Mahapatra, D. Ganguli and J. Livage, Mater. Lett., 2003, 57, 4429.

105 P. R. Bueno, R. C. Faria, C. O. Avellaneda, E. R. Leite and L. O. S. Bulhões, Solid State Ionics, 2003, 158, 415.

106 Y. Djaoued, P. V. Ashrit, S. Badilescu and R. Brüning, Proc. Soc. Photo-Opt. Instrum. Eng., 2003, 5123, 202.

107 B. Orel, A. Šurca Vuk, R. Ješe, P. Lianos, E. Stathatos, P. Judeinstein and Ph. Colomban, Solid State Ionics, 2003, 165, 235.

108 D. L. Sun, S. Heusing, J. Puetz and M. A. Aegerter, Solid State Ionics, 2003, 165, 181.

109 A. Šurca Vuk, B. Orel, H. Spreizer and P. Colomban, Solid State Ionics, 2003, 165, 247.

110 A. Šurca Vuk, B. Orel and P. Colomban, Acta Chim. Slov., 2003, 50, 601

111 I. Turyan, B. Orel, R. Reisfeld and D. Mandler, Phys. Chem. Chem. Phys., 2003, 5, 3212.

112 A. Cremonesi, D. Bersani, P. P. Lottici, Y. Djaoued and P. V. Ashrit, J. Non-Cryst. Solids, 2004, 345\&346, 500.

113 G. Garcia-Belmonte, P. R. Bueno and F. Fabregat-Santiago, J. Appl. Phys., 2004, 96, 853.

114 G. Leftheriotis, S. Papaefthimiou and P. Yanoulis, Sol. Energy Mater. Sol. Cells, 2004, 83, 115.

115 A. Patra, K. Auddy, D. Ganguli, J. Livage and P. K. Biswas, Mater. Lett., 2004, 58, 1059.

116 A. Pawlicka, D. C. Dragunski, K. V. Guimarães and C. O. Avellaneda, Mol. Cryst. Liq. Cryst., 2004, 416, 105.

117 R. Solarska, B. D. Alexander and J. Augustynski, J. Solid State Electrochem., 2004, 8, 748.

118 S. A. Agnihotry, R. Sharma, M. Kar and T. K. Saxena, Sol. Energy Mater. Sol. Cells, 2006, 90, 15.

119 C. O. Avellaneda and L. O. S. Bulhões, Sol. Energy Mater. Sol. Cells, 2006, 90, 395

120 M. Deepa, R. Sharma, A. Basu and S. A. Agnihotry, Electrochim. Acta, 2005, 50, 3545 .

121 F. Huguenin, E. R. Gonzalez and O. N. Oliveira, Jr., J. Phys Chem. B, 2005, 109, 12837.

122 A. Novinrooz, M. Sharbatdaran and H. Noorkojouri, Cent. Eur. J. Phys., 2005, 3, 456.

123 A. K. Srivastava, M. Deepa, S. Singh, R. Kishore and S. A. Agnihotry, Solid State Ionics, 2005, 176, 1161

124 T. Pauporté, J. Electrochem. Soc., 2002, 149, C539.

125 R. Vijayalakshmi, M. Jayachandran and C. Sanjeeviraja, Curr. Appl. Phys., 2003, 3, 171 .

126 M. Deepa, M. Kar and S. A. Agnihotry, Thin Solid Films, 2004 468, 32 .

127 Yu. S. Krasnov and G. Ya. Kolbasov, Electrochim. Acta, 2004, 49, 2425.

128 T. Pauporté, M. C. Bernard, Y. Soldo-Olivier and R. Faure J. Electrochem. Soc., 2004, 151, H21.

129 M. Deepa, A. K. Srivastava, T. K. Saxena and S. A. Agnihotry, Appl. Surf. Sci., 2005, 252, 1568.

130 A. Kraft, M. Rottmann and K.-H. Heckner, Sol. Energy Mater. Sol. Cells, 2006, 90, 469.

131 G. A. Tsirlina, K. Miecznikowski, P. J. Kuleza, M. I. Borzenko, A. N. Gavrilov, L. M. Plyasova and I. Yu. Molina, Solid State Ionics, 2005, 176, 1681.

132 T. Ivanova, K. A. Gesheva, M. Ganchev and E. Tzvetkova, J. Mater Sci.: Mater. Electron., 2003, 14, 755. 
133 T. Ivanova, K. Gesheva, F. Hamelmann, G. Popkirov, M. Abrashev, M. Ganchev and E. Tzvetkova, Vacuum, 2004, 76, 195.

134 T. Ivanova, K. A. Gesheva, G. Popkirov, M. Ganchev and E. Tzvetkova, Mater. Sci. Eng., B, 2005, 119, 232.

135 S.-H. Baeck, T. F. Jaramillo, D. H. Jeong and E. W. McFarland, Chem. Commun., 2004, (4), 390.

136 K. R. Padmanabhan, Nucl. Instrum. Methods Phys. Res., Sect. B, 2004, 219-220, 942.

137 A. Rougier, A. Blyr, J. Garcia, Q. Zhang and S. A. Impey, Sol. Energy Mater. Sol. Cells, 2002, 71, 343.

138 E. Pehlivan, F. Z. Tepehan and G. G. Tepehan, Solid State Ionics, 2003, 165, 105.

139 D. Yang and L. Xue, Thin Solid Films, 2004, 469-470, 54.

140 A. E. Aliev and H. W. Shin, Solid State Ionics, 2002, 154-155, 425

141 M. Yuan, Y. Lu, B. Tian, H. Yang, B. Tu, J. Kong and D. Zhao, Chem. Lett., 2004, 33, 1396.

142 P. S. Patil, S. H. Mujawar, A. I. Inamdar and S. B. Sadale, Appl. Surf. Sci., 2005, 250, 117

143 N. R. de Tacconi, C. R. Chenthamrakshan, K. L. Wouters, F. M. MacDonnell and K. Rajeshwar, J. Electroanal. Chem., 2004, 566, 249.

144 A. Medina, J. L. Solis, J. Rodriguez and W. Estrada, Sol. Energy Mater. Sol. Cells, 2004, 80, 473.

145 M. Yagi and S. Umemiya, J. Phys. Chem. B, 2002, 106, 6355.

146 E. Ozkan Zayim, P. Liu, S.-H. Lee, C. E. Tracy, J. A. Turner, J. R. Pitts and S. K. Deb, Solid State Ionics, 2003, 165, 65.

147 M. Yagi, K. Sone, M. Yamada and S. Umemiya, Chem.-Eur. J., 2005, 11, 767.

148 Z. Hussain, J. Electron. Mater., 2002, 31, 615.

149 Z. Hussain, J. Appl. Phys., 2002, 91, 5745.

150 T. S. Sian, G. B. Reddy and S. M. Shivaprasad, Electrochem. Solid-State Lett., 2005, 8, A96.

151 S.-H. Lee, M. J. Seong, C. E. Tracy, A. Mascarenhas, J. R. Pitts and S. K. Deb, Solid State Ionics, 2002, 147, 129.

152 A. Taj and P. V. Ashrit, J. Mater. Sci., 2004, 39, 3541.

153 T. Ivanova, K. A. Gesheva and A. Szekeres, J. Solid State Electrochem., 2002, 7, 21.

154 T. Ivanova, M. Surtchev and K. Gesheva, Mater. Lett., 2002, 53, 250.

155 K. A. Gesheva, T. Ivanova, G. Popkirov and F. Hamelmann, J. Optoelectron. Adv. Mater., 2005, 7, 169.

156 T. M. McEvoy, K. J. Stevenson, J. T. Hupp and X.-J. Dang, Langmuir, 2003, 19, 4316.

157 A. Azens and C. G. Granqvist, Appl. Phys. Lett., 2002, 81, 928.

158 P. S. Patil, R. K. Kawar and S. B. Sadale, Electrochim. Acta, 2005, 50, 2527.

159 P. S. Patil, R. K. Kawar and S. B. Sadale, Appl. Surf. Sci., 2005, 49, 367

160 Y. Jung, J. Lee and Y. Tak, Electrochem. Solid-State Lett., 2004, 7, H5.

161 J. Yano, K. Noguchi, S. Yamasaki and S. Yamasaki, Electrochem. Commun., 2004, 6, 110.

162 L. Sziráki and L. Bóbics, Electrochim. Acta, 2002, 47, 2189.

163 J. Backholm, A. Azens and G. A. Niklasson, Sol. Energy Mater Sol. Cells, 2006, 90, 414

164 K. D. Lee, J. Korean Phys. Soc., 2005, 46, 1383.

165 H. Tokudome and M. Miyauchi, Angew. Chem., Int. Ed., 2005, 44, 1974.

166 F. Artuso, F. Decker, A. Krasilnikova, M. Liberatore, A. Lourenco, E. Masetti, A. Pennisi and F. Simone, Chem. Mater., 2002, 14, 636.

167 M. Benmoussa, A. Outzourhit, A. Bennouna and E. L. Ameziane, Thin Solid Films, 2002, 405, 11.

168 L. Ottaviano, A. Pennisi, F. Simone and A. M. Salvi, Opt. Mater., 2004, 27, 307.

169 M. Seman, J. Marino, W. Yang and C. A. Wolden, J. Non-Cryst. Solids, 2005, 351, 1987.

170 C. O. Avellaneda and L. O. S. Bulhões, Solar Energy Mater. Solar Cells, 2006, 90, 444

171 M. Benmoussa, A. Outzourhit, A. Bennouna and E. L. Ameziane, J. Phys. IV, 2005, 123, 41

172 M. Liberatore, F. Decker, A. Šurca Vuk, B. Orel and G. Dražič, Sol. Energy Mater. Sol. Cells, 2006, 90, 434
173 P. Liu, S.-H. Lee, C. E. Tracy, J. A. Turner, J. R. Pitts and S. K. Deb, Solid State Ionics, 2003, 165, 223.

174 S. Neves, R. F. Santos, W. A. Gazotti and C. P. Fonseca, Thin Solid Films, 2004, 460, 300.

175 K. Takahashi, Y. Wang and G. Cao, Appl. Phys. Lett., 2005, 86, 053102 .

176 W. Chen and Y. Kaneko, J. Electroanal. Chem., 2003, 559, 83.

177 Y. Kaneko, S. Mori and J. Yamanaka, Solid State Ionics, 2002, $151,35$.

178 Y. Kaneko and W. Chen, J. Electroanal. Chem., 2003, 559, 87.

179 C.-G. Wu and M.-H. Chung, J. Solid State Chem., 2004, 177, 2285 .

180 J. Verlevska and M. Ristova, Sol. Energy Mater. Sol. Cells, 2002, 73, 131.

181 K. D. Lee and W. C. Jung, J. Korean Phys. Soc., 2004, 45, 447.

182 I. Bouessay, A. Rougier, B. Beaudoin and J. B. Leriche, Appl. Surf. Sci., 2002, 186, 490.

183 I. Bouessay, A. Rougier and J.-M. Tarascon, J. Electrochem. Soc., 2004, 151, H145.

184 I. Bouessay, A. Rougier, P. Poizot, J. Moscovici, A. Michailowicz and J.-M. Tarascon, Electrochim. Acta, 2005, 50, 3737.

185 N. Penin, A. Rougier, L. Laffont, P. Poizot and J.-M. Tarascon, Sol. Energy Mater. Sol. Cells, 2006, 90, 422.

186 K.-S. Ahn, Y.-C. Nah and Y.-E. Sung, Jpn. J. Appl. Phys., 2002, 41, L533.

187 K.-S. Ahn, Y.-C. Nah and Y.-E. Sung, J. Vac. Sci. Technol. A, 2002, 20, 1468.

188 K.-S. Ahn, Y.-C. Nah and Y.-E. Sung, J. Appl. Phys., 2002, 92, 1268

189 K.-S. Ahn, Y.-C. Nah and Y.-E. Sung, J. Appl. Phys., 2002, 92, 7128

190 K.-S. Ahn, Y.-C. Nah and Y.-E. Sung, Appl. Surf. Sci., 2002, 199, 259.

191 K.-S. Ahn, Y.-C. Nah, J.-H. Yum and Y.-E. Sung, Jpn. J. Appl. Phys., 2002, 41, L212.

192 M. C. A. Fantini, F. F. Ferreira and A. Gorenstein, Solid State Ionics, 2002, 152-153, 867

193 S. R. Jiang, P. X. Yan, B. X. Feng, X. M. Cai and J. Wang, Mater. Chem. Phys., 2002, 77, 384.

194 Y.-Y. Shi, Z.-Y. Zhou and X.-O. Yang, Sol. Energy Mater. Sol. Cells, 2002, 71, 51.

195 K.-S. Ahn, Y.-C. Nah, J.-Y. Park, Y.-E. Sung, K.-Y. Cho, S.-S. Shin and J.-K. Park, Appl. Phys. Lett., 2003, 82, 3379.

196 K.-S. Ahn, Y.-C. Nah and Y.-E. Sung, Solid State Ionics, 2003, 156, 433

197 K.-S. Ahn, Y.-C. Nah and Y.-E. Sung, Solid State Ionics, 2003, 165,155

198 F. Iwata, K. Mikage, H. Sakaguchi, M. Kitao and A. Sasaki, Solid State Ionics, 2003, 165, 7.

199 S.-H. Lee, C. E. Tracy and J. R. Pitts, Electrochem. Solid-State Lett., 2004, 7, A299.

200 C. R. Magaña, D. R. Acosta, A. I. Martínez and J. M. Ortega, Sol. Energy, 2006, 80, 161.

201 S. A. Mahmoud, A. A. Akl, H. Kamal and K. Abdel-Hady, Physica B, 2002, 311, 366.

202 H. Kamal, E. K. Elmaghraby, S. A. Ali and K. Abdel-Hady, Thin Solid Films, 2005, 483, 330.

203 R. Cerc Korošec, P. Bukovec, B. Pihlar, A. Šurca Vuk, B. Orel and G. Dražič, Solid State Ionics, 2003, 165, 191

204 Z. Jiao, M.-H. Wu, Z. Qin and H. Xu, Nanotechnology, 2003, 14, 458.

205 R. Cerc Korošec and P. Bukovec, Thermochim. Acta, 2004, 410, 65.

206 L. Ottaviano, A. Pennisi and F. Simone, Surf. Interface Anal., 2004, 36, 1335.

207 K. Nakaoka, J. Ueyama and K. Ogura, J. Electroanal. Chem., 2004, 571, 93.

208 A. Azens, J. Isidorsson, R. Karmhag and C. G. Granqvist, Thin Solid Films, 2002, 422, 1

209 E. Avendaño, A. Azens, J. Isidorsson, R. Karmhag, G. A. Niklasson and C. G. Granqvist, Solid State Ionics, 2003, 165,169 .

210 E. Avendaño, A. Azens, G. A. Niklasson and C. G. Granqvist, J. Solid State Electrochem., 2003, 8, 37.

211 E. Avendaño, A. Azens, G. A. Niklasson and C. G. Granqvist, Sol. Energy Mater. Sol. Cells, 2004, 84, 337. 
212 H.-J. Ahn, S.-S. Shim, Y.-S. Kim, C.-Y. Kim and T.-Y. Seong, Electrochem. Commun., 2005, 7, 567.

213 S.-H. Lee, E. Tracy, Y. Yan, J. R. Pitts and S. K. Deb, Electrochem. Solid-State Lett., 2005, 8, A188.

214 E. Avendaño, A. Azens, G. A. Niklasson and C. G. Granqvist, Mater. Sci. Eng., B, to be published.

215 F. F. Ferreira and M. C. A. Fantini, Solid State Ionics, 2004, 175, 517.

216 Z. He, Z. Ji, S. Zhao, C. Wang, K. Liu and Z. Ye, Sol. Energy, 2006, 80, 226

217 Y.-S. Huang, Y.-Z. Zhang and X.-F. Hu, Sol. Energy Mater. Sol. Cells, 2003, 77, 155.

218 M. A. Aegerter, M. Schmitt and Y. Guo, Int. J. Photoenergy, $2002,4,1$.

219 L. Melo, C. O. Avellaneda and A. Pawlicka, Mol. Cryst. Liq. Cryst., 2002, 374, 101.

220 A. V. Rosario and E. C. Pereira, Sol. Energy Mater. Sol. Cells, 2002, 71, 41.

221 P. R. Bueno, R. C. Faria and L. O. S. Bulhões, Solid State Ionics, 2005, 176, 1175 .

222 S. Heusing, D.-L. Sun, J. Otero-Anaya and M. A. Aegerter, Thin Solid Films, 2006, 502, 240.

223 H.-H. Wang, C.-J. Zhao, M.-M. Yan and Z.-Y. Jiang, Acta Chim. Sin., 2002, 60, 1203.

224 Y.-N. NuLi, Z.-W. Fu, Y.-Q. Chu and Q.-Z. Qin, Solid State Ionics, 2003, 160, 197.

225 K.-Y. Park and M. F. Toney, Electrochem. Commun., 2005, 7, 151.

226 N. Naghavi, C. Marcel, L. Dupont, J.-B. Leriche and J.-M. Tarascon, Solid State Ionics, 2003, 156, 463.

227 M. Pflughoefft and H. Weller, J. Phys. Chem. B, 2002, 106, 10530.

228 L.-C. Chen, Y.-H. Huang and K.-C. Ho, J. Solid State Electrochem., 2002, 7, 6.

229 N. R. De Tacconi, K. Rajeshwar and R. O. Lezna, Chem. Mater., 2003, 15, 3046.

230 C. Salinga, H. Weis and M. Wuttig, Thin Solid Films, 2002, 414, 275.

231 H. R. Wilson, R. Blessing, H. Hagenström, M. G. Hutchins, D. Dvorjetski and W. J. Platzer, in Proc. 4th Int. Conf. on Coatings on Glass, ed. C.-P. Klages, H. J. Gläser and M. A. Aegerter, Fraunhofer-Institut für Schicht- und Oberflächentechnik, Braunschweig, Germany, 2002, p. 649.

232 X. C. Xu, H. Shen and X. Y. Xiong, Thin Solid Films, 2002, 415, 290.

233 A. Martucci, M. Pasquale, M. Guglielmi, M. Post and J. C. Pivin, J. Am. Ceram. Soc., 2003, 86, 1638.

234 J. Okumu, F. Koerfer, C. Salinga and M. Wuttig, J. Appl. Phys., 2004, 95, 7632 .

235 H. Shanak, H. Schmitt, J. Nowoczin and C. Ziebert, Solid State Ionics, 2004, 171, 99.

236 H. Cheong, H. C. Jo, K. M. Kim and S.-H. Lee, J. Korean Phys. Soc., 2005, 46, S121.

237 J. Nowoczin, H. Shanak, C. Ziebert, H. Schmitt and K. H. Ehses, Phys. Status Solidi A, 2005, 202, 1073.

238 H. Shanak, H. Schmitt, J. Nowoczin and K.-H. Ehses, J. Mater. Sci., 2005, 40, 3467.

239 H.-S. Shim, H.-J. Ahn, T.-Y. Seong and K.-Y. Park, Electrochem. Solid-State Lett., 2005, 8, A277.

240 C. Alcomber, F. Alvarez, S. A. Bilmes and R. J. Candal, J. Mater. Sci. Lett., 2002, 21, 501

241 W. Feng, T. R. Zhang, L. Wei, R. Lu, Y. B. Bai, T. J. Li, Y. Y. Zhao and J. N. Yao, Mater. Lett., 2002, 54, 309

242 T. He, Y. Ma, Y. Cao, X. Hu, H. Liu, G. Zhang, W. Yang and J. Yao, J. Phys. Chem. B, 2002, 106, 12670

243 T. He, Y. Ma, Y. Cao, W. Yang and J. Yao, Phys. Chem. Chem. Phys., 2002, 4, 1637.

244 H. Ikake, Y. Fukuda, S. Shimizu, K. Kurita and S. Yano, Kobunshi Ronbunshu, 2002, 59, 608.

245 C. O. Avellaneda and L. O. S. Bulhões, Solid State Ionics, 2003, $165,117$.

246 Y. He, Z. Wu, L. Fu, C. Li, Y. Miao, L. Cao, H. Fan and B. Zou, Chem. Mater., 2003, 15, 4039.

247 R.-G. Xie, J.-Q. Zhuang, L.-L. Wang, W.-S. Yang, D.-J. Wang, T.-J. Li and J.-N. Yao, Chem. J. Chin. Univ., 2003, 24, 2086.
248 M. F. Al-Kuhaili, S. M. A. Durrani and E. E. Khawaja, Thin Solid Films, 2002, 408, 188

249 S. M. A. Durrani, E. E. Khawaja, M. A. Salim, M. F. Al-Kuhaili and A. M. Al-Shukri, Sol. Energy Mater. Sol. Cells, 2002, 71, 313 .

250 M. Merz, J. Eisenmenger, B. Heinz and P. Ziemann, Phys. Rev. B, 2002, 66, 184102

251 M. Miyakawa, K. Ueda and H. Hosono, J. Appl. Phys., 2002, 92, 2017.

252 M. Miyauchi, A. Nakajima, T. Watanabe and K. Hashimoto, Chem. Mater., 2002, 14, 2812.

253 B. Canut, A. Merlen, V. Teodorescu, C. Ghica, C. S. Sandu, S. M. M. Ramos, C. Bovier, R. Espiau de la Maestre, A. Broniatowski and H. Bernas, Nucl. Instrum. Methods Phys. Res., Sect. B, 2003, 209, 335.

254 E. Ozkan Zayim and N. Dogan Baydogan, Sol. Energy Mater. Sol. Cells, 2006, 90, 402.

255 C. Wang, M. Shim and P. Guyot-Sionnest, Appl. Phys. Lett., $2002,80,4$.

256 P. Guyot-Sionnest and C. Wang, J. Phys. Chem. B, 2003, 107, 7355.

257 X.-S. Yang, Y. Wang, L. Dong and L.-Z. Qi, Acta Phys. Sin., 2004, 53, 2724

258 X.-S. Yang, Y. Wang and Y. Zhao, Mater. Lett., to be published.

259 H. Mizoguchi, M. Orita, M. Hirano, S. Fujitsu, T. Takeuchi and H. Hosono, Appl. Phys. Lett., 2002, 80, 4732.

260 P. M. S. Monk, Crit. Rev. Solid State Mater. Sci., 1999, 24, 193.

261 G. A. Niklasson, L. Berggren and A.-L. Larsson, Sol. Energy Mater. Sol. Cells, 2004, 84, 315.

262 J. B. Goodenough, in Progress in Solid State Chemistry, ed H. Reiss, Pergamon, Oxford, UK, 1971, vol. 5, p. 145.

263 J. M. Honig, in Electrodes of Conductive Metallic Oxides, ed S. Trasatti, Elsevier, Amsterdam, The Netherlands, 1980, p. 2.

264 A.-L. Larsson, B. E. Sernelius and G. A. Niklasson, Solid State Ionics, 2003, 165, 35.

265 R. B. Goldner, D. H. Mendelsohn, J. Alexander, W. R. Henderson, D. Fizpatrick, T. E. Haas, H. H. Sample, R. D. Rauh, M. A. Parker and T. L. Rose, Appl. Phys. Lett., 1983, 43, 1093.

266 R. B. Goldner, A. Brofos, G. Foley, E. L. Goldner, T. E. Haas, W. Henderson, P. Norton, B. A. Ratnam, N. Weis and K. K. Wong, Sol. Energy Mater., 1985, 12, 403.

267 J. S. E. M. Svensson and C. G. Granqvist, Appl. Phys. Lett., 1984, 45, 828 .

268 A. Hjelm, C. G. Granqvist and J. M. Wills, Phys. Rev. B, 1996, 54, 2436.

269 R. Chatten, A. V. Chadwick, A. Rougier and P. J. D. Lindan, J. Phys. Chem. B, 2005, 109, 3146.

270 A. Magnéli, Ark. Kemi, 1949-1950, 1, 513.

271 O. Glemser and H. Sauer, Z. Anorg. Chem., 1943, 252, 144.

272 S. R. Elliott, Physics of Amorphous Materials, 2nd edn, Longman, Harlow, UK, 1990.

273 S. Zh. Karazhanov, Y. Zhang, A. Mascarenhas, S. Deb and L.-W. Wang, Solid State Ionics, 2003, 165, 43.

274 S. Zh. Karazhanov, Y. Zhang, L.-W. Wang, A. Mascarenhas and S. Deb, Phys. Rev. B, 2003, 68, 233204.

275 C. Bechinger, M. S. Burdis and J. G. Zhang, Solid State Commun., 1997, 101, 753

276 J.-G. Zhang, D. K. Benson, C. E. Tracy, S. K. Deb, A. W. Czanderna and C. Bechinger, J. Electrochem. Soc., 1997, 144, 2022.

277 G. A. de Wijs and R. A. de Groot, Phys. Rev. B, 1999, 60, 16463.

278 P. W. Anderson, Phys. Rev. Lett., 1975, 34, 953.

279 G. A. de Wijs and R. A. de Groot, Electrochim. Acta, 2001, 46, 1989.

280 M. Stolze, B. Camin, F. Galbert, U. Reinholz and L. K. Thomas, Thin Solid Films, 2002, 409, 254.

281 T. J. Vink, E. P. Boonekamp, R. G. F. A. Verbeek and Y. Tamminga, J. Appl. Phys., 1999, 85, 1540.

282 A. S. Foster, V. B. Sulimov, F. Lopez Gejo, A. L. Shluger and R. M. Nieminen, Phys. Rev. B, 2001, 64, 224108.

283 L. Berggren, Optical Absorption and Electrical Conductivity in Lithium Intercalated Amorphous Tungsten Oxide Films, $\mathrm{Ph}$ D. Thesis, Uppsala University, 2004.

284 L. Berggren, A. Azens and G. A. Niklasson, J. Appl. Phys., 2001, 90, 1860 . 
285 C. Lemire, D. B. B. Lollman, A. Al Mohammad, E. Gillet and K. Aguir, Sens. Actuators B, 2002, 84, 43.

286 L. Lozzi, M. Passacantando, S. Santucci, S. La Rosa and N. Yu. Svetchnikov, Surf. Rev. Lett., 2002, 9, 375.

287 L. Ottaviano, F. Busoletti, L. Lozzi, M. Passacantando, S. La Rosa and S. Santucci, Thin Solid Films, 2003, 436, 9.

288 G. Soto, W. De La Cruz, J. A. Díaz, R. Machorro, F. F. Castillón and M. H. Farías, Appl. Surf. Sci., 2003, 218, 281.

289 E. Zampiceni, E. Comini, G. Faglia, G. Sberveglieri, S. Kaciulis, L. Pandolfi and S. Viticoli, Sens. Actuators B, 2003, 89, 225.

290 M. Katoh and Y. Takeda, Jpn. J. Appl. Phys., 2005, 43, 7292.

291 A. Temmink, O. Anderson, K. Bange, H. Hantsche and X. Yu, Thin Solid Films, 1990, 192, 211.

292 A. Temmink, O. Anderson, K. Bange, H. Hantsche and X. Yu, Vacuum, 1990, 41, 1144.

293 A. Henningsson, Ion Insertion into Electrode Materials Studied with X-Ray and Electron Spectroscopic Methods, Ph. D. Thesis, Uppsala University, 2002.

294 A. Kuzmin and J. Purans, J. Phys.: Condens. Matter, 1993, 5, 267.

295 T. Pauporté, Y. Soldo-Olivier and R. Faure, J. Phys. Chem. B, 2003, 107, 8861

296 T. Pauporté, Y. Soldo-Olivier and R. Faure, J. Electroanal. Chem., 2004, 562, 111.

297 A.-L. Larsson, G. A. Niklasson and L. Stenmark, Proc. Soc. Photo-Opt. Instrum. Eng., 1999, 3738, 486.

298 L. Berggren and G. A Niklasson, Appl. Phys. Lett., 2006, 88, 081906.

299 S.-H. Lee, H. M. Cheong, C. E. Tracy, A. Mascarenhas, A. W. Czanderna and S. K. Deb, Appl. Phys. Lett., 1999, 75, 1541.

300 C. Bittencourt, R. Landers, E. Llobet, X. Correig and J. Calderer, Semicond. Sci. Technol., 2002, 17, 522.

301 S. Hashimoto and H. Matsuoka, J. Appl. Phys., 1991, 69, 933.

302 S. Hashimoto and H. Matsuoka, J. Electrochem. Soc., 1991, 138, 2403.

303 F. Bussoletti, L. Lozzi, M. Passacantando, S. La Rosa, S. Santucci and L. Ottaviano, Surf. Sci., 2003, 538, 113.

304 A. J. Bard and L. R. Faulkner, Electrochemical Methods: Fundamentals and Applications, Wiley, New York, USA, 1980

305 M. Strømme, R. Ahuja and G. A. Niklasson, Phys. Rev. Lett., 2004, 93, 206403.

306 C. M. Julien, Mater. Sci. Eng., R, 2003, 40, 47.

307 E. Broclawik, A. Góra, P. Liguzinski, P. Petelenz and M. Slawik, Catal. Today, 2005, 101, 155.

308 W. R. McKinnon, in Solid State Electrochemistry, ed. P. G. Bruce, Cambridge University, Cambridge, UK, 1995, p. 163.

309 G. A. Niklasson, L. Berggren, A. K. Jonsson, R. Ahuja, N. V. Skorodumova, J. Backholm and M. Strømme, Sol. Energy Mater. Sol. Cells, 2006, 90, 385.

310 L. Berggren, J. Ederth and G. A. Niklasson, Sol. Energy Mater. Sol. Cells, 2004, 84, 329.

311 N. F. Mott and E. A. Davis, Electronic Processes in NonCrystalline Materials, Oxford University, Oxford, UK, 1971.

312 G. P. Triberis, X. Zianni, A. N. Yannacopoulus and V. C. Karavolas, J. Phys.: Condens. Matter, 1991, 3, 337.

313 O. F. Schirmer, V. Wittwer, G. Baur and G. Brandt, J. Electrochem. Soc., 1977, 124, 749.

314 A. Nakamura and S. Yamada, Appl. Phys. (Berlin), 1981, 24, 55.

315 A. Nakamura, T. Kawauchi, K. Urabe, M. Kitao and S. Yamada, J. Vac. Soc. Jpn., 1981, 24, 471.

316 M. Green and Z. Hussain, J. Appl. Phys., 1991, 69, 7788.

317 E. Burstein, Phys. Rev., 1954, 93, 632.

318 T. S. Moss, Proc. Phys. Soc., London, Sect. B, 1954, 67, 775.

319 I. Hamberg, C. G. Granqvist, K.-F. Berggren, B. E. Sernelius and L. Engström, Phys. Rev. B, 1984, 30, 3240.

320 I. Hamberg and C. G. Granqvist, J. Appl. Phys., 1986, 60, R123.

321 Z.-C. Jin, I. Hamberg and C. G. Granqvist, J. Appl. Phys., 1988, 64, 5117.

322 B. E. Sernelius, K.-F. Berggren, Z.-C. Jin, I. Hamberg and C. G. Granqvist, Phys. Rev. B, 1988, 37, 10244.

323 F. Gervais, Mater. Sci. Eng., R, 2002, 39, 29.

324 H. Fröhlich, Adv. Phys., 1954, 3, 325.

325 C. Persson, personal communication, 2004.

326 M. J. DeVries, C. Trimble, T. E. Tiwald, D. W. Thompson and J. A. Woollam, J. Vac. Sci. Technol. A, 1999, 17, 2906.
327 R. Schmitt, D. McCann, B. Marquis and D. E. Kotecki, J. Appl. Phys., 2002, 91, 6775.

328 E. K. H. Salje, Eur. J. Solid State Inorg. Chem., 1994, 31, 805.

329 J. Ederth, A. Hoel, G. A. Niklasson and C. G. Granqvist, J. Appl. Phys., 2004, 96, 5722.

330 V. V. Bryksin, Fiz. Tverd. Tela, 1982, 24, 1110, (Sov. Phys. Solid State, 1982, 24, 627)

331 B. W. Faughnan, R. S. Crandall and P. M. Heyman, RCA Rev., 1975, 36, 177 .

332 A. Azens, A. Talledo, A. M. Andersson, G. A. Niklasson, B. Stjerna and C. G. Granqvist, Proc. Soc. Photo-Opt. Instrum. Eng., 1992, 1728, 103.

333 M. Denesuk and D. R. Uhlmann, J. Electrochem. Soc., 1996, 143, L186.

334 R. M. Torresi, S. I. Cordoba de Torresi and E. R. Gonzalez, J. Electroanal. Chem., 1999, 461, 161.

335 F. Huguenin, F. C. Nart, E. R. Gonzalez and O. N. Oliveira, Jr., J. Phys. Chem. B, 2004, 108, 18919.

336 W. Q. Hong, J. Phys. D: Appl. Phys., 1989, 22, 1384.

337 W. Weppner and R. A. Huggins, J. Electrochem. Soc., 1977, 124, 1569.

338 M. Strømme Mattsson, Solid State Ionics, 2000, 131, 261.

339 M. Strømme Mattsson, Phys. Rev. B, 1998, 58, 11015.

340 W. R. McKinnon and R. R. Haering, in Modern Aspects of Electrochemistry, ed. R. E. White, J. O’M. Bockris and B. E. Conway, Plenum, London, UK, 1983.

341 M. D. Levi and D. Aurbach, J. Phys. Chem. B, 1997, 101, 4641.

342 Q. Zhong, J. R. Dahn and K. Colbow, Phys. Rev. B, 1992, 46, 2554.

343 A. Hoel, personal communication, 2004

344 C. M. Lampert, T. R. Omstead and P. C. Yu, Proc. Soc. PhotoOpt. Instrum. Eng., 1985, 562, 2.

345 J. S. E. M. Svensson and C. G. Granqvist, Appl. Phys. Lett., 1986, 49, 1566.

346 J. S. E. M. Svensson and C. G. Granqvist, Sol. Energy Mater., 1987, 16, 19.

347 J. S. E. M. Svensson and C. G. Granqvist, Appl. Opt., 1987, 26, 1554

348 S. Gottesfeld, J. D. E. McIntyre, G. Beni and J. L. Shay, Appl. Phys. Lett., 1978, 33, 208.

349 E. Avendaño, Electrochromism in Nickel-Based Oxides: Coloration Mechanisms and Optimization of Sputter-Deposited Thin Films, Ph.D. Thesis, Uppsala University, 2004.

350 E. Avendaño, A. Azens, G. A. Niklasson and C. G. Granqvist, J. Electrochem. Soc., 2005, 152, F203.

351 E. Avendaño, H. Rensmo, A. Azens, A. Sandell, G. A. Niklasson, H. Siegbahn and C. G. Granqvist, J. Phys. Chem. B, to be published.

352 A. Lourenco, E. Masetti and F. Decker, Electrochim. Acta, 2001, 46, 2257

353 E. Masetti, F. Varsano, F. Decker and A. Krasilnikova, Electrochim. Acta, 2001, 46, 2085.

354 F. Varsano, F. Decker, E. Masetti and F. Croce, Electrochim. Acta, 2001, 46, 2069.

355 F. Artuso, F. Bonino, F. Decker, A. Lourenco and E. Masetti, Electrochim. Acta, 2002, 47, 2231

356 R. Zanoni, F. Decker, C. Coluzza, F. Artuso, N. Cimino, G. Di Santo and E. Masetti, Surf. Interface Anal., 2002, 33, 815.

357 S. Passerini, B. Scrosati, A. Gorenstein, A. M. Andersson and C. G. Granqvist, J. Electrochem. Soc., 1989, 136, 3394.

358 F. Decker, S. Passerini, R. Pileggi and B. Scrosati, Electrochim. Acta, 1992, 37, 1033.

359 K.-F. Chiu, C. Y. Chang and C. M. Liu, J. Electrochem. Soc., 2005, 152, A1188

360 N. Tsuda, K. Nasu, A. Fujimori and K. Siratori, Electronic Conduction in Oxides, 2nd edn, Springer, Berlin, Germany, 2000.

361 H. Bode, K. Dehmelt and J. Witte, Electrochim. Acta, 1966, 11, 1079

362 H. Bode, K. Dehmelt and J. Witte, Z. Anorg. Allg. Chem., 1969, $366,1$.

363 D. R. Lide, CRC Handbook of Chemistry and Physics, 73rd edn, CRC Press, Boca Raton, USA, 2000

364 P. Kofstad, Oxid. Met., 1995, 44, 3.

365 D. Adler and J. Feinleib, Phys. Rev. B, 1970, 2, 3112. 
366 P. Lunkenheimer, A. Loidl, C. R. Ottermann and K. Bange, Phys. Rev. B, 1991, 44, 5927.

367 J. Hugel and M. Belkhir, Solid State Commun., 1990, 73, 159.

368 T. M. Schuler, D. L. Ederer, S. Itza-Ortiz, G. T. Woods, T. A. Callcott and J. C. Woicik, Phys. Rev. B, 2005, 71, 115113.

369 B. H. Brandow, Adv. Phys., 1977, 26, 651.

370 R. J. Powell and W. E. Spicer, Phys. Rev. B, 1970, 2, 2182.

371 H. A. E. Hagelin-Weaver, J. F. Weaver, G. B. Hoflund and G. N. Salaita, J. Electron Spectrosc. Relat. Phenom., 2004, 134, 139.

372 R. S. Jayashree, P. Vishnu Kamath and G. N. Subbanna, J. Electrochem. Soc., 2000, 147, 2029.

373 D. M. MacArthur, Power Sources, 1971, 3, 91.

374 M. Rajamathi and P. Vishnu Kamath, J. Power Sources, 1998, 70, 118.

375 W. Visscher, J. Phys. (Paris), 1983, 44, C10-213.

376 W. Visscher and E. Barendrecht, J. Electroanal. Chem., 1983, 154, 69.

377 H. Dittrich, P. Axmann, M. Wohlfart-Mehrens, J. Garche, S. Albrecht, J. Meese-Marktscheffel, A. Olbrich and G. Gille, Z. Kristallogr., 2005, 220, 306.

378 M. K. Carpenter and D. A. Corrigan, J. Electrochem. Soc., 1989, 136, 1022

379 J. Zaanen, G. A. Sawatzky and J. W. Allen, J. Magn. Magn. Mater., 1986, 54-57, 607.

380 P. A. Cox, The Electronic Structure and Chemistry of Solids, Oxford University, Oxford, UK, 1998.

381 M. K. Carpenter, R. S. Conell and D. A. Corrigan, Sol. Energy Mater., 1987, 16, 333

382 P. Delichere, S. Joiret, A. Hugot-Le Goff, K. Bange and B. Metz, J. Electrochem. Soc., 1988, 135, 1856.

383 Y. G. Wu, G. M. Wu, X. Y. Ni and X. Wu, Sol. Energy Mater. Sol. Cells, 2000, 63, 217

384 E. Avendaño, A. Kuzmin, J. Purans, A. Azens, G. A. Niklasson and C. G. Granqvist, Phys. Scr., 2005, T115, 464.

385 G. A. Sawatzky and J. W. Allen, Phys. Rev. Lett., 1984, 53, 2339.

386 S. V. Faleev, M. van Schilfgaarde and T. Kotani, Phys. Rev. Lett. 2004, 93, 126406.

387 R. Eder, A. Dorneich and H. Winter, Phys. Rev. B, 2005, 71, 045105.

388 J.-L. Li, G.-M. Rignanese and S. G. Louie, Phys. Rev. B, 2005, 71, 193102

389 V. M. Zainullina, M. A. Korotin, Y. P. Zaikov and N. I. Shurov, Solid State Sci., 2004, 6, 1139.

390 J. F. Moulder, W. F. Stickle, P. E. Sobol and K. D. Momben, Handbook of X-ray Photoelectron Spectroscopy, Physical Electronics, Inc, MN, USA, 1995.

391 S. Uhlenbrock, C. Scharfschwerdt, M. Neumann, G. Illing and H.-J. Freund, J. Phys.: Condens. Matter, 1992, 4, 7973.

392 A. N. Mansour, Surf. Sci. Spectra, 1994, 3, 231.

393 A. N. Mansour and C. A. Melendres, Surf. Sci. Spectra, 1994, 3, 263.

394 A. N. Mansour, Surf. Sci. Spectra, 1994, 3, 239.

395 A. N. Mansour and C. A. Melendres, Surf. Sci. Spectra, 1994, 3, 247.

396 A. N. Mansour and C. A. Melendres, Surf. Sci. Spectra, 1994, 3, 255.

397 A. N. Mansour and C. A. Melendres, Surf. Sci. Spectra, 1994, 3, 271 .

398 F. Urbach, Phys. Rev., 1953, 92, 1324.

399 J. Bullot, P. Cordier, O. Gallais, M. Gauthier and J. Livage, J. Non-Cryst. Solids, 1984, 68, 123.

400 J. Bullot, P. Cordier, O. Gallais, M. Gauthier and F. Babonneau, J. Non-Cryst. Solids, 1984, 68, 135.

401 K. M. E. Miedzinska, B. R. Hollebone and J. G. Cook, J. Phys. Chem. Solids, 1988, 49, 1355.

402 R. Newman and R. M. Chrenko, Phys. Rev., 1959, 114, 1507.

403 J. Scarminio, W. Estrada, A. Andersson, A. Gorenstein and F. Decker, J. Electrochem. Soc., 1992, 139, 1236.

404 T. M. J. Nilsson and G. A. Niklasson, Proc. Soc. Photo-Opt. Instrum. Engr., 1990, 1272, 129.

405 N. Nakajima, H. Kato and Y. Sakisaka, J. Electron Spectroscopy Related Phenomena, 2005, 144-147, 873.

406 S.-H. Lee and S.-K. Joo, Sol. Energy Mater. Sol. Cells, 1995, 39, 155.
407 J. H. G. Mathew, S. P. Sapers, M. J. Cumbo, N. A. O’Brien, R. B. Sargent, V. P. Raksha, R. B. Ladaherne and B. P. Hichwa, J. Non-Cryst. Solids, 1997, 218, 342.

408 A. Azens, L. Kullman, G. Vaivars, H. Nordborg and C. G. Granqvist, Solid State Ionics, 1998, 113-115, 449.

409 R. Lechner and L. K. Thomas, Sol. Energy Mater. Sol. Cells, 1998, 54, 139.

410 J. Nagai, G. D. McMeeking and Y. Saitoh, Sol. Energy Mater. Sol. Cells, 1999, 56, 309.

411 J. Karlsson and A. Roos, Sol. Energy, 2000, 68, 493.

412 A. Azens, G. Vaivars, M. Veszelei, L. Kullman and C. G. Granqvist, J. Appl. Phys., 2001, 89, 7885.

413 C. Person, I. Porqueras, M. Vives, C. Corbella, A. Pinyol and E. Bertran, Solid State Ionics, 2003, 165, 73

414 A.-K. Jonsson, M. Furlani and G. A. Niklasson, Sol. Energy Mater. Sol. Cells, 2004, 84, 361.

415 A.-L. Larsson and G. A. Niklasson, Sol. Energy Mater. Sol. Cells, 2004, 84, 351

416 A. K. Jonsson, A.-L. Larsson, G. A. Niklasson and M. Strømme, J. Electrochem. Soc., 2005, 152, A377.

417 A.-L. Larsson and G. A. Niklasson, Mater. Lett., 2004, 58, 2517.

418 A. Azens, E. Avendaño and C. G. Granqvist, Proc. Soc. PhotoOpt. Instrum. Eng., 2003, 5123, 185.

419 A. Azens, E. Avendaño, J. Backholm, L. Berggren, G. Gustavsson, R. Karmhag, G. A. Niklasson, A. Roos and C. G. Granqvist, Mater. Sci. Eng., B, 2005, 119, 214.

420 A. Azens, E. Avendaño, J. Backholm, L. Berggren, G. Gustavsson, R. Karmhag, G. A. Niklasson, A. Roos and C. G. Granqvist, Proc. Soc. Photo-Opt. Instrum. Engr.,, 2005, 5946, 359.

421 A. Bessière, C. Marcel, M. Morcrette, J.-M. Tarascon, V. Lucas, B. Viana and N. Baffier, J. Appl. Phys., 2002, 91, 1589.

422 A. Bessière, L. Beluze, M. Morcrette, V. Lucas and N. Baffier, Solid State Ionics, 2003, 165, 23.

423 A. Bessière, L. Beluze, M. Morcrette, V. Lucas, B. Viana and J.-C. Bardot, Chem. Mater., 2003, 15, 2577.

424 A. Bessière, L. Beluze, M. Morcrette, B. Viana, J. C. Badot and V. Lucas, Radiat. Eff. Defects Solids, 2003, 158, 215.

425 M. Wigginton, Glass in Architecture, Phaidon, London, UK, 1996.

426 A. Campagno, Intelligente Glasfassaden / Intelligent Glass Façades, 5th edn, Birkhäuser, Basel, Switzerland, 2002.

427 E. Avendaño, A. Azens, J. Backholm, G. Gustavsson, R. Karmhag, G. A. Niklasson and C. G. Granqvist, in Proc. EuroSun 2004: 14th Int. Sonnenforum, PSE GmbH, Freiburg, Germany, 2004, vol. 2, p. 799.

428 E. Avendaño, A. Azens, G. A. Niklasson and C. G. Granqvist, in Electrochromic Materials and Applications, ed. A. Rougier, D. Rauh and G. A. Nazri, The Electrochemical Society, Pennington, USA, 2003, vol. PV 2003-17, p. 80.

429 A. Z. Menshivov, Yu. A. Dorofeev, A. G. Klimenko and N. A. Mironova, Phys. Status. Solidi B, 1991, 164, 275.

430 Z. Feng and M. S. Seehra, Phys. Rev. B, 1992, 45, 2184.

431 E. F. de Oliveira and Y. Hase, Vib. Spectrosc., 2003, 31, 19.

432 Z. Ji, Z. He, K. Liu, S. Zhao and Z. He, J. Cryst. Growth, 2005, 273, 466.

433 Y. R. Park and K. J. Kim, J. Cryst. Growth, 2005, 258, 380.

434 A. Z. Mosfegh, R. Azimirag and O. Akhavan, Thin Solid Films, 2005, 484, 124.

435 D. L. MacAdam, Color Measurement: Theme and Variations, Springer, Berlin, Germany, 1981.

436 S. J. Williamson and H. Z. Cummins, Light and Color in Nature and Art, Wiley, New York, USA, 1983.

437 A. P. Giri and R. Messier, Mater. Res. Soc. Symp. Proc., 1984, 24 221.

438 A. Azens, L. Kullman and C. G. Granqvist, Sol. Energy Mater. Sol. Cells, 2003, 76, 147.

439 F. Bardé, M. R. Palacin, B. Beaudoin and J.-M. Tarascon, Chem. Mater., 2005, 17, 470.

440 W. Wixwat, J. R. Stevens, A. M. Andersson and C. G. Granqvist, in Second Int. Symp. on Polymer Electrolytes, ed. B. Scrosati, Elsevier Applied Sciences, London, UK, 1990, p. 461.

441 T. Kubo, J. Tanimoto, M. Minami, T. Toya, Y. Nishikitani and H. Watanabe, Solid State Ionics, 2003, 165, 97. 
442 T. Kubo, T. Shinada, Y. Kobayashi, H. Imafuku, T. Toya, S. Akita, Y. Nishikitani and H. Watanabe, Solid State Ionics, 2003, 165, 209.

443 J. Schütt, J.-C. Giron, F. Béteille and X. Fanton, in Proc. 4th Int. Conf. on Coatings on Glass, ed. C.-P. Klages, H. J. Gläser and M. A. Aegerter, Fraunhofer-Institut für Schicht- und Oberflächentechnik, Braunschweig, Germany, 2002, p. 661.

444 H. W. Kua and S. E. Lee, Build. Environ., 2002, 37, 231.

445 Membrane Designs and Structures in the World, ed. K. Ishii, Shinkenchikusa-sha, Tokyo, Japan, 1999.

446 Membrane Structures, ed. K.-M. Koch, Prestel, Munich, Germany, 2004.

447 E. Syrrakou, S. Papaefthimiou and P. Yianoulis, Sol. Energy Mater. Sol. Cells, 2005, 85, 205.

448 D. Garg, P. B. Henderson, R. E. Hollingsworth and D. G. Jensen, Mater. Sci. Eng., B, 2005, 119, 224.

449 J. M. Bell, J. P. Matthews and I. L. Skryabin, Solid State Ionics, 2002, 152-153, 853.

450 J. Krč, M. Topič, F. Smole, U. Opara Krašovec, U. Lavrenčič Stangar and B. Orel, Sol. Energy Mater Sol. Cells, 2002, 71, 387.

451 E. S. Lee and D. L. DiBartolomeo, Sol. Energy Mater. Sol. Cells, 2002, 71, 465

452 M. A. Green, K. Emery, D. L. King, S. Igari and W. Warta, Prog. Photovoltaics Res. Dev., 2005, 13, 49.
453 M.-L. Persson and A. Roos, Energy Build., to be published.

454 A. Roos, D. Covalet, X. Fanton, M.-L. Persson, W. Platzer, T. R. Nielsen, H. R. Wilson, M. Zinzi, M. Köhl, M. Heck and B. Chevalier, in Proc. Int. Conf. on Durability of Building Materials and Components, Lyon, France, 17-20 April, 2005, published on $\mathrm{CD}$.

455 F. Aleo, A. Pennisi, S. Scalia and F. Simone, Electrochim. Acta, 2001, 46, 2243.

456 F. Gugliermetti and F. Bisegna, Build. Environ., 2003, 38, 479.

457 M. A. Porta-Gándara, N. Chargoy and J. L. Fernández, in Emerging Fields in Sol-Gel Science and Technology, ed. T. M. Lopez, D. Avnir and M. A. Aegerter, Kluwer, Boston, USA, 2003, pp. 351-363.

458 M. N. Assimakopoulos, A. Tsangrassoulis, G. Guarracino and M. Santamouris, Energy Build., 2004, 36, 415.

459 E. S. Lee, D. L. DiBartolomeo, F. M. Rubinstein and S. E. Selkowitz, Energy Build., 2004, 36, 503.

460 P. A. B. James and A. S. Bahaj, Energy Build., 2005, 37, 1058.

461 E. S. Lee, D. L. DiBartolomeo and S. E. Selkowitz, Energy Build., 2006, 38, 30.

462 M. A. Porta-Gándara and V. Gómez-Muños, Energy, 2005, 30, 2474.

463 M. Buyan, P. A. Brühwiler, A. Azens, G. Gustavsson, R. Karmhag and C. G. Granqvist, Int. J. Ind. Ergon., 2006, 36, 11. 